\title{
The Experiences of West Virginians Participating in Extension- Sponsored Educational Programming in Ireland: A Narrative Analysis
}

Tina A. Cowger

Follow this and additional works at: https://researchrepository.wvu.edu/etd

\section{Recommended Citation}

Cowger, Tina A., "The Experiences of West Virginians Participating in Extension-Sponsored Educational Programming in Ireland: A Narrative Analysis" (2017). Graduate Theses, Dissertations, and Problem Reports. 5402.

https://researchrepository.wvu.edu/etd/5402

This Dissertation is protected by copyright and/or related rights. It has been brought to you by the The Research Repository @ WVU with permission from the rights-holder(s). You are free to use this Dissertation in any way that is permitted by the copyright and related rights legislation that applies to your use. For other uses you must obtain permission from the rights-holder(s) directly, unless additional rights are indicated by a Creative Commons license in the record and/ or on the work itself. This Dissertation has been accepted for inclusion in WVU Graduate Theses, Dissertations, and Problem Reports collection by an authorized administrator of The Research Repository @ WVU.

For more information, please contact researchrepository@mail.wvu.edu. 


\title{
The Experiences of West Virginians Participating in Extension-Sponsored Educational Programming in Ireland: A Narrative Analysis
}

\author{
Tina A. Cowger
}

\author{
Dissertation submitted \\ to the College of Education and Human Services \\ at West Virginia University \\ Doctorate of Education in \\ Curriculum \& Instruction \\ Melissa Sherfinski, Ph.D., Chair \\ Sharon Hayes, Ph.D. \\ Audra Slocum, Ph.D. \\ Julie Tritz, Ph.D. \\ Department of Curriculum \& Instruction
}

Morgantown, West Virginia 2017

Keywords: Rural, Appalachia, culture, Ireland, Extension Service, international, Copyright 2017 Tina Cowger 


\title{
ABSTRACT \\ The Experiences of West Virginians Participating in Extension-Sponsored Educational Programming in Ireland: A Narrative Analysis
}

\author{
Tina A. Cowger
}

\begin{abstract}
In this dissertation, I asked the major research question of: How do non-formal international experiences influence the life stories of participants from Appalachia as they perceive it? I wanted to understand how non-formal educational experiences in an international setting affect the lives of the participants. I especially wanted to understand the ways in which the life stories of the participants from Appalachia were affected by their international experiences.
\end{abstract}

People tell stories of their lives and their various experiences can impact these narratives and how they share them. From birth and throughout our lives, listening to and telling stories surround us. Society exists through a process of transmission whereas the older communicate habits of doing, thinking, and feeling to the younger and thus, social life survives (Dewey, 1944). Mimicking or imitating is a way in which younger individuals observe accepted social actions and behaviors of others. However, learning to distinguish the appropriate ways to act in different situations is a very important accomplishment in all communities, no matter the age of the individual (Rogoff, 2003). Dewey (1963) and Freire (1972), in their own ways, advocate for the development of active, self-aware learners who have the capacity and freedom to frame their own purposes (Tennant \& Pogson, 1995).

The method that I chose for my investigation is narrative inquiry. According to Clandinin and Connelly (2000), narrative inquiry allows the researcher to view the experience in question on several levels. Not only is the investigator able to delve into the context of the experience, but is striving to look for growth within the life story as well. Living a life and telling a story are iterative processes. The data analysis revealed a shared group story involving fear outside the comfort level of the participants; judgment regarding cultural comparisons; and intergenerational connections between members of the group.

This process has also led me to see how the Extension Service must change our mindset when it comes to our premise. Our communities have a need for critical pedagogy and our people have a need for connections with one another. Our Extension Service needs to defy the current push for following business models and once again work toward instantiating relationship-building as an essential service. 


\section{Dedication}

This work is dedicated to my Lord and Savior, who has given me the knowledge and strength for this process.

To Mamaw and Papaw Cowger, you were the driving force behind my father's education, who became the driving force behind mine.

To Dad and Mom, who never once told me that I could not or should not do something related to my education. 


\section{Acknowledgements}

I would first like to state that "with man this is impossible, but with God, all things are possible" Matthew 19:26. To my chair, Dr. Melissa Sherfinski, your help, your support, and your confidence in me has been instrumental as I worked through each step of this process. Thank you for all the time and effort you spend on this endeavor. I realize that the time you spent with me was time away from other academic responsibilities and your family. For that, I will be eternally grateful. Thank you to the other members of my dissertation committee: Dr. Sharon Hayes, Dr. Audra Slocum, and Dr. Julie Tritz, words cannot express my gratitude for your advice and your assistance in this endeavor. Your comments and support aided tremendously with my research project.

Also, I am grateful for the support of Dr. Erin McHenry-Sorber and Dr. Nathan Sorber, who worked with me at the beginning of this process. I appreciate your reviews and comments that improved my work. I would also like to thank all the other faculty members from the College of Education and Human Services who were my instructors. Each one of you have influenced me and my work during this academic journey. I would also like to offer best wishes and good luck to all my fellow classmates in the C\&I program with your future endeavors.

I would like to acknowledge my family for their encouragement and support: my parents, Ralph and Margaret Cowger; my brother, sister-in-law, niece, and nephews, Scott, Nina, Sadie, Austin, and Brayden Cowger; Mamaw Cowger; all my aunts and uncles; and my cousins who asked about my progress regularly. Papaw Cowger, Papaw and Mamaw Riggs would have been tickled to see this day and I know they are watching me from above.

Also, I want to acknowledge my writing partner, Stephanie Yoho Jones. Our writing sessions are what got me through difficult mental blocks and propelled this work forward. I would like to thank my current and former office co-workers who supported me throughout this process as I balanced work and school: Brandi Adkins, Eva Beto, Louise Donato, Laura Hooper, Diana Marple, John Murray, and Lauren Prinzo. I would also like to acknowledge a wonderful colleague, Jodi Smith, who served as my editor. To my friends and colleagues who have been in my cheering section during this entire process: Lucretia Beafore, Brent Clark, Becca Fint-Clark, Mary Donato, Jennifer Murray, Natalie Summers, and Lesley Woodrum.

A few years ago, my nephew, Brayden, made a comment when he found out I was in school (like him): "If she hasn't learned it by now, I doubt she will." Well, B...I've learned it. 


\section{Table of Contents}

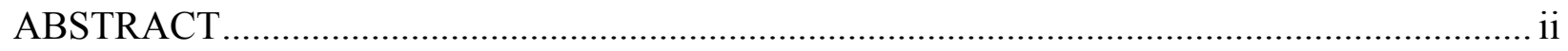

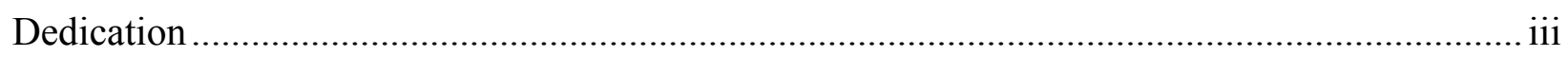

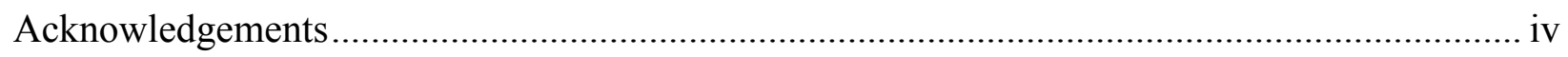

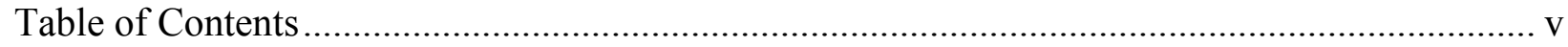

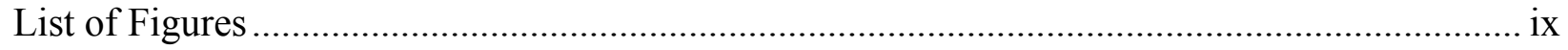

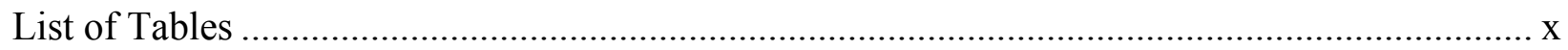

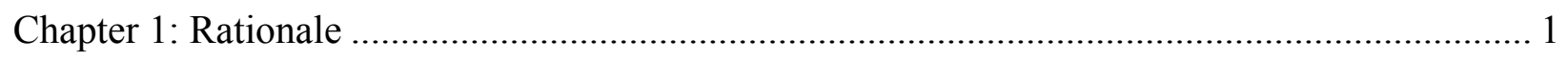

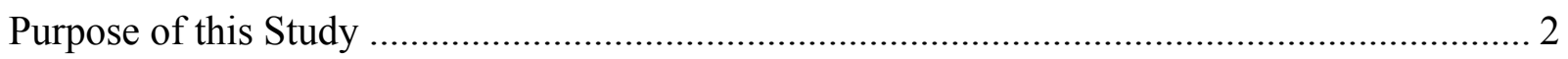

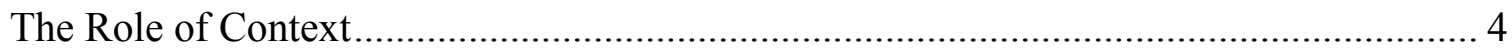

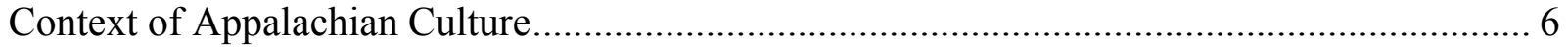

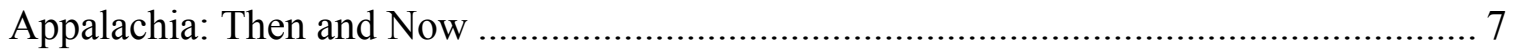

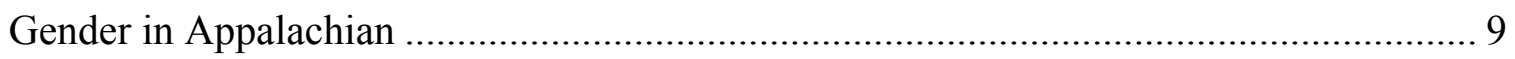

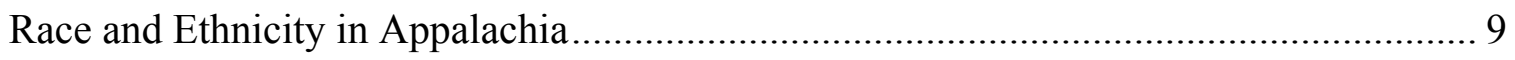

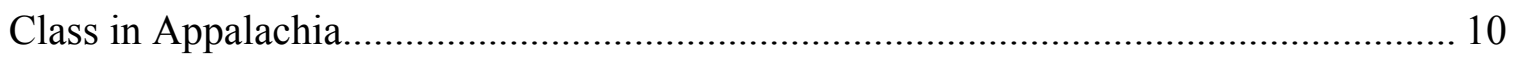

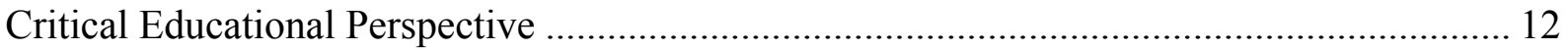

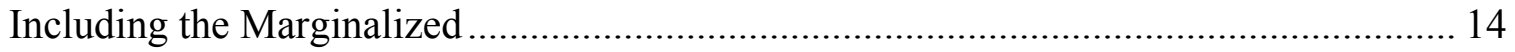

Appalachia from a Critical Perspecitve ................................................................ 16

Progressive Educational Perspective ................................................................................ 20

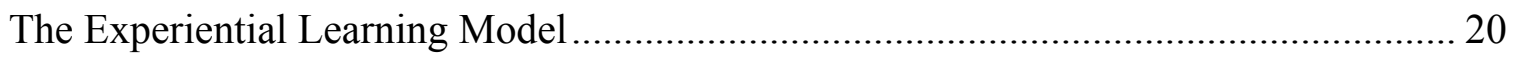

International Programs as Multicultural Education .................................................. 25

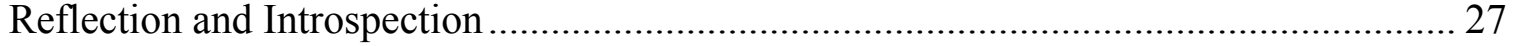

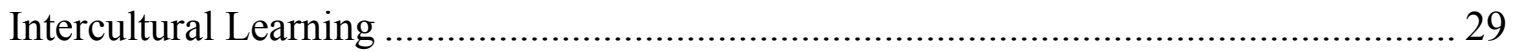

Bennett's Developmental Model of Intercultural Sensitivity .................................. 30

Brief Overview of WVUES International Programs ......................................................... 32

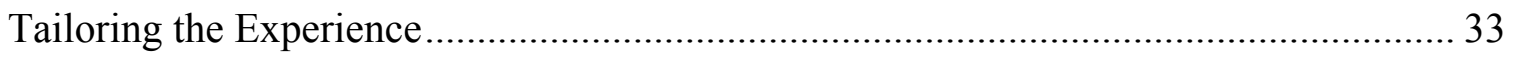

Presentations of Outbound Programs …................................................................ 35

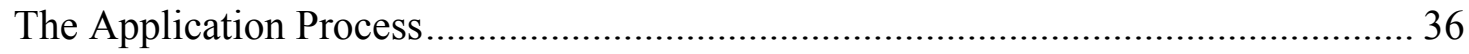

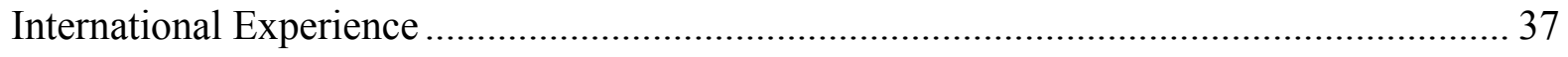

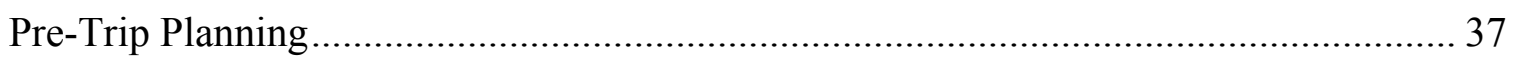

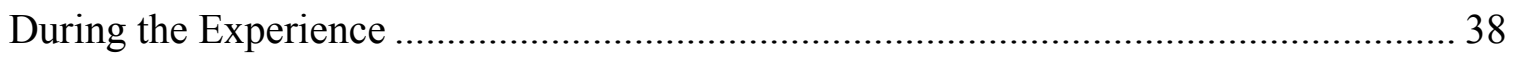




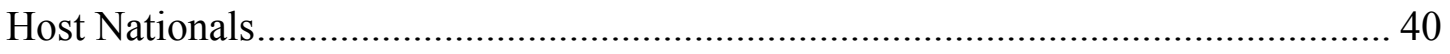

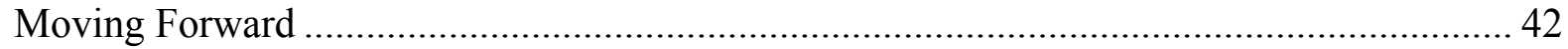

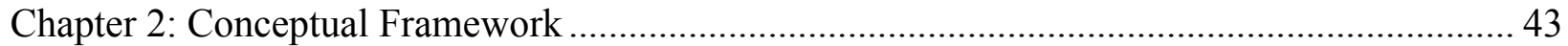

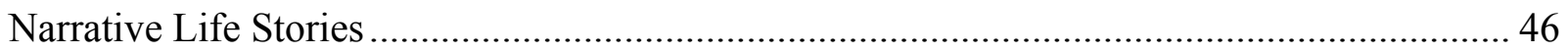

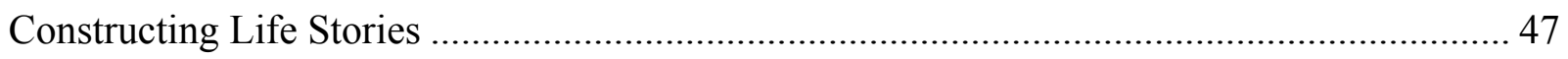

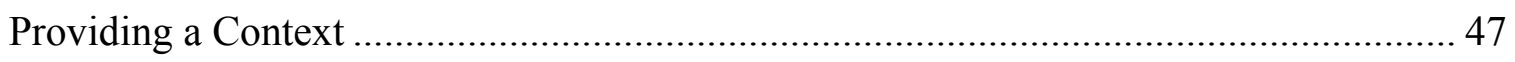

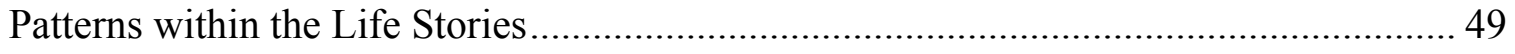

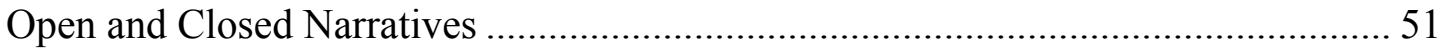

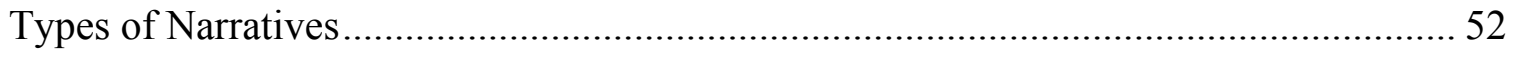

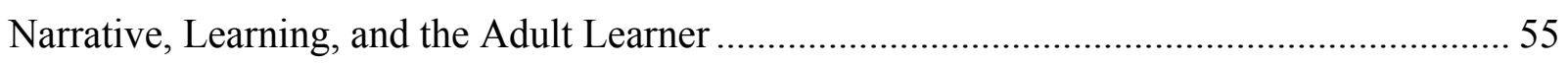

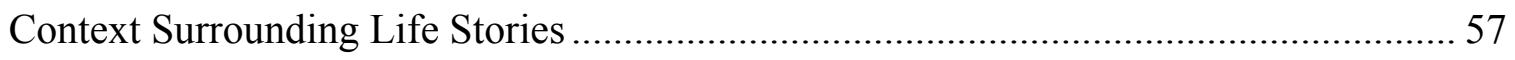

The Process of Narrative Learning .............................................................. 59

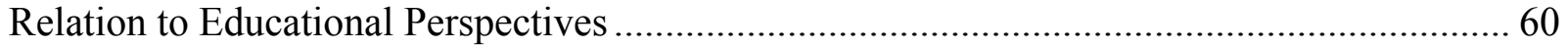

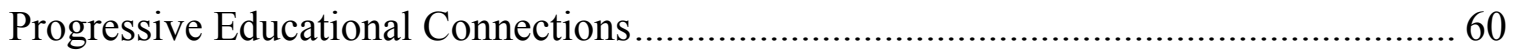

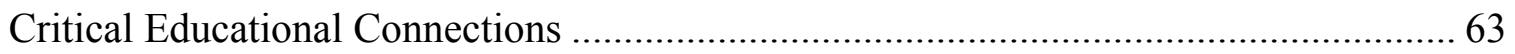

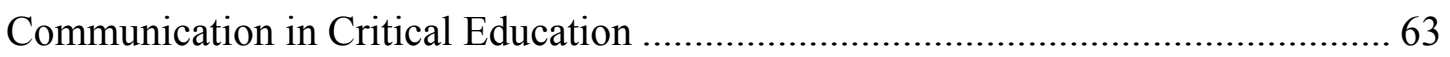

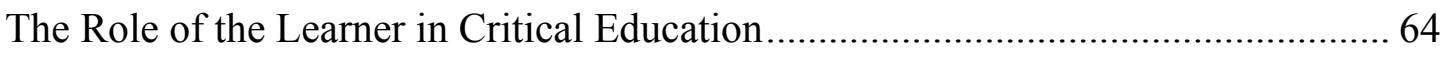

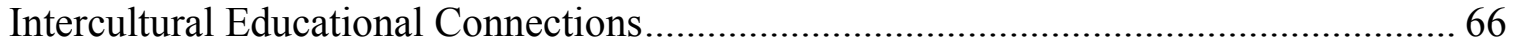

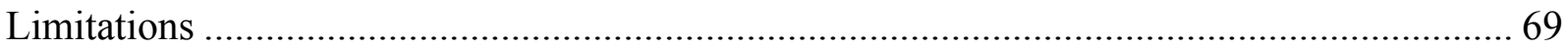

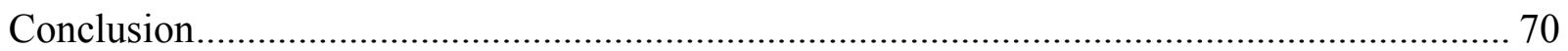

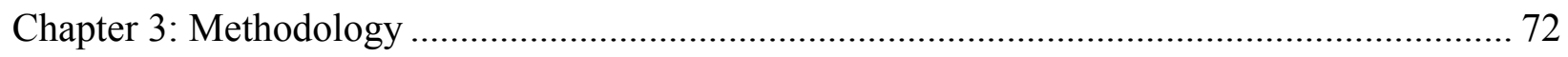

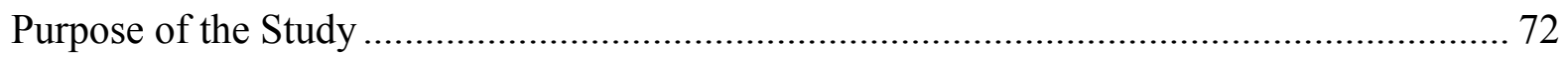

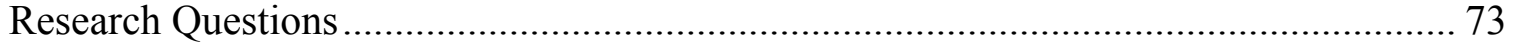

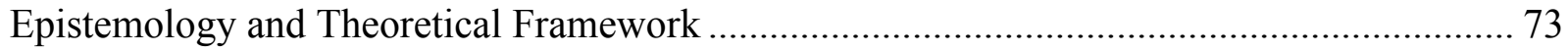

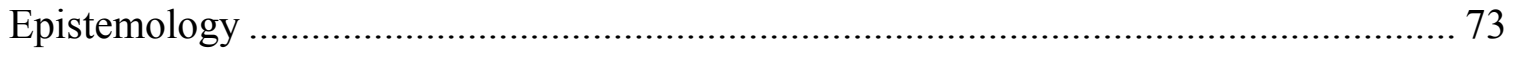

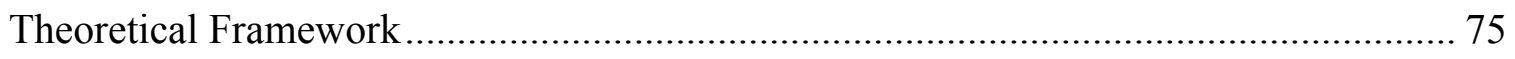

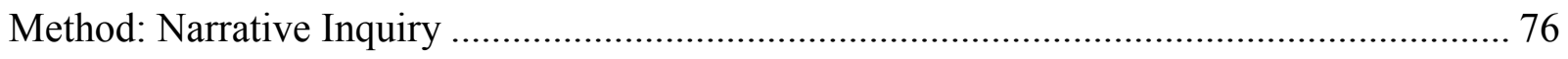

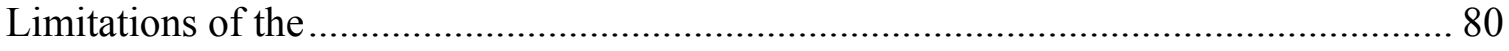

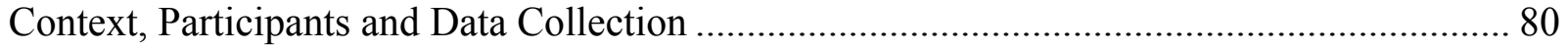

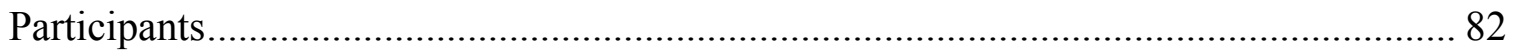

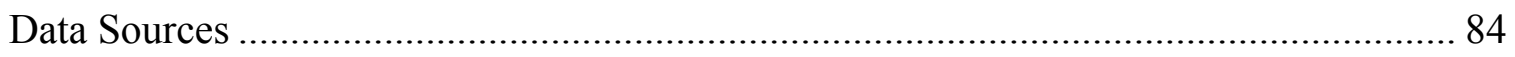

Data Collection Plan ....................................................................................... 85 


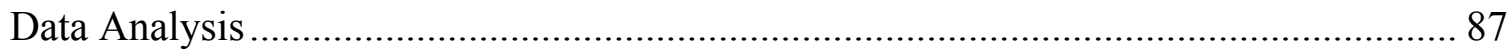

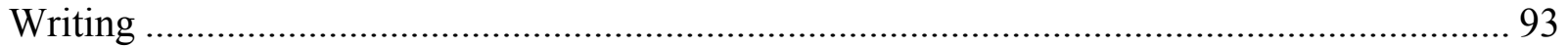

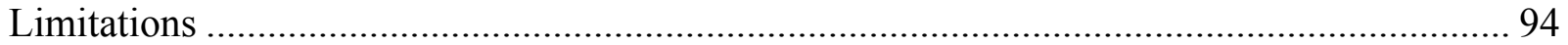

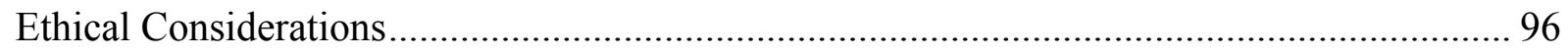

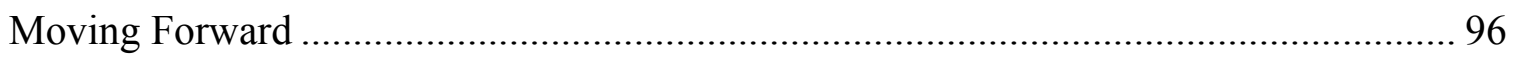

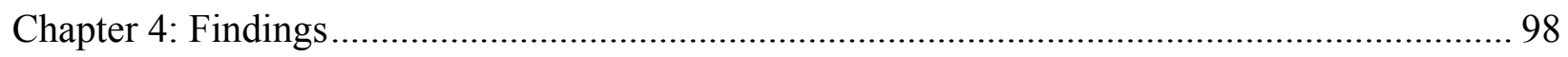

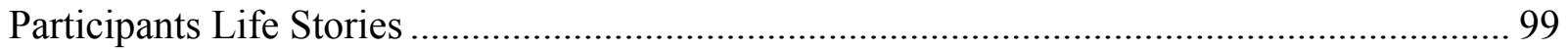

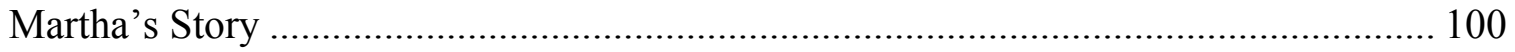

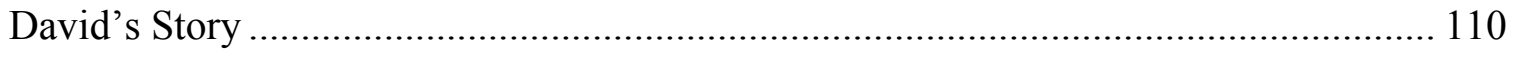

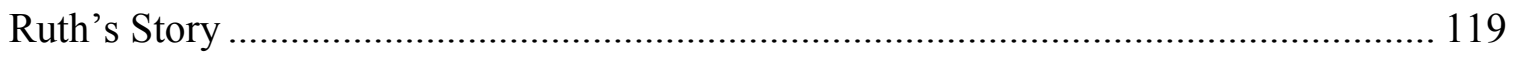

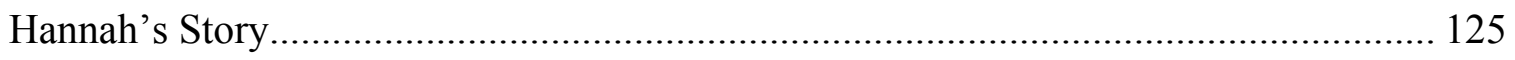

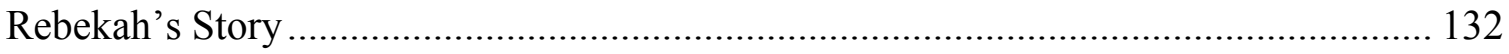

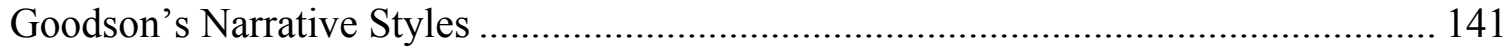

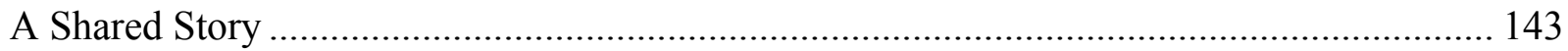

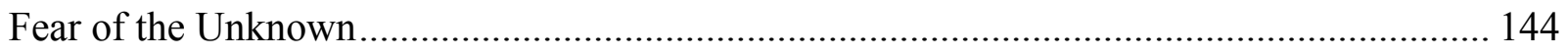

Traveling with the Familiar ….................................................................... 145

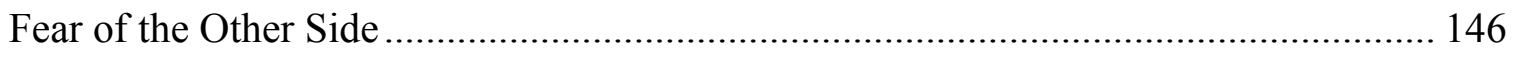

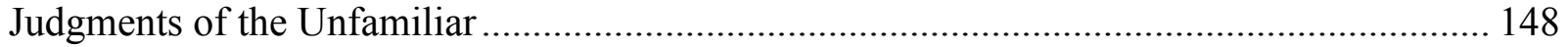

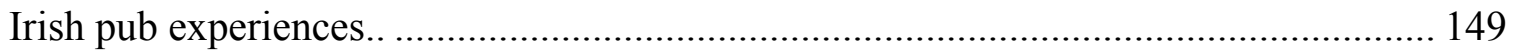

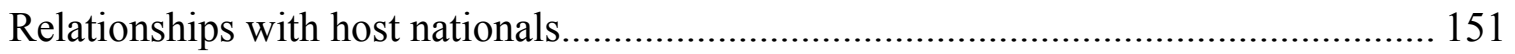

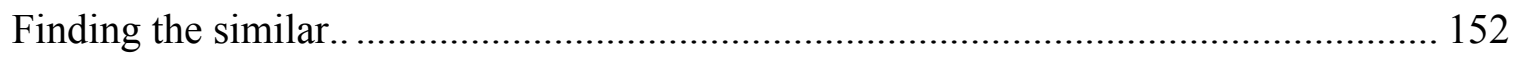

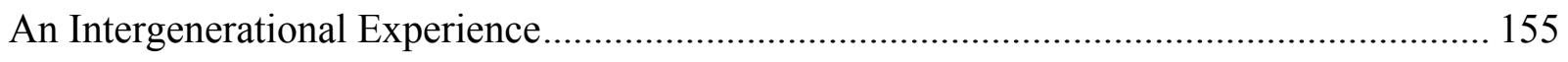

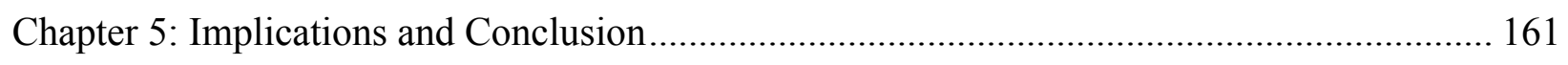

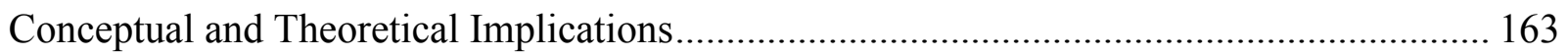

A Strong Foundation: Learning in Community ..................................................... 163

How Participants Troubled Identity and Learning Theories..................................... 165

Finding the "Right" Theoretical Fit in Context...................................................... 167

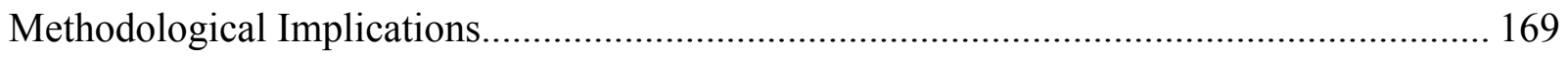

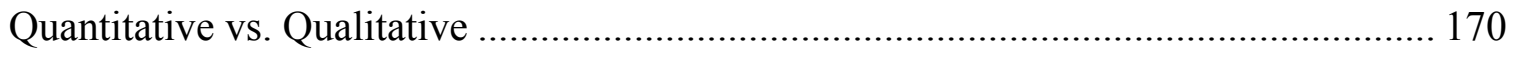

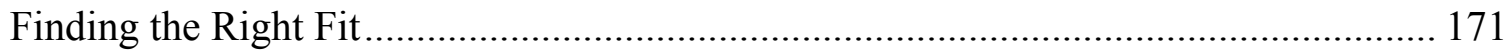

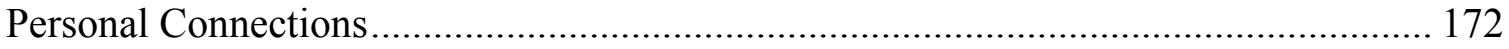

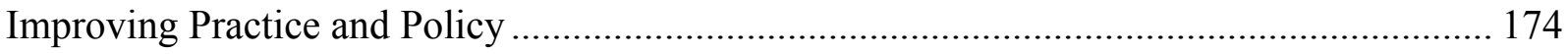




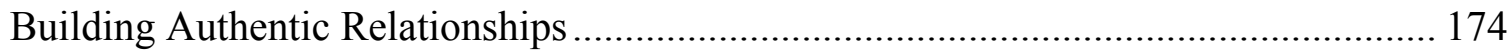

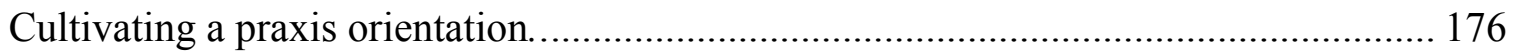

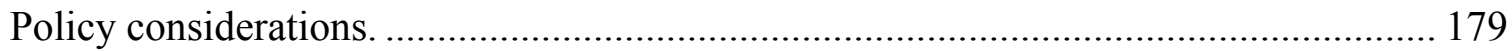

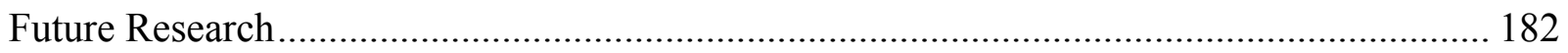

Promoting Collaborative Research ........................................................................ 182

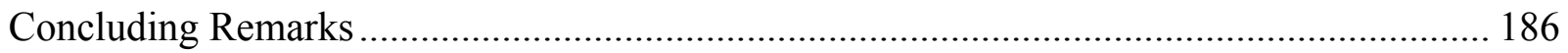

Appendix A: 2013 CEOS Trip to Ireland Final Schedule ....................................................... 188

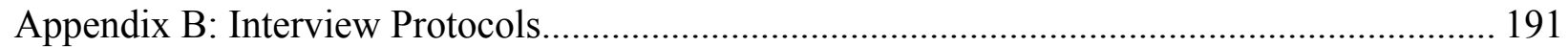

Appendix C: West Virginia University 2020 Plan Goal 5.................................................... 195

Appendix D: 2013 CEOS Trip to Ireland Photographs .......................................................... 196

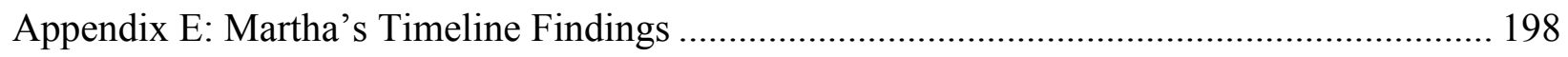

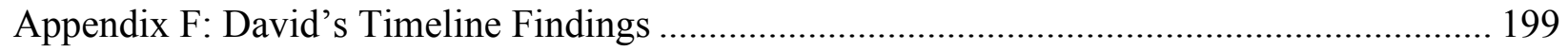

Appendix G: Ruth's Timeline Findings................................................................................. 200

Appendix H: Hannah's Timeline Findings ............................................................................. 201

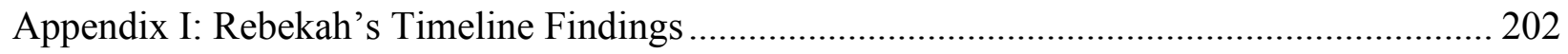

Appendix J: Content Analysis Example from Martha ................................................................. 203

Appendix K: Content Analysis Example from Hannah.......................................................... 204

Appendix L: Critical Event Analysis Findings ……………………………………........... 205

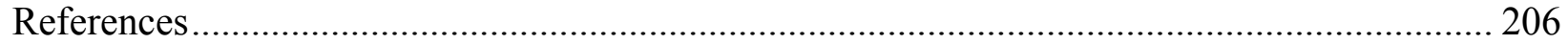




\section{List of Figures}

Figure 1: Bennett's Developmental Model of Intercultural Sensitivity ...............................31

Figure 2: Map of Main Visits During the 2013 CEOS Trip to Ireland ................................39

Figure 3: Cover of ICA Recipe Book..........................................................................41

Figure 4: The Spectrum of Narrative Characters .........................................................54

Figure 5: Spiral Process of Narrative Learning ...............................................................60

Figure 6: Cows Grazing, Port Oriel, Clogherhead Photo ...............................................101

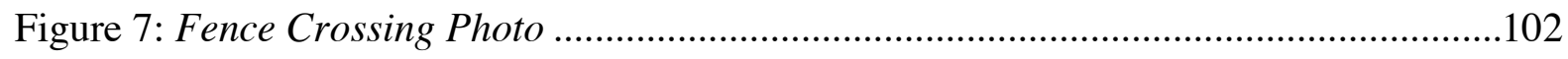

Figure 8: Cliffs at Port Oriel, Clogherhead Photo ............................................................126

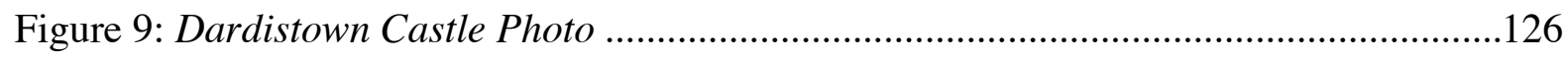

Figure 10: Hay bales beside An Grianan (lodging) Photo ...............................................135

Figure 11: Peace Wall in Belfast Photo ........................................................................135 


\section{List of Tables}

Table 1: Appalachia Context in the United States $(A R C, 2014)$........................................17

Table 2: Language Differences between Ireland and the U.S. .........................................66

Table 3: Demographic Information of Participants .......................................................83

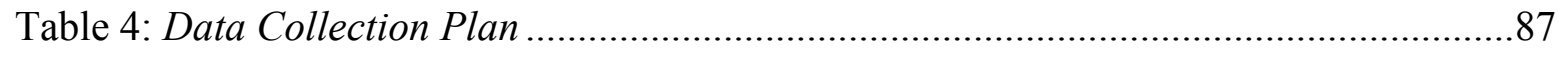

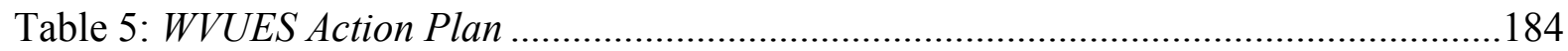




\section{Chapter 1: Rationale}

On January 4, 2001, I was almost 22 years old and was preparing to fly in an airplane for the second time in my life. I was leaving my home state of West Virginia for an independent study abroad trip for four months in Santander, Spain. This was the first time I had been away from my home state for more than 10 days. Little did I know this would become the first of many international travel opportunities I would experience. Traveling to Spain caused a focal shift in my life narrative. It caused me to have each foot planted in a separate life: my love of home, and my love of being abroad. The benefits I have seen within my own life, such as being more open to other people and their cultures, forming deep connections, and craving new experiences, have stretched me as an individual and an educator. From my first international trip, I was able to learn that culture is in constant change. The context in which a person lives as well as other people in their life can cause a cultural change on both the individual level and the communal level. For example, my family hosted three exchange students during my early teen years, which provided me a thirst for new cultures and changed my perceptions of the Appalachia context in relation to other places. This began my interest in how international travel affects the stories that participants tell about themselves, their communities, and the world. These stories have the potential to affect cultural change on both individual and communal levels.

A bit later in my life, there was a second pivotal opportunity to learn from non-formal study experiences abroad. I grew up in a youth organization called 4-H, which is a part of the Extension Service of the land-grant university system. Two months before I was hired as a 4-H and Youth Development Agent for the West Virginia University (WVU) Extension Service, I was selected (as a 4-H volunteer) to assist with a 4-H project in Mexico due to my fluency in Spanish. Since that trip in January 2008, I have served as a member or co-faculty lead on various 
other trips abroad for a wide range of audiences: faculty members, adult participants, and youth participants. Additionally, I have organized hosting delegations from Mexico, China, and Japan. Most recently, I have taken Extension participants to Ireland. Through this work, I have seen the need for quality international educational programming that provides participants the opportunity to learn from their experiences abroad and also bring back this knowledge to share with families, friends, and others at home. Moreover, very little research has been done on these types of noncollege age or non-youth international programs.

\section{Purpose of this Study}

In this dissertation, I asked the major research question of: How do non-formal international experiences influence the life stories of participants from Appalachia as they perceive it? I wanted to understand how non-formal educational experiences in an international setting affect the lives of the participants. First, I wanted to understand how non-formal educational experiences in Ireland influenced participants from Appalachia both when they were abroad and when they returned from the experience. Within this research, I wanted to understand the ways in which the viewpoints of the participants from Appalachia were shaped, created, reflected, and/or formed in relation to the international education experience as they perceived it. I especially wanted to understand the ways in which the life stories of the participants from Appalachia were affected by their international experiences. This research was not a full assessment of all participants from non-formal international educational programs, but rather it was one that focused on how the participants from Appalachia perceived their experiences in order to better understand their influences. My goal was to add to the body of current research in the area of non-formal educational experiences in an international setting. 
Within WVU Extension Service, I work with a subgroup of colleagues who collaboratively plan and deliver non-formal international programs. Additionally, we work together to address any pre-trip and post-trip matters, so this groundbreaking pilot study will impact our work moving forward. This research focused on West Virginian adult participants from a non-formal educational program to Ireland sponsored by the local West Virginia University Extension Service (WVUES). I selected this trip to Ireland for Extension participants because English is the dominant language in Ireland, and it was viewed as a safe place to travel by our Extension participants. Therefore, the group members should not be too far out of their comfort levels. Additionally, some of the participants traced their lineage to Ireland; this is in line with the fact that Irish and Scottish ethnic influences exist in Appalachia (Tritz, Dransfield, \& Scott, 2012). During the trip to Ireland, these individuals had the opportunity to explore a new place, construct new meanings on how they viewed their lives, and reflect on the roles these opportunities played within their stories.

The findings of the dissertation begin with the five participants' individual narratives of their journeys and their documented deep self-reflections, revealing much about the patterns with which these individuals communicated their stories. While these programs shaped the participants in meaningful ways, and even caused them to act differently as citizens within their communities upon their return, the stories reveal more nuanced details. Through narrative life stories, the effects of international education on these adult participants should be found by also striving to understand the life within the historical and social context in which that life is lived (Goodson, 2013). These particularities can contribute to how WVUES designs subsequent programs, but this study also contributes more generally to understanding how contemporary rural Appalachian education initiatives are shaped by participants. 


\section{The Role of Context and Culture}

People usually do what they know. If a person grew up with a certain lifestyle or viewpoint, they would typically continue with that outlook. Society exists through a process of transmission whereas the older communicate habits of doing, thinking, and feeling to the younger and thus, social life survives (Dewey, 1944). Mimicking or imitating is a way in which younger individuals observe accepted social actions and behaviors of others. However, learning to distinguish the appropriate ways to act in different situations is a very important accomplishment in all communities, no matter the age of the individual (Rogoff, 2003). It does not matter if the individual is a child or an adult, it is crucial to be able to interact with individuals from a variety of cultures. According to Bourke and Burns (1998), a person should learn and utilize their self-preservation techniques in order to maneuver diverse environments, settings, and community; thus, the individual becomes adept at being a member of multiple learning cultures and communities. Using self-preservation as the premise aligns more with a "tolerating diversity" mindset than an "accepting diversity" mindset; however, it does demonstrate how people learn about other countries and cultures in comparison to their own. As such, both youth and adults must be cognizant of the differences surrounding all aspects of diversity.

Understanding and appreciating diversity is part of a major goal of study abroad experiences so that the participants learn to value the host culture as well as their own. Since this research focuses on adults, age is a factor to consider when examining an individual's perspectives and perceptions of themselves and the world. As Erickson (1968) explains, adults are more likely to have a further developed sense of self, or perception of oneself, than youth due to exposure to multiple contexts in the life-long and open process of identity development. 
Worldviews and identities (for example as rural, from Appalachia, White, working class, and American) are formed by the continuous interaction between the person and the context. If the context remains within the same vein, then one's worldviews and identities would continue to develop along that same thread. Bennett (2004) argues that individuals who have received largely monocultural socialization normally have access only to their own cultural worldview, so they are unable to experience the difference between their own perception and that of people who are culturally different. By providing the adult participants of this study with cultural differences, there is likely to be growth in the individual's understanding of diversity and potential changes in one's worldview.

In this chapter, I explore the role of Appalachian cultural influences in non-formal education abroad and explain how these programs create opportunities of agency for these participants from Appalachia. More so, I refer to residents of Appalachia rather than calling them Appalachians so that I honor the vast diversity amongst the people of this region and to aid in dispelling commonly held assumptions. Next, I investigate critical educational perspectives and their relation to Appalachia's cultural context, not just from a historical viewpoint, but a current one as well. Then, I examine how progressive educational perspectives undergird our non-formal international education programs. Particularly, I delve into the progressive movement's connection with the programs of the WVU Extension Service. Lastly, I consider how international programs are a part of multicultural and intercultural education, specific to the Appalachian region. The importance of this study includes both an individual and a societal perspective as it takes into consideration the historical, social, and political contexts in which the experience occurred. This research looks at the life of the participants and how the non-formal international education experience shapes their outlooks, trajectories, and life stories. 


\section{Context of Appalachian Culture}

When considering one's context, it is just as important to look at their past as it is their present (Rogoff, 2003). The same consideration exists with the people of Appalachia and their region, especially with respect to its cultural and socio-political positioning (Whisnant, 1983). In

order to better discuss the contexts of Appalachian culture, the concepts of "culture," "rural," and "Appalachia" must first be defined as they relate to this study. First, "culture" can be defined as the following for the parameters of this research:

Culture can be understood as the ever-changing values, traditions, social and political relationships, and worldview created, shared, and transformed by a group of people bound together by a combination of factors that can include a common history, geographic location, language, social class, and religion. (Nieto, 1992, p. 129)

Nieto's definition of "culture" clearly articulates the categories that factor into creating a culture, including components from historical, behavioral, and moral perspectives. This definition was chosen because it takes into consideration key aspects that influence context: a common background, locality, speech, class, and spirituality.

\section{The Concept of 'Rural'}

As for the concept of "rural," it has often been used interchangeably with "country" in common discourse, often with a negative connotation meaning poverty and "backwards" culture (Whisnant, 1983). "Rural," according to the United States Census Bureau, is comprised of open country and settlements with fewer than 2,500 residents; urban areas comprise larger places and densely settled areas around them of 50,000 or more people (Economic Research Service, 2013). As this definition considers both geography and number of inhabitants when classifying a 
location as "rural," it was used in this study. Lastly, the term "Appalachian" refers to the geographical area in the United States known as Appalachia, and is comprised of parts of these 13 states: Alabama, Georgia, Kentucky, Maryland, Mississippi, New York, North Carolina, Ohio, Pennsylvania, South Carolina, Tennessee, and Virginia as well as the entire state of West Virginia (Appalachian Regional Commission [ARC], 2014). According to the ARC (2014), 42\% of Appalachia is considered rural; whereas $51.3 \%$ of West Virginia residents live in a rural environment (United States Census Bureau, 2016). As most residents of Appalachia live in rural settings, it is important to look at the complexities of Appalachian and rural identities through an intersectional approach that includes facets such as social class and gender. The definitions of these concepts for the scope of this study are necessary as I discuss the context of Appalachian culture below.

\section{Appalachia: Then and Now}

In studying culture, it is imperative to remember that "no one generalization holds true for the entire region or over time" (Lewis, 1999, p. 22). This is the case with Appalachia as well as other cultures, both mainstream and marginalized. From the outside looking in, residents of Appalachia are often stereotyped as hillbillies and ignorant. As Sohn (2006) explains: “A hundred years of outsiders coming to this region...outsiders who had used up resources and moved away, or like missionaries and government workers, had given the impression that local people could not solve their own problems and that their ways were somehow not good enough" (p. 50). This notion of the hillbilly stems from outsiders needing justification to exploit the resources of this region. This characterization was utilized for more than two hundred years in order to validate the manipulation of the people of this region by outsiders who viewed the residents as unfit to grasp the economic value of their land (Shapiro, 1978). Unfortunately, we 
still live in a society that believes the "colonizer" is a better caretaker of the land than the natives (Sohn, 2006).

Furthermore, this project has taken on more complex global dimensions. In industries like timbering, coal mining, chemicals, and now fracking, residents of Appalachia provide the workforce that allows for an economic influence for the duration of these "booms," while the environmental impact lasts much longer. From the first travelers to the mountains of Appalachia to the present, the stereotypes have not changed, nor has the rationale behind their usage. According to Ledford (1999), "When we find hillbillies today in movies, newspapers, and plays, their presence still reflects the nation's struggle over the uneven ground of economics and class" (p. 64). Part of the economic and class aspect is why there is poverty in Appalachia.

The generally held myth about poverty in Appalachia is that it is a result of their isolation from the outside world, yet it is actually due to their integration with the capitalist economy (Billings \& Blee, 2000). This myth directly correlates to the aforementioned discussion of the hillbilly stereotype and company and corporate interests, as well as to the current context of globalization in which marginalized labor has become more complex and diffuse. These companies came and continue to enter Appalachia as "caretakers" of their resources, take the assets, and then move on to another location. This aspect of the Appalachian economy is cyclical as it has occurred from the $18^{\text {th }}$ century to present day; and it is a continual component that affects their culture. Around the world and particularly in the developing countries, the effects of globalization and the marginalization of workers contains parallels to Appalachia; whereas the particular histories and stories differ, globalizing influences from above and below affect lives in disturbing and inequitable ways (Apple, Kenway, \& Singh, 2005). 


\section{Gender in Appalachia}

The previous paragraph discussed class in relation to Appalachia and globalization; this next paragraph will discuss how gender affects Appalachian culture as well (Latimer \& Oberhauser, 2004; Sachs, 2014). Most often, women from Appalachia, whether married or single, are the primary caretakers of the home and of the children (Manoogian, Jurich, Sano, \& Ko, 2015). More rural women have entered the workforce; however, this is in order to maintain their standard of living with the decline of rural men's employment (Sachs, 2014). For example, research indicates that women in the coal mining industry are limited in their advancement due to gender stereotyping. Similar issues with gender bias can be seen as well in the maledominated oil and gas industry, especially with the perceptions of job expectations by both rural women and men (McHenry-Sorber, Schafft, Burfoot-Rochford, \& Hall, 2016). I have seen this occur personally during my time with a local energy company and it is one of the reasons I began looking elsewhere for employment. I felt as though there were only a few jobs for which women were 'best suited' and those were not positions that I would find challenging. Instead, they were secretarial or administrative in nature. In Appalachia, there has been a recent economic restructuring where more women are entering the workforce; however, they are disproportionately employed in casual, flexible jobs, primarily in the service-sector (Struthers, 2014).

\section{Race and Ethnicity in Appalachia}

In addition to class and gender, race and ethnicity have also affected Appalachian culture. Racial and ethnic diversity has existed in Appalachia for many years. According to Lewis (1999), the region was originally inhabited by Native Americans and then European/Caucasian settlers arrived. Next, African slaves were brought to the area before immigrants from other 
nations came to Appalachia. Most of these immigrants, as well as a number of African Americans, worked in the mining industry in Appalachia. However, the workers with English heritages were more likely to be in the upper echelon positions, whereas Blacks and immigrants worked in the lower, more dangerous jobs (Lewis, 1999). There are still remnants of this racial/ethnic divide today. For example, during my 22 months with a local energy company, I rotated to three mine sites with roughly 450 individuals at each, totaling 1,350 employees. The majority of these individuals were white males; the remainder were either African American or biracial.

While I worked for this company, there was only one African American in a supervisory role and he was from a regional office, not one of the three mine sites. Other African Americans were union, or hourly, employees. Ralph Cowger, my father, worked for this same corporation for 37 years and in his time, he remembers four African American employees in company positions, while there were at least three times as many African American employees in the union, showing inequity regarding advancement. According to Cowger, most of these African American employees had indicated they were not interested in salary jobs anyway; however, the company is the one who offers the positions (R. Cowger, personal communication, January 11, 2015). Unfortunately, race and gender continue to be negative economic factors in rural areas, such as Appalachia, resulting in women and people of color being at greater disadvantage in these labor markets (Latimer \& Oberhauser, 2004; Sachs, 2014). Individuals with these characteristics make up the subset of the low socio-economic class in Appalachia.

\section{Class in Appalachia}

Class, or socio-economic status, is a force that shapes and interrelates with one's cultural perspective when growing up in Appalachia (Whisnant, 1983). Maintaining a divide amongst 
classes was the original rationale for stereotyping residents of Appalachia as 'ignorant' and this has had a residual effect. Research has demonstrated that residents of a rural setting have more economic difficulties than those who live in an urban setting due to reasons such as job shortages, lack of upward mobility, etc. (Sachs, 2014). While urban residents may see fewer businesses, fewer stores, and fewer restaurants as a negative factor, rural residents see positives, such as less traffic, less pollution, and less congestion. There is also the assumption that there is less crime in rural areas as opposed to urban locales; however, it is false (Sage, et al., 2013). The act of turning a negative critique into a positive one demonstrates how residents of Appalachia possess a need "to be respected for who they are and what they bring to the multicultural table" (Sohn, 2006, p. 2). Both urban and rural locales have positive and negative aspects, neither is better or worse than the other, even though adverse perceptions persist of these marginalized populations. As for residents of Appalachia, they seek to be appreciated as a whole and viewed as equals to other regions of the nation, no better and no worse (Sohn, 2006).

The idea of being the "Other" is a continual thread throughout the historical and cultural context that encompasses Appalachia (Shapiro, 1978). Often, this region and its citizens are portrayed as ignorant and serve as the punch line to jokes; however, like any marginalized group, they request an "etiquette of equality" which asks that they "be treated as equals...regardless of economic and social status" (Fiene, 1988, p. 53). Therefore, it is important to look at the educational systems through a critical perspective, which I will explain and connect to Appalachia and its people from its past to current times. Additionally, the combination of an international experience and a critical theory viewpoint should provide more reflective opportunities where residents of Appalachia may reject their passive role in society and promote an awakened mindset in the current world. 


\section{Critical Educational Perspectives}

In Pedagogy of the Oppressed, Paulo Freire (1970) says that "human beings are praxisthe praxis which, as the reflection and action which truly transform reality, is a source of knowledge and creation" (p.100). Seeing action and reflection as a continuum to create knowledge aligns with John Dewey’s (1944) work, as Dewey believed that a forward and backward connection between our actions and their consequences was needed for learning to occur. Dewey felt that thinking needs to be involved with experience so that an individual can learn from the positive or negative results of the actions taken. To connect the action to consequence allows for the learner to push the reflection further in order to understand the linkage between the active-passive event of 'learning from experience' (Dewey, 1944). Freire's literacy-as-practice work with marginalized populations in Brazil and other locations around the world is applicable to Appalachia, its history, and the present. In the United States, Freire considered its educational system to be a "banking system," where the participants are receptacles waiting for the knowledge of the educator to fill them. His problem-posing pedagogy promoted political knowledge and action toward changing status quo power relations that was interrelated with education.

Stereotypically, residents of Appalachia are seen as ignorant and knowledge from outsiders is viewed as a gift to aid in improving the lives of citizens of Appalachia (Shapiro, 1978). However, the knowledge is shared through the "banking system," which is based on memorization and regurgitation (Freire, 1970). It lacks any authentic thinking done by the participant. This enables a classed and raced social system to flourish and keep the oppressed in their current state. By utilizing an educational approach such as this, the marginalized accept their role as passive and adapt to the world in its current state (Freire, 1970). This has occurred 
from the first timber company arriving in Appalachia for its natural resources to the present day belief that Appalachia would have nothing left without the mining industry (Lewis, 1998).

On the other hand, what Freire (1970) termed the problem posing educational system creates an environment where the educator and the participants learn from one another. Unlike the banking approach, this method does not dichotomize the activity of the teacher-student. In the problem-posing approach, all parties are involved in the process; the teacher and the students create an environment where true knowledge will emerge. This is done as the educators and youth take responsibility of both the actions and the results in problem-posing. This approach also includes a reflection component after the results have been determined. This latter method of education humanizes the participants, which leads to an individual arriving at a fully realized humanity. A fully realized humanity culminates to freedom for the community involved, not as individuals. This freedom would be for the oppressed that are no longer seen as objects by the oppressor in addition to the oppressor regaining his/her humanity that was lost by oppressing others.

In the case of Appalachia, the oppressors were religious organizations that saw the region as "unchurched" as well as outside businesses that came for Appalachia's natural resources (Whisnant, 1983). Essentially, the oppressors were those who saw themselves as better stewards of the parts of Appalachia in which they were interested, i.e. coal, timber, and souls. Freedom from the oppressors has been occurring in recent years in this region. Some residents of Appalachia have been fighting against companies that are destroying the environment, such as those doing surface mining. Conservation has become a focus, as has recent research and action into maintaining the Appalachian dialect (Hazen, 2014). 
If attempts are made by the oppressor to free the oppressed, without their participation, it is considered "false generosity" (Freire, 1970). "False generosity" is not a new concept to Appalachia. In 1964, President Lyndon B. Johnson visited eastern Kentucky to promote the "War on Poverty." Yet, fifty years later, one third of residents from Appalachia are still living in poverty (Fessler, 2014). In a recent article discussing the fiftieth anniversary of the "War on Poverty," a resident from Appalachia Lee Mueller explained why this false generosity did not work and what actually occurred as a result of this agenda: "We knew the region was poor, but there wasn't a stigma to it - to us..." (Fessler, 2014, para. 12). Fessler went on to explain that this was the case because people did not think of themselves as poor; there were not any rich people around to show them otherwise. Whereas residents of Appalachia in this example were oppressed by their poverty, they wanted to retain their agency rather than be told who they were and what they needed by the government.

According to Freire (1970), no matter what the reasons, if one takes away another person's ability to make decisions, one has made that person an object. Being able to make their own decisions and participate in "authentic thinking" allows an individual to regain their free will and subsequently their humanity (Freire, 1970). Historical trends indicate the need for the marginalized to regain their humanity and their freedom. While Freire's work is primarily related to social classes, it is applicable to most marginalized groups, such as race, gender, ethnicity, age, religion, sexuality, etc.

\section{Including the Marginalized}

With respect to gender, its differences, and the societal effects on gender, the impact that Western society has on this subject focuses on only having the options of "man" and "woman" (Lloyd, 2004). In my experience as a Western culture native, having two accepted genders in a 
society channels the individuals of those two genders into norms of socially permissible behaviors. However, when looking at these two gender groups, society focuses on the differences between them. Those same permissible behaviors that are accepted within one gender must be dissimilar in the other gender to avoid the "sameness taboo" (Lorber, 1994). This is especially true in Appalachia. Gender in Appalachia is very much a structure in which a person operates as dictated by society, what is expected, and how to respond accordingly (Latimer \& Oberhauser, 2004). There may be disruptions to this structure on an individual level, but the gender norms still exist. Along with these generalizations, there is inequality based upon them when a correlation exists between gender and the hierarchy in Appalachian culture. While gender discrimination is illegal, the inequality occurs in positions of power, for example governmental and military power, and can also occur within the home (Lorber, 1994).

Different characteristics, such as ethnicity, gender-role, and class, affect one's personal and professional achievement, positively and/or negatively (Sachs, 2013). Individuals were, and in many cases still are, assessed on their abilities based upon stereotypes associated with their gender-role, race, or class. The WVU Extension Service works with these perspectives in a variety of ways. The Agriculture and Natural Resources Unit sponsors a "Women in Ag" Conference annually to advocate for women in a male-dominated field, collaborating with outside agencies to offer the conference. As few women are going into the hard science fields in college, the 4-H/Youth Development Unit utilizes a science, technology, engineering, and math (STEM) curriculum during the camping season and throughout the year with assistance from other colleges at WVU. The goal is to make STEM fun and engaging, thus exposing girls and boys to the opportunities available in these majors. The Families and Health Unit collaborates with the Agriculture and Natural Resources Unit to provide education for men and women on the 
proper techniques of processing venison. Historically, women from Appalachia were the primary caretakers of the home (ARC, 2004; Sachs, 2013), so this program addresses an educational need for them as well as offers new or renewed skills to men from Appalachia. These programs are good examples of collaborating with others to provide educational programming.

As international education is a topic for both sexes, we should offer programs that speak to men and women. Our CEOS Trip to Ireland was predominately female in attendance as is the CEOS organization. So, it is imperative to look at how more men can be reached. The programs are open to anyone who would like to participate, including individuals and/or couples who are LGBTQ+. Logistical considerations would need to be considered to ensure their physical and emotional safety, such as restroom usage, roommate options, and program planning. While these aspects need to be reflected, it is also imperative to ensure that the individual does not feel "outed" by any of these considerations either. This could be achieved by collaborating with other Extension Units, other colleges within WVU, or even outside organizations.

\section{Appalachia from a Critical Perspective}

Specific to the U.S. and Appalachia, statistics related to age, class, race, etc. come from the Appalachian Regional Commission (ARC). The ARC data show more alignment in national and regional demographics than what is stereotypically held as "true." Table 1 includes a comparison of the demographics between Appalachia and national averages (ARC, 2014). 
Table 1

Appalachian Context in the United States (ARC, 2014)

\begin{tabular}{|l|c|c|}
\hline \multicolumn{1}{|c|}{ Demographic Information } & Appalachia & United States \\
\hline Percentage of citizens that live in rural areas & $40.0 \%$ & $20.0 \%$ \\
\hline Percentage of citizens under the age of 18 & $22.4 \%$ & $23.9 \%$ \\
\hline Percentage of citizens ages 18-24 & $9.7 \%$ & $10.0 \%$ \\
\hline Percentage of citizens ages 25-64 & $52.7 \%$ & $52.9 \%$ \\
\hline Percentage of citizens ages 65 and older & $15.2 \%$ & $13.2 \%$ \\
\hline $\begin{array}{l}\text { Percentage of citizens who are White, non- } \\
\text { Hispanic }\end{array}$ & $83.5 \%$ & $63.7 \%$ \\
\hline $\begin{array}{l}\text { Percentage of citizens who are Black, non- } \\
\text { Hispanic }\end{array}$ & $9.1 \%$ & $12.2 \%$ \\
\hline $\begin{array}{l}\text { Percentage of citizens who are Hispanic or } \\
\text { Latino }\end{array}$ & $4.2 \%$ & $16.4 \%$ \\
\hline $\begin{array}{l}\text { Percentage of citizens who are "Other"*, Not } \\
\text { Hispanic }\end{array}$ & $3.1 \%$ & $14.7 \%$ \\
\hline $\begin{array}{l}\text { Percentage of citizens that live below the } \\
\text { poverty line }\end{array}$ & $16.6 \%$ & $\$ 43,735$ \\
\hline Average income based off of per capita & $8.1 \%$ & $8.1 \%$ \\
\hline Percentage of citizens who are unemployed & $84.1 \%$ & $85.7 \%$ \\
\hline $\begin{array}{l}\text { Percentage of citizens with a high school } \\
\text { diploma or more }\end{array}$ & $21.3 \%$ & $28.5 \%$ \\
\hline $\begin{array}{l}\text { Percentage of citizens with a completed } \\
\text { bachelor's degree or more }\end{array}$ & $15.6 \%$ & $11.9 \%$ \\
\hline Percentages of citizens who have a disability & $10.4 \%$ & $9.3 \%$ \\
\hline $\begin{array}{l}\text { Percentages of citizens who are veterans } \\
\text { (ages 18 and over) }\end{array}$ & $1 n \% 949$ \\
\hline
\end{tabular}

* "Other" includes the following racial groups: American Indian and Alaska Native; Asian; Native Hawaiian and Other Pacific Islander; Some other race; and two or more races.

There are four components of Table 1 which are particularly relevant for this study. First, the average per capita income in Appalachia is $\$ 7,886$ less than the national average, which equals to \$21.60 dollars less per day earned for the average worker in Appalachia. With this data in mind, it leads to the concern that individuals involved in Extension programs in Appalachia may have less disposable income for activities such as international travel. This is especially troubling because traveling internationally can be quite expensive. Roundtrip airline tickets can range from $\$ 400$ to $\$ 2,000$ per person, depending on the destination (Priceline, 2015). This is especially relevant since the largest economic disparities shown in the above statistics are with 
the citizens that live in rural areas. There are no international airports within the state of West Virginia. In order to travel outside of the U.S. from there, a person must either drive outside of the state or use a regional airport to connect them to an international airport. So, not only are the individuals involved in Extension programming in Appalachia making less money than their mainstream American counterparts, their travel costs are higher as it requires more domestic travel to reach an international airport within the U.S. Third, a slight difference exists around high school education, with the graduation rate being 1.6\% lower in Appalachia than that of the U.S. as a whole. Yet, the percentage of residents of Appalachia with bachelor's degree (or higher) is $7.2 \%$ lower than the national average. Thus, residents of Appalachia are graduating high school, but not graduating or perhaps even attending a traditional four-year college; therefore, since traditional international study abroad is designed for the junior or senior year of college, study abroad programs are not as widely available to this population. The people involved in Extension programs tend to have less opportunity to participate in international programs affiliated with universities and colleges as they are less likely to attend and/or graduate from these higher education institutions.

Lastly, the racial and ethnic populations vary as the percentage of Hispanics in Appalachia is only one-fourth of the national percentage; Blacks in Appalachia are three-fourths of the national percentage, and "other" racial groups in Appalachia are close to one-half of the national percentage. Racial and ethnic diversity in Appalachia will depend on the area in which a person lives, but it is not nearly as high as the national averages. While the data above does not include a number of groupings, i.e. class, family, (dis)abilities, and interests, it does indicate how residents of Appalachia fall into the majority with respect to race and ethnicity. Individuals involved in Extension programs are no different and are primarily white. The 2014 estimates 
state that $61 \%$ of the world's population is Asian (World Population Statistics, 2015). This indicates that while most citizens of Appalachia are in the racial/ethnic majority at home and may not understand how it feels to be a part of a minority population. Yet on a global perspective, residents of Appalachia are a part of the minority and this could lead to a number of experiences should they travel to non-Western countries. Being cognizant of this fact as well as other differences from the international perspective contributes to cross-cultural understanding. The notion of cross-cultural understanding is the ability for a person to become more or less "sensitive" to cultural difference (Bennett, 2004). Cross-cultural understanding is one of the goals of global education and awareness as it focuses on moving an individual from an ethnocentric viewpoint of the world to one that is aware of various cultures and their customs and values. This type of educational programming is needed not only within the traditional school system, but outside of it as well, and it is a key goal of the non-formal educational international programs that are the focus of this study.

These non-formal educational international programs are based on a social constructivist viewpoint and ideally create an environment where both the learner and educator learn from each other, such as described previously with Freire's “problem-posing” educational system. Realizing that fluid learning exists allows for reflection on previous experiences as well as generating opportunities to apply this newly gained knowledge to future endeavors. This notion of fluidity in learning and other commonalities are explored in the next section. Specifically, I discuss Dewey's Progressive Experiential Educational Theory, which has similarities to Freire's work and is integrated with the efforts of the WVU Extension Service. 


\section{Progressive Educational Perspectives}

A progressive educational perspective focuses on the education of the whole individual, not from the position of the educator or the content (Dewey, 1944). This philosophy is rooted in the learner experiencing the world and testing ideas since learning is an active process, not a passive one (Kolb, 2015). As such, progressive educators emphasize the process of how a person learns. Rogoff (2003) believes that people learn and develop through participation in shared endeavors that are grounded in communication and coordination with others. John Dewey, a leading progressive educator in the United States, viewed education, in its broadest sense, as the means of this social continuity of life (Dewey, 1944). Other key aspects of Dewey's (1944) progressive education approach include: education is a social function with a goal of developing a socialized mind; the context of subject matter is present in life, not separate from it; and education must have growth and be a process, it is not just to learn facts and dates. A linkage exists between his ideals and the curriculum and pedagogy designed and delivered through the Extension Service. Dewey believed in an individual-centered approach. Furthermore, he believed that education was the "reconstruction or reorganization of experience which adds to the meaning of experience, and which increases ability to direct the course of subsequent experience" (Dewey, 1944, p. 76). In theory, this connects directly to the Extension Service through their use of experiential education; in practice, however, improvements should be made.

\section{The Experiential Learning Model}

The Experiential Learning Model used by Extension is a participant-centered approach applicable to all ages. Moreover, participants of WVU Extension programs have chosen to be a part of these activities and the hands-on experiences they receive indicate the high level of involvement within their select endeavor(s). Dewey (1944) argued for this type of approach as it 
fully engages the attention of the individual in a manner that easily allows learning to occur. WVU Extension activities are based on the experiential learning model so that people can increase their knowledge and ultimately apply what was learned to other instances. Being able to generalize the learning to affect the future endeavors of an individual is another indicator of an individual-centered approach. In the WVUES programs, this occurs so that participants are taught life-related skills, gaining further independence, and being assets in society. Particularly in the adult programming, it is visible in promoting the continuing education of residents of Appalachia to create individuals who strive to learn new information for the rest of their lives. For all ages, Dewey (1944) was an advocate of individuals receiving skills essential to life and learning. Education is the social continuity of life and continuing to learn can have a positive effect on a community, from babies to the elderly.

The Extension Service is a proponent of this model that can be explained in three simple steps: do, reflect, and apply. They consider learning to be a process that involves breaking the experience down into the three parts mentioned above. First, they have the action of participating and working in a different environment. The next step is to think or reflect about that experience and context. And lastly, they strive to encourage their participants to develop their critical thinking and problem solving skills as they reconstruct their event or action in order to apply what they learned to new and other experiences (Pagano \& Roselle, 2009). Additionally, this is all a continual process, so one is capable of constantly processing their experiences in order to learn from them. After looking at the Experiential Learning Model, one can see Dewey's influence throughout. The model's three steps — do, reflect, and apply — are found in his argument that it is imperative to have a forward and backward connection between our actions and their consequences (Dewey, 1944). For Dewey, this is how a person learns from their 
experiences, looking back to reflect on our actions in order to apply what we have learned to future situations. Just as Dewey argues that learning is growth and a constant process, the same reasoning is seen in the Experiential Learning Model. An area of growth would be in the ability of the educator to facilitate the 'reflect' and 'apply' portion of the model. Dewey would allow the learner to state various aspects during these two stages, as long as they would be able to articulate the learning achieved. However, some educators tend to lead the learner to only the pieces they deem as important to remember. With our non-formal international educational experience, it was imperative to allow the participants to reflect daily on the information they felt held significant learning for them. Below is a reflective blog entry by one of our participants prior to leaving for the non-formal educational international trip to Ireland:

It is hard to believe that we will be heading to Ireland in just a few days. This trip is a lot of firsts for me. I've never been out of the country and this will be the longest vacation I have ever taken. With that being said, I could not be more excited. From getting my passport to finding out about the differences in power voltage for my electronics, I have enjoyed every moment of the journey so far. I know that this is just the tip of the iceberg for the wealth of knowledge I will gain on our ten-day trip. Of course, getting ready for the trip has been interesting. I sat down last week to begin writing out my packing list to ensure that I have everything that I would need for the trip. However, all I could come up with was bread and milk. For some reason, my shopping list kept coming into my mind. I do realize that I won't need to pack either of those for this trip. Each day I keep looking over the list so that I will remember to pack what I need. While I will be blogging the journey for CEOS, I will also be journaling for my own benefit. I haven't written in a journal since fifth grade but I want to make sure that I can look back on all of the 
memories that are made throughout the trip. Between the small mementos that I collect and pictures I take, I know that the journal will serve as a reminder of a trip to a country where I have always wanted to visit and that contains so much of my family's history. (David, August 20, 2013)

From this short excerpt, the learning that was occurring for this individual involved learning how to travel internationally as well as methods to document the experience. This blog entry also reflects Dewey's viewpoint on the continuous nature of learning across the spatial spectrum. The individual is referring to the past, present, and future. The reflective blog also contains a familial reference, which demonstrates the interest the learner possesses in the location, which is an essential component of Dewey’s approach as previously mentioned.

Since Dewey (1944) felt the purpose of education was to offer learning activities that appeal to the dominant interest of the individual, this is why they should have a say in their learning. In the case of the 2013 Community Educational Outreach Service (CEOS) trip to Ireland, the interested individuals were asked what types of classes they would be interested in taking, and three were selected from those suggested by the participants. Then each participant was able to select the class in which they would partake while in country. Also, the WVUES Community Educational Outreach Service (CEOS) demonstrates this ideal with their selection process for their adult educational lesson topics. The Continuing Education Committee (comprised CEOS members from around the state) selects these adult educational lesson topics annually from a list of proposed subjects. In the past five years, at least one of these 12 selected topics have had an international premise. Members also choose whether or not to participate in club, county, state, national and/or international events. Also regarding WVU Extension efforts, 
clientele can opt to join organizations that volunteer annually (i.e., 4-H, CEOS, or Master Gardeners), sporadically (i.e., 4-H or CEOS), or simply take a one-time class or series (i.e., Energy Express, Food Preservation, Venison 101, and Dining with Diabetes). The effort on the part of the community resident can be as minimal as choosing to be on the mailing list to receive their County Extension newsletter or picking up their free WVUES Garden Calendar each January. Each of these areas includes an international component that will hopefully spark the interest of local residents. Dewey (1944) says that education is a fostering, nurturing, and cultivating process. However, if there is no interest on the part of the individual, true learning will not occur. Also, if the individuals involved do not see or agree with the importance of the topic, it is difficult to educate others on a subject. There are some individuals within the Extension Service that do not understand the importance of global awareness, thus they are less likely to promote international programs.

As previously mentioned, demonstrating the link between local and global has become more pressing in recent years. There is ample research to support the importance of global awareness as well as the barriers that exist for non-participation in international programs (Boyd et. al, 2001). While rural areas are often quite culturally homogenous, globalization affects these regions just as it impacts urban locales (Louisy, 2001). Additionally, rural residents need to comprehend the relationships between countries and cultures on a global scale as they strive to overcome their own social marginalization (Jackiewicz, 2006). A limitation is the lack of information on non-formal educational programs in an international setting, such as those led by the Cooperative Extension Service. This is particularly the case with research on participants from rural areas like much of Appalachia and pertaining to the learning that occurs from these 
types of programs. The following section details how international programs are utilized as a multicultural educational approach.

\section{International Programs as Multicultural Education}

International programs should be utilized as a way in which multicultural education can be taught. One approach would be by providing a perspective that allows individuals to focus on the different ways people learn as they participate in and are guided by the values and practices of their cultural communities (Rogoff, 2003). Essentially, the participants are made aware of the learning that occurs both within and outside of their cultures. Thus, educators would promote a multicultural citizenship that allows participants to maintain their cultural and ethnic connections while helping them to attain the knowledge and skills needed to participate in the larger civic culture and community (Banks, 2001). Proponents of multicultural education advocate for the inclusion of context within teachings. This refers to not only the educational environment, but the perspective of the educator as well. The educational setting and the knowledge produced within it still operate within the context of geographical, cultural, and political forms of oppression (Tamdgidi, 2011). This is especially important when most K-12 educators are white, middle class citizens (Banks, 2001) and were educated within the aforementioned forms of oppression themselves. As further stated by Banks, when one's cultural connections are not incorporated within the teaching, then a monocultural education is promoted; unfortunately, a consequence of monocultural experiences is the tendency to view oneself as noncultural and nonethnic beings who are colorblind and raceless. Consequently, this leads to the privileged educating the majority and the marginalized, which connects to Freire's (1968) view on 'false generosity' that was mentioned previously. Stemming from Freire's work is the following definition to be utilized in this study that incorporates the majority of the points illustrated above: 
multicultural education focuses on basic education for all students, and it accepts and affirms the pluralism (ethnic, racial, linguistic, religious, economic, and gender, among others) that students, their communities, and teachers represent (Nieto, 1992).

Looking at WVU Extension international programs, multicultural concerns do influence their development. These include concerns for nondiscrimination in program attendance as well as specific learning theories that support education. More importantly, the personal development of residents of Appalachia who participate in WVUES programs demonstrates how valuable diversity is in addition to creating opportunities for the individuals to continue to learn through the life span, or life-long learning. However, the participants from Appalachia typically fall into the categories of gender and class diversity. Ethnic, racial, linguistic, and religious variations largely depend on their location within the state, as minorities in these categories make up a small percentage of the population in Appalachia and are clustered in particular micro-regions. If the educators and the participants fall into the same demographic set, then it increases the difficulty of allowing for the pluralism within the population to be a part of the programming. While it is imperative to create an atmosphere centered on the participants of its programs and ensure their availability to all interested residents, it is also vital to address the role of the educator. This can be done through educational programming, such as international experiences, that are designed to help educators construct new concepts of race, culture, and ethnicity (Banks, 2001).

A multicultural educational perspective is an essential aspect of program planning as it reiterates the notion that diversity is an asset (Banks, 2001). First of all, each country will have different laws, rules, and gender norms from the United States and the Appalachian region. It is important to address these cultural differences in order to be respectful of other people and their 
cultures. Participants can benefit from an increase in cross-cultural competency, which means possessing a skill set that will allow an individual to acknowledge and interact with individuals from other cultures, in both the personal world and the professional world. This may even lead to a large change in where they choose to live, or they may seek a promotion or even a different job altogether. An example is the programming in Ireland, where WVUES faculty members chose a country where a number of residents of Appalachia have genealogical ties. The Irish culture and the Appalachian culture are different even though similarities exist. Secondly, the programming includes participants no matter their ethnicity, race, language, social class, religion, gender, or sexual preference. Being able to include a variety of participants enriches the context of the programming and promotes an optimal learning experience as there are differences within the group from which the participants can learn. The members see not only a myriad of dissimilarities while participating in the program and meeting individuals from other countries, but also amongst themselves. This promotes better understanding of the participants' own communities and cultures from which they come. In other words, it takes multicultural education from the macro level to the micro level.

\section{Reflection and Introspection}

Non-formal educational international programming enables participants to learn new experiences "through a window and a mirror" (A. Slocum, personal communication, November 12, 2014). By looking through the window, it is as though the participant is looking at others and the outside, where they can learn from other individuals. This could be as a collective/cultural level or individually. Secondly, using a mirror, the participant is looking at him/herself, utilizing personal reflection. The mirror side is how the individual takes what they have learned from the window and applies it to their own life. The mirrors symbolize learning about one's own culture 
and self, while the windows are to increase knowledge about others outside of an individual's culture. The combination of being both introspective and oriented towards the outside maximizes the opportunities for learning for all parties involved. This also permits the participants to ascertain how the experiences have impacted others as well as themselves.

In my professional experience, there are challenges in doing this work. Primarily it falls within the personalities of the audience. I have seen individuals discuss how accepting they are of others, yet will tell a joke or use a term that is biased towards the groups of which they state they are accepting. I have heard people justify their overt racism based on their assumptions of that group or the opinions of a minority section of that population. Others have said to me that they "know" what it is like because they have friends from a certain race or ethnicity. However, that is not the case and it can be challenging for people to realize their notions are misguided. As a white person who traveled around parts of Mexico and Guatemala, I have experienced being in the racial minority for a short time, but that does not mean that I know what it is like on a daily basis, and I have not experienced systematic and institutional injustice due to race.

Similarly, I cannot state that I personally know poverty in Appalachia simply because I was born and raised in this region. My family is white and middle class, and even though I have heard "what it was like" stories of family members who grew up in impoverished environments, I still do not know from experience. Educating the populous from a multicultural perspective is one example of connecting the everyday to the issues of the world with a goal of taking an individual from an egocentric cultural view to an exocentric perspective. From a global multicultural perspective, it is important to advocate for a comprehensive outlook because it illustrates how the local can no longer maintain its current existence without the global and vice versa. With relation to Appalachia, this viewpoint is also essential as it connects the residents to 
others outside of their 'norm' and hopefully strengthens their sense of community on a social level.

\section{Intercultural Learning}

For many years, international educators have promoted international educational experiences to young adults as a manner in which to educate this population on cross-cultural competencies, second language acquisition, other life skills, etc. (Hadis, 2005; Quezada, 2005; Rios, Montecinos, \& van Olphen, 2007) that pertain to the area of intercultural education. Intercultural educators often identify improvements in terms of concern about international affairs, appreciation of different cultures, maturation, self-awareness and independence as well as various kinds of second language acquisition gains (Hadis, 2005). According to Rios, Montecinos, and van Olphen (2007), the most effective intercultural programs contain robust experiences where the following are incorporated: the participant practices in reflection and reconsiders their assumptions, flexibility and creativity in acknowledging one's always evolving identities as an open-minded perspective is formed, and seeking and strengthening "authenticity" without trivializing these experiences. This viewpoint of Rios, Montecinos, and van Olphen is essentially the same as Slocum's reference to the mirror and the window. The reflection component permits the participant to contemplate their personal assumptions about the new culture, as they look through "the window" of their observations of others. More so, "the mirror" involves ruminating over their own self-perceptions as they experience the culture and communicate with host nationals. These aspects are indicative to making the most of international experiences and gaining new insights.

The above components pertain to increasing intercultural sensitivity because they reveal how to further one's experiences abroad and ability to achieve new understandings. However, in 
order to capture the learning that occurs both during and post experience, various models of intercultural sensitivity exist. One such model is Milton Bennett's (1993) Developmental Model of Intercultural Sensitivity, which focuses on the growth of an individual's skills and abilities through utilizing different experiences with the end result being the learner has changed their behavior or has gained in knowledge. This model will be explained in more detail in the following paragraphs.

Bennett's Developmental Model of Intercultural Sensitivity. The basis of the Developmental Model of Intercultural Sensitivity (DMIS) stems from a constructivist viewpoint and argues that culture is a result of a lived experience of participating in social action (Bennett, 2013). The model is centered on the notion of how experiences impact knowledge and includes six stages based on how an individual's dealings with others influence his/her cultural awareness. As defined by Bennett (2004), Cultural Competence is the manner by which a person learns to value and respond respectfully to people from a variety of cultures, and as a person gains this competence, they move from ethnocentrism to ethnorelativism. Ethnocentrism is the first stage of Bennett's model and refers to the beliefs and behaviors that a person observes in their "reality" are unquestioned or "that is how life is." With the second stage, ethnorelativism is the antithesis of ethnocentrism. It refers to these same beliefs and behaviors but one option among a multitude of possibilities (Bennett, 2004). In other words, the more a person interacts with other people from various backgrounds, the more this individual seeks cultures different from their own. This can be done through understanding their importance, taking the cultural differences into account, or even integrating them into one's everyday life. The stages of the DMIS model are explained in more detail below in Figure 1. 

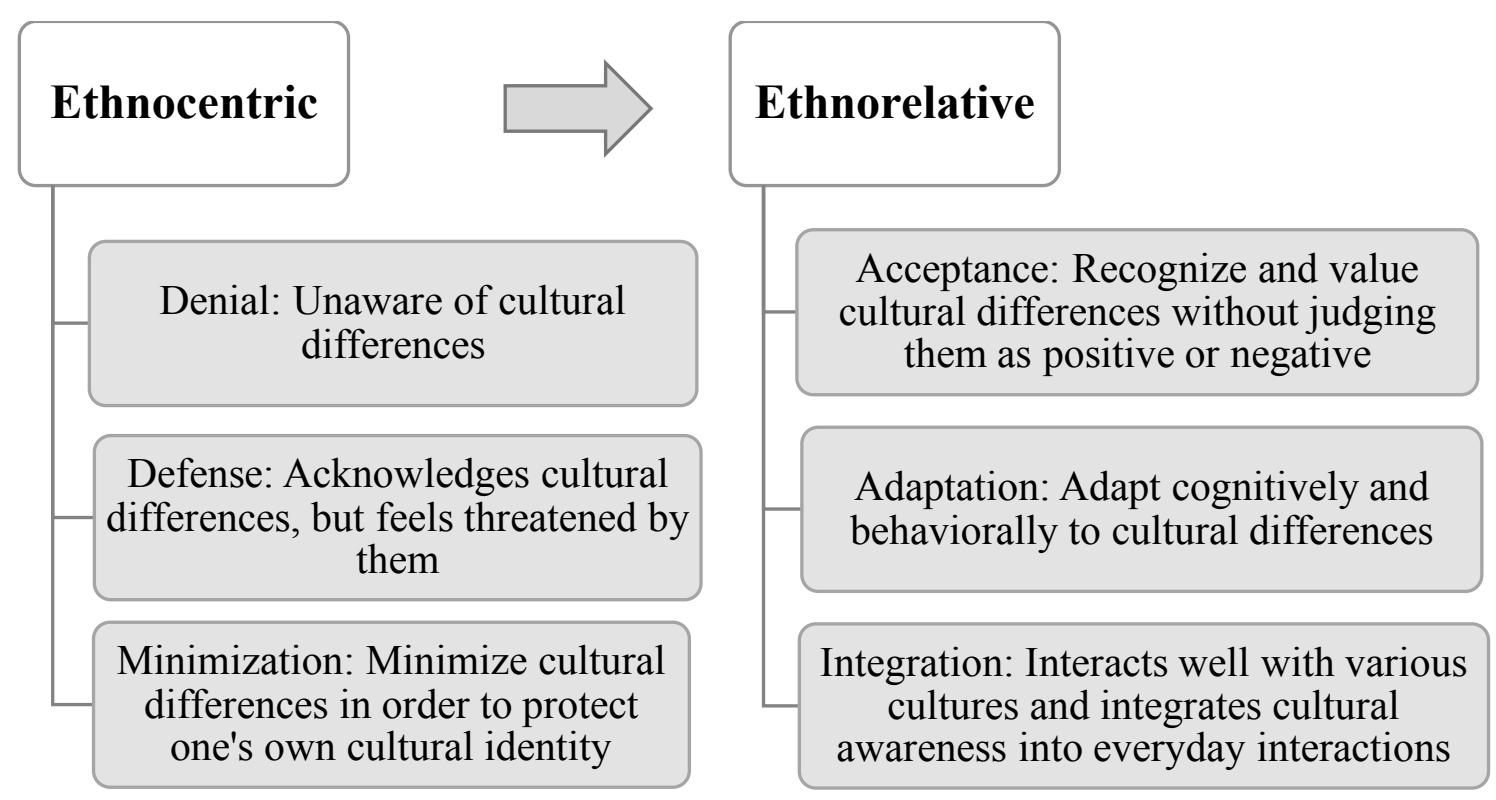

Figure 1: Bennett's Developmental Model of Intercultural Sensitivity (Bennett, 2004)

From Figure 1, one can see how Bennett's DMIS could be utilized for any type of experience as it deals with the context of cultural exchanges; it does not describe knowledge, affect, or behaviors. Ultimately, Bennett's DMIS is a model of how the assumed underlying worldview moves from an ethnocentric to a more ethnorelative condition, thus generating greater intercultural sensitivity and the potential for more intercultural competence (Sharma, Phillion, Rahatzad, \& Sasser, 2014). As the DMIS model is learner-focused and includes the importance of communication, it connects well to the educational perspectives in this study.

Both multicultural and intercultural education emphasize the importance of cultural learning since nations are no longer homogeneous as they have been in the past, as interdependency has become a guiding concept to examine the plethora of national conditions that have become transnational dilemmas (Roberts, 2007). The intensions of cultural learning are to expose the participants to a practice that enhances the knowledge of subject(s) in another culture, thus understanding the international context(s) involved (Pagano \& Roselle, 2009). Roberts (2007) also states that cultural learning emphasizes the inclusiveness of diverse 
populations and recognizes that modern life cannot be separated from local, national, and global struggles. Whether a person is living in an urban setting or in a rural locale, there is the need to understand the relationships that exist between the countries of the world. The premise of WVUES International Programming is to offer these types of learning opportunities to residents of Appalachia so that they can better navigate life, wherever they happen to choose to live. In the next section, I explain how WVU Extension organizes educational services to support international programs and explain some of the key features of the programs generally.

\section{Brief Overview of WVUES International Programs}

Looking at international programming within Extension, there is quite a time commitment involved due to differences in cultures and even working across time zones. Some planning can be done with electronic communication and some still are best suited with phone calls. Program planning can begin as much as two years in advance and may last even a year after the event when evaluation is considered. Time away from other work responsibilities while developing and running international programs must be considered as well. From an economic perspective, Extension personnel may submit faculty development grants from WVU in order to assist with the financial costs of international travel or may even use their county travel budgets as well. At times, Extension faculty involved invest their own personal funds to assist with these costs as well. Lastly, most 4-H educators are women and similarities exist between the teachers and Extension. The feminization of teaching has led to results such as devoting time to education preparation, professional development, and seeing the education of others as a valuable profession worthy of investment (Montgomery, 2009). The Extension personnel involved in international programming have these contextual influences that may affect their efforts as much as the contexts surrounding the event and the participants themselves. 
With respect to the WVU Extension, their international programs are based upon the premise of expanding the community to a global village. Essentially, the programs are designed to aid residents of Appalachia in becoming globally aware citizens. They also visually demonstrate how the country, the states, and local communities are a part of the global dimension and not separate from it. The premise of global education and engagement work is to assist citizens in becoming cognizant of the changing world environment, seeking more global awareness for themselves as well as their communities. From a long-term outlook, potential outcomes would be increasing knowledge of good decisions about improving the nature of all communities and social improvements toward positive citizenship (West Virginia University Extension Service Global Education \& Engagement Team, 2012). This foundation will be seen in the subsequent section that outlines current approaches to non-formal educational international experiences.

\section{Tailoring the Experience}

Depending on the international program, participants either register for the event (in which they are automatically included) or apply for the opportunity (in which persons are selected based on program criteria, such as language skills and previous camping experience). The recent trips to Ireland were with registered participants, while the 4-H trips to Romania, Chile, and Mexico were application-based. These specific countries were selected because of pre-existing relationships in the host country and WVU Extension was invited to participate or partner with an event. The duration of these trips was between seven to twenty days long and occurred between 2004 and the present. All of the trips have been planned by WVU Extension faculty members in collaboration with the partner institution or group of the host country. With the two trips to Ireland, there were a total of 33 adults and 10 youth who attended. The 4-H trip 
to Romania included three Extension Agents and one WVU student (who is now an agent). The three trips to Chile included five Extension faculty members, the former Director of Extension, one volunteer, and five college-age students. The seven Mexico trips have included eight Extension faculty, the former Director of Extension, two volunteers, seven high school students, and seven college-age students with some of these individuals making repeat trips. To assess learning and understand participants' experiences, most of the trips included formative reflections while in the host country and a summative written evaluation component completed by participants upon their return.

Multicultural education was explicitly taught and it was tailored to the locations and type of excursions selected. In some of these programs, participants visited impoverished communities and learned about the socio-economic situations in other countries. In another program, guided excursions provided a history of religious conflicts within the host country. Indirectly, all of these programs taught multicultural ideals through both structured and unstructured interactions with host nationals and subsequent reflection pieces. Formative evaluation techniques, such as debriefings and blog entries, demonstrated a commitment to narrative and storytelling as a form of experience-based learning (Downy \& Gray, 2012). Reflection and self-study (Conle et al., 2000) were important in developing multicultural awareness as these pedagogies assist participants in becoming reflective practitioners who can monitor their own perspectives and biases (Cruz \& Patterson, 2005).

When hosting delegations from other countries, the visitors have also been given a choice for most of their activities. Upon arriving in West Virginia, the delegations choose which 4-H camp classes in which they will participate for the week. The adults choose either to participate in a class or to teach a class to the West Virginia 4-H campers. As other activities are planned 
after the camp has ended, the delegations have typically requested to modify this time to include unstructured time with U.S. residents. The trips to Romania, Chile, and Mexico all included components where the participants were involved in the communities through assisting in organized camps and colloquiums with local youth. The previous outbound trips to Russia and the current hosting of Japanese students both have a host family component, which contributes to the participants' adjustment as well as promoting various developmental and attitudinal changes (Armfield, 2004). Moreovoer, Brislin (1981) stated that developing close interpersonal relationships with people from a different culture is one way to ensure positive outcomes of cross-cultural experiences. The contact with host nationals must be genuine and not artificial in order to for the close relationships to occur (Gareis, 1995).

Presentations of outbound experiences. Almost all of the outbound programs include participants sharing their experiences upon their return via presentations on the county and state levels at 4-H and CEOS events and meetings. The participants are aware that sharing their experiences is a part of the program sponsored by the WVU Extension Service. Some participants choose to give a presentation to their local club or county event, while others are involved with the state presentations at camps and conferences. The participants develop the presentations themselves and may ask for assistance by the faculty leads of the trips. In most cases, the faculty leads arrange for technology equipment or special items, such as food, for the state level presentations. All other components are arranged by the participants. The state level presentations have taken place at the WVU Extension State Office in Morgantown, West Virginia and WVU Jackson's Mill in Weston, West Virginia. The club and county level presentations have occurred all around the state. If it is a CEOS trip, then CEOS members are the target audience. If it is a 4-H related trip, then 4-H members are attendees. If a group has assisted 
financially to the experience, they are also invited. The attendance number depends on the location of the presentation. On the club level, it ranges between 10-20 individuals. At the county level, there are less than 50 individuals. State level presentations have ranged between 30 presentations for small workshops to $150-200$ talks for entire event presentations. Formal presentations last roughly 45 minutes to one hour and informal presentations are more likely to be 20 minutes in duration, sometimes less. This forum allows the participants a space to educate others on a variety of topics, such as history, culture, current events, gastronomy, art, music, etc. It also allows for conversations to occur related to accepting and honoring different groups of people. These efforts are to reiterate how interconnected we all are and visually demonstrate the larger picture.

Upon return from international trips, participants' sharing of experiences is included so that more individuals will be able to learn from the program. The rationale for this component is that international travel is expensive and not everyone can afford to participate. The registrationbased international experiences are geared towards middle to high income participants as they have the disposable income to afford the trip. Payment plans are available, which is a good option if the information is provided with ample time in order to not limit participation based on social class.

The application process. The application-based international programs are available to people from any social class because an expectation of working on behalf of the WVUES while studying abroad exists. Initially, the only cost to the young adult participants of the 4-H in Mexico trips was the cost of their passports, but it changed during the last few trips where these individuals needed to pay for their airfare and passports. Again, payment plans were available to the participants. This change occurred due to the increase in the number of trips to Mexico and 
the increase in hosting international groups from different countries at that time. In order to become more inclusive to all income levels, one suggestion is to lengthen the time frame for payments that allows individuals more time to save or even fundraise for registration-based programs. Also, an idea for increasing inclusivity is continuing to offer application-based programs, but with more promotion of these opportunities so that anyone interested can apply.

\section{International Experience in Ireland}

Due to the response of previous adult educational lessons on international topics for CEOS members, three WVUES faculty members proposed a topic of Irish and Scottish Influences in Appalachia. There was an overwhelming response to the lesson, which led to discussions of a non-formal international educational experience for the CEOS members. After the necessary steps were taken through both WVU Extension and the CEOS organization, a trip was planned for late summer 2013. In the following paragraphs, I will explain the planning process of the 2013 international experience. Also, I will detail the educational components the participants could choose throughout the excursion. Lastly, the interactions with the main host nationals are also described in the subsequent section.

\section{Pre-Trip Planning}

The CEOS Trip to Ireland involved 20 months of preparation that started in March 2012. Former Irish Countrywomen's Association Executive Director, Mr. John O'Callaghan provided a sample 10-day itinerary of a visit to Ireland as well as indicated a desire for the ICA to partner with CEOS in developing this visit. The trip was approved by the West Virginia CEOS Board in April 2012. An overall Planning Committee, consisting of nine WVU Extension faculty and staff, was formed in May 2012. As a part of the marketing piece, Mr. O’Callaghan and Ms. Harrahill attended the 2012 CEOS Conference in September 2012, which also allowed CEOS 
members to learn more about the Irish Countrywomen's Association and the country of Ireland. Registration for this trip was available from late November 2012 through January 25, 2013. All of these efforts resulted in 22 registered participants for the experience, including a $\$ 1,000$ nonrefundable down payment by January 25, 2013.

In spring of 2013, emails and letters were sent to the participants to provide passport requirements, the remaining payment deadlines $(\$ 2,000$ balance $)$, the pre-departure orientation in late July, and other logistical information regarding the Ireland trip. By mid-summer, three individuals canceled their reservations for the trip due to various reasons. This reduced the number of participants to 19 . On July 29, 2013, a mandatory pre-departure orientation was organized for all participants at WVU's Jackson's Mill in Weston. This orientation had multiple purposes: 1) It provided a discussion/training held on travel considerations, such as handling money, medical prescriptions, and other health and safety topics; 2) it allowed time for other travel logistical information to be discussed, i.e. airport transportation and the schedule while in Ireland; and 3) it provided an opportunity for the group to connect for the first time.

\section{During the Experience}

The group left the United States on Sunday, August 25, 2013 from two different airports (Pittsburgh International Airport and Chuck Yeager Regional Airport) and met each other, plus a third group at Dulles International Airport before arriving in County Louth, Ireland (via Dublin) the next day. The trip coordinators had a set itinerary designed prior to the departure, but they were able to work with the hosts at An Gríanan throughout the trip as changes or additions to the schedule were made. As for a final schedule for the 2013 CEOS Trip to Ireland, please look at Appendix A to see the modifications that were made during the trip. Figure 2 is the map of the 
area around the accommodations while in country and was the area in which many of the excursions took place.

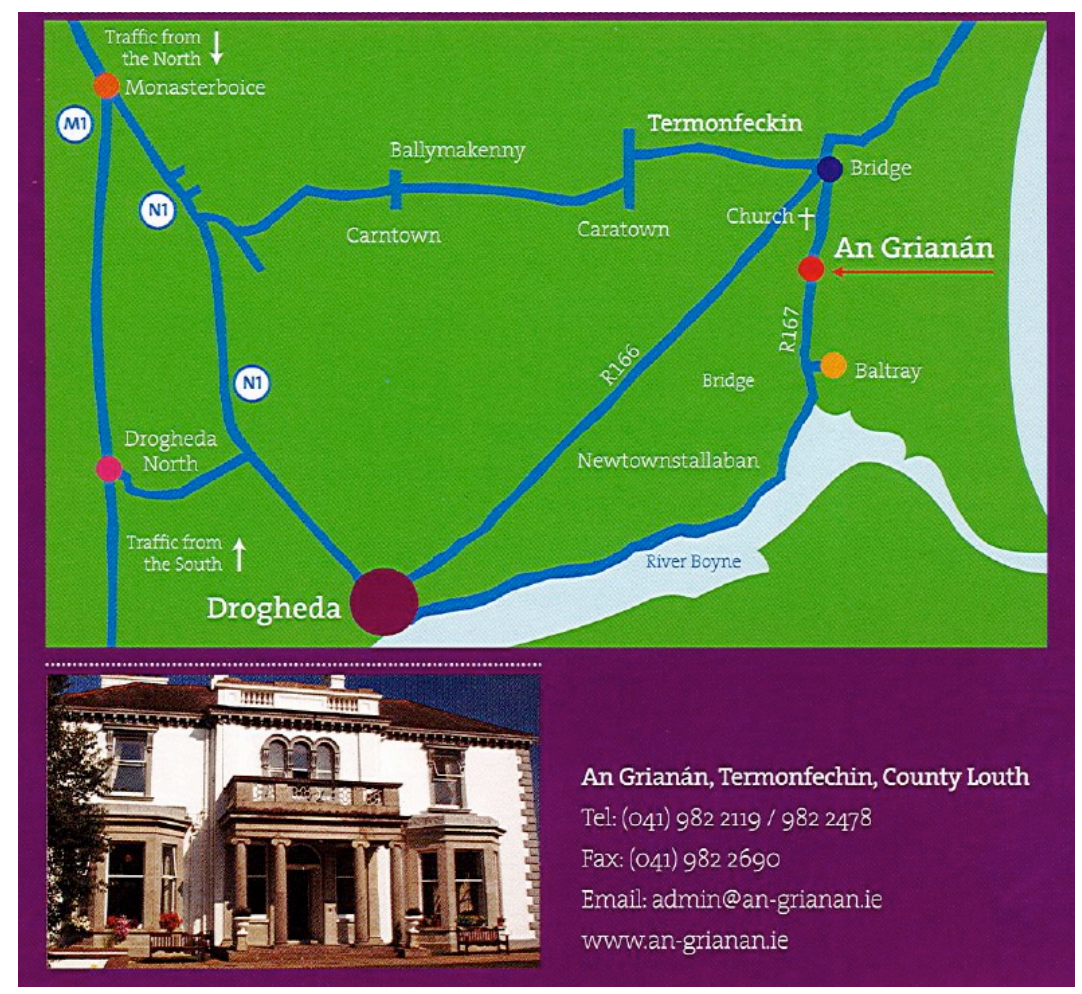

Figure 2: Map of Main Visits During the 2013 CEOS Trip to Ireland

During the Ireland trip, participants chose their own classes. While more classes were offered during registration, the participants ended up choosing two main classes: 1) Digital Photography or 2) Cookery, Gardening, and Rambling (walking). Digital Photography was a three-day class and Cookery, Gardening, and Rambling was a second three-day class with each topic lasting one day. The instructors of the courses were experts in these subject areas. The Digital Photography teacher was a photographer who has been published in the New York Times and the Cookery instructor has his own weekly cooking television show based in Dublin. The Gardening and Rambling teachers were locals whose personal interests lie in those areas. At times, the classes were held at the learning center of An Grianan and other times the participants 
were traveling the local countryside with their class. Members were able to choose to see the Book of Kells or begin shopping in Dublin. All of the evening activities were planned in coordination with the staff of An Gríanan, but the participants could choose to attend the activities or relax at the facility. In July 2015, a subsequent youth trip to Ireland was planned with a similar nature.

Host nationals. The staff at An Gríanan and ICA, the host organization, were very accommodating to the group and also provided gifts to the participants. This was similar to the behaviors exhibited by the CEOS membership when individuals from ICA visited West Virginia in October 2012, which included gifts, celebratory meals, and opportunities to share their culture with West Virginians. In Ireland, each participant from Appalachia received a knitted scarf and mitten package that were a part of an ICA national fund raiser. The items were made by the members of their organization with the name of the person who made the pieces provided in the package. Additionally, a heart was knitted into each one as it was to raise awareness of heart disease. The group could select between the colors of purple or red. Also, the participants received a gift, The Irish Countrywomen's Association Cookbook, from the organizers. This compilation of Irish recipes was from their membership all around the country, and each recipe contains the name of the ICA member and her guild (which is their term for club). Figure 3 is a picture of the front cover of the book. 


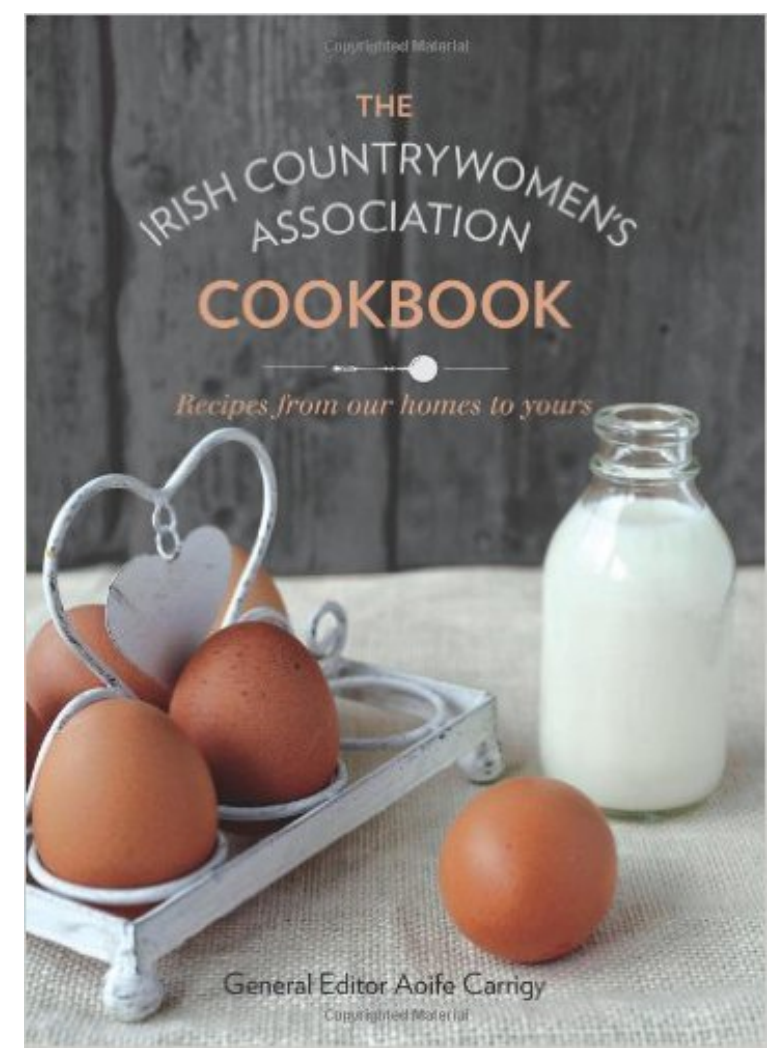

Figure 3: Cover of ICA Recipe Book

These gifts and the locals' accommodating nature are two examples of the comradery between the CEOS members and the ICA and An Gríanan that was formed during the trip, which is indicative of the close relationship needed for positive results of international experiences. This was also evident in the opportunities members had to share details and perceptions about their trip to other residents of Appalachia upon their return from Ireland. When the members spoke of their experience to those at home, it led to more learning opportunities through both formal and informal presentations. There were times during the international excursion where different members shared stories about what they were learning and were making connections to life at home. After these discussions, I began to wonder what bearing the experience would have on the lives of the participants, thus the premise of this research project was commenced. 


\section{Moving Forward}

When looking at a non-formal educational international experience, such as the trip to Ireland, one question that comes to mind is: How have these experiences affected the life stories of the participants? Furthermore, I wanted to understand how the participants were influenced both during and after the trip as well as how these experiences were viewed within the life stories of the participants. These were the complexities I wanted to understand more.

This research looks at the life of the participants and how the non-formal international education experience shapes their outlooks, trajectories, and life stories. This chapter outlined the role of Appalachian cultural influences in non-formal educational international programming. It is through these programs that opportunities of agency are created for participants of Appalachia. The possibility for agency is a key aspect due to the connection between Freire's critical educational perspectives and Appalachia's cultural context, both historically and contemporarily. This chapter also focused on the influence of Dewey's progressive educational perspectives as the center of our non-formal international education programs and the connection between the progressive movement and WVUES programming. Lastly, I discussed how international programs are a part of multicultural and intercultural education, specific to Appalachia. In the next chapter, I will begin the discussion on life stories. I will also explore the role of adult learning as well as the connection of life stories to the aforementioned educational perspectives. The limitations of life narratives will conclude the next chapter. 


\section{Chapter 2: Conceptual Framework}

The aim is to provide a story of individual action within a theory of context.

(Goodson, 2013)

I am interested in the stories of people's lives and how their various experiences impact these narratives and how they tell them. From birth and throughout our lives, listening to and telling stories surround us. As discussed earlier, Dewey (1963) and Freire (1972), in their own ways, advocate for the development of active, self-aware learners who have the capacity and freedom to frame their own purposes (Tennant \& Pogson, 1995). It is this notion of individualcentered learning that influences the life stories of the persons involved, and then culminates with the group story. The individual life story is the social script a person utilizes when telling their story; it is based on a small number of acceptable types taken from the whole of society (Goodson, 2013). It is the life story that demonstrates the type of storyteller the individual is through their voice and life details. For example, a young boy and his family move from a very rural area to a more economic city around age 12 . Some people may view this as the family wanting to better their lives; however, in actuality it was because the father lost the family farm. The life story is how a person tells a story. I am interested in how people understand and make sense of their experiences, which can be explored through the use of life stories. Through one's perceptions of their learning, I can better understand the influences related to the context, which are then explored by bringing in an analysis of timelines, documents, and historical texts about the local region. My specific research questions are:

- How have non-formal educational experiences in Ireland influenced participants from Appalachia both during the time abroad and after their return?

- How are these experiences viewed within the life stories of the participants? 
In order to examine both the learning and the stories of the participants within a historical and cultural context, I utilized narrative theory (Goodson, 2013) as my main framework through which to explore my research questions. Narrative theory stems from a social constructivist viewpoint in that the stories cannot be separated from their location in time and space, social history, and social geography. Narrative theory takes the stories we tell and views them as social patterns that involve the context in which the stories were developed, for "our stories and storylines need to be understood, not just as personal constructions but as expressions of particular historical and cultural opportunities" (Goodson, p. 6). The contextual viewpoint that narrative theory includes allows me the opportunity to understand any overlap between the life stories and the non-formal educational international experience in which the individuals participated. The utilization of narrative theory itself includes a focus on the historical and cultural context of the participants as residents of Appalachia, which is a main theme within this dissertation. With the inclusion of these societal and personal contexts, it demonstrates how life stories represent the community and its culture as well as the individual.

According to Rogoff (2003), science, religion, proper behavior, community tradition, and history are taught and learned through narratives in many communities, where narratives serve as instruction, both intentionally and incidentally. Children are often read bedtime stories, such as fairy tales or nursery rhymes, as a part of their nightly routine. It is a part of our human development as communicators. We begin telling stories at a young age when asked, "How was your day today?" or "What did you do at school?" As children, we learn to use the narrative format preferred in our cultural community to recount events by the actions of our caregivers (Rogoff, 2003). Some individuals are naturally more adept at telling stories than others; however, all partake within this realm to further mutual understanding. Everyone has a story to tell and by 
looking at them individually and collectively, we can move from a personal outlook to a public perspective. It is from the life stories of men and women that form life stories, thus offering an opportunity to delve into patterns of social relations, interactions, and historical constructions (Goodson, 2013). Moreover, the inclusion of these life stories focuses the individual experience as part of the collective with the placement of the learner at the center of the learning process.

Deliberately storying and restorying one's life is, therefore, a fundamental method of personal (or social) growth: it is a fundamental quality of education (Clandinin \& Connelly, 1989). Additionally, a person must repeat information seven to sixteen times in order to remember or retain the material (R. Walls, personal communication, Fall 2003), so telling stories is a way to keep memories "alive." In the Appalachian region, the act of telling of stories has a long history as an oral method of sharing a part of one's self and their life. Not only were family histories passed down from generation to generation, but a part of culture was included in these stories, i.e. customs, traditions, and beliefs. An example of this can be seen with the West Virginia Liars Contest that has been hosted by the West Virginia Division of Culture and History for more than 30 years (Elliott, 2006). However, another aspect to consider with the usage of storytelling is the insider versus the outsider perspective. Cautionary notes exist from both viewpoints. For example, "an insider may only have experience in one community and often assume the way things are done in their own community is the only reasonable way" (Rogoff, 2003, p. 28). Some comments from participants during the non-formal educational experience in Ireland that illustrate this point were, "They are driving on the wrong side of the road!" and requesting water for meals because "they drink too much tea and coffee." On the other side, the outsider is not neutral either as it only pertains to some situations of when the individual was present. Therefore, neither view is an absolute truth. Individuals should reflect on their 
interactions and observations with others in order to make inferences and further their awareness of the differences observed. Such action translates into revisions of understanding where both the outsider and the insider can contribute to a more enriching story collaboratively than either perspective separately.

This chapter begins by introducing generally how life stories are constructed. Then I explore the patterns that develop from life stories. Following this I discuss how the adult learner is incorporated within this framework. After this I examine the connection between life stories and critical educational, progressive educational, and intercultural perspectives. Finally, I elaborate on the limitations of this framework. Throughout the chapter, concepts are mentioned repeatedly and across different sections, which is due to the overlapping nature of these concepts and aspects of narrative life stories.

\section{Narrative Life Stories}

Our lived experiences are like a road map of our narrative story, which allows a reader to better understand the "why" and the "how" behind the individual. These narrative stories are considered central to being human because much of our sense of purpose and meaning, selfhood, values, and aspirations are based on our narratives (Grassie, 2008). Also, in some communities in which reserve is valued, messages and instruction are conveyed indirectly to people through proverbs and stories (Rogoff, 2003). From my perspective, a reserved demeanor is not overly emotional or boisterous, but quiet and modest. In some cases, a reserved character is viewed as being aloof or standoffish. One example of a reserved community is the Amish (Howley \& Howley, 2010), whereas another example is seen in Native American communities (Rogoff, 2003). Communities that have a large Christian religious influence also may value a reserved nature due to the Biblical teachings of Jesus that are provided primarily through parables. 
Historically, Appalachia had both a Native American population prior to a large influx of Christian missionaries (Shapiro, 1978) with both reserved cultures utilizing stories as instruction. As previously mentioned, many cultures use stories to teach others about their societal norms and values. Additionally, narratives are essential for humans to construct coherence and continuity in life (Taylor, 1989). It is the manner in which we, as humans, make sense of the world around us.

Ivor Goodson (2013) figures prominently in the field of narrative life stories and his work offers a strong foundation for this dissertation. As this theory was being developed, Goodson began to ask questions about life stories and the storytellers, such as why do some people spend so much time in interior thought and self-conservation about their life story while others seem far less concerned and are willing to accept an externally generated script? Essentially, he was being reflective about the notion of whether or not the researcher should accept these nuances as personality differences, or if other reasons need to be considered, such as historical and social influences? Additionally, these questions were asked as well: Do these different kinds of narrativity crucially affect our identity and agency? Do people's creativity and learning styles respond to these differences? Are there certain historical periods which favor certain kinds of narrativity over others? All of these questions speak to the desire to know some background on the individual that could impact their life story.

\section{Constructing Life Stories}

\section{Providing a Context}

The setting of the narrative needs to be identified. Whereas the historical perspective can be concrete, the cultural component of the life story is much less tangible as it is often a subjective topic. Aspects of culture such as common background, locale, dialect, class, and 
spirituality are important to recognize as they pertain to life narratives, which vary considerably according to historical periods and cultural contexts (Goodson, 2013). Since culture plays an integral part in speaking to the context of the participants, it may also influence their expectations of the experience as well as their learning while abroad. Furthermore, their experience may have some effect on their context upon their return and that is an equally significant component of this study. Rogoff (2003) explains that such changes and "borrowing" has always occurred:

Communities have continuously changed practices (often by force but also by choice or accident), and they have also maintained themes from prior generations. They have borrowed ideas from each other to enhance means of subsistence and artistic expression. They have forced ideas on each other in massive and small-scale crusades of religious practices, formal education, and moral values. They have traded and purchased and stolen ideas and knowledge from each other, such as ceramic techniques, systems of warfare, and writing technologies. And they have combined traditions and heritages as people from different communities intermarry, are captured by enemies, migrate, or engage in common endeavors that require collaboration. (p. 91)

Thus, culture is alive and ever-changing as the individuals within each culture adapt and change dependent upon both external and internal factors. This notion of culture can be observed from an overarching perspective as well as a personal viewpoint, as both connect to narratives. It is the patterns within these stories that tell us much about the society at large in addition to the individual.

\section{Patterns within the Life Story}


As Rogoff (2003) mentions above, communities change their ways as well as maintain practices from previous generations. Such themes include education, values, religious customs, and methods of communication. These customs may be traditional, more recent, or a bit of both. What a person chooses to say and how they choose to say it may be tied to the context of their culture. Cultural context is again relevant to life stories since they look at the patterns in communications, and how the person may tell their story may relate to the culture in which they were raised. These patterns in the life story pertain to how the individuals tell their story and what type of information they include. Goodson and Gill (2011) call this an individual's narrativity or their narrative character. A person that is very reflective and thoughtful will have a higher narrativity than an individual who thinks in sequential details. It is the participant's narrative character that provides the key as to how events will be integrated into the life narrative (Goodson, 2013). Narrativity takes into account the manner in which a person views their life, the events of it, and how it's all related.

In Appalachia, a notion exists that a person should not "get above their raisin"” (Sohn, 2006). While Sohn connects this concept primarily to education, I was raised to utilize the term in reference to any matter where a person "puts on airs" or acts better than from where they came. This cultural context may affect the life story, especially when an individual begins the process of 're-selfing' or developing one's sense of self and identity. In other words, a person may choose to reflect more modestly as to maintain the condition in which they were raised. I have observed this trait to be transitional, just as Rogoff implies, as it is currently seen in more of the older generations from Appalachia and less so in younger. As the culture has changed and this idea becomes applicable, generational changes in narrative character may also occur. Most life storytellers hold to a dominant style of narrative character, which demonstrates how they 
approach and recount the transitions and critical events in life (Goodson, 2013). In some cases, that may be through ruminating over choices made or simply stating events in chronological order. Below is a blog entry from one of the participants that will demonstrate as an example of her narrative style.

It's difficult to put into words my feelings thus far about Ireland. At this point, I don't believe I could write anything that could do justice to this wonderful place and its people. The fact that I have already taken over 250 pictures in two short days highlights my weak attempt at capturing visual images so that I might remember my experience here long after I am back home. I think thus far the most amazing thing I have discovered in Ireland is the people we have encountered. Their level of kindness and hospitality are beyond anything I have ever experienced. From the staff at An Grianan where we are staying to the tour guides, bus drivers, and locals, we have been greeted with a sense of warmness and welcoming that quite frankly, I haven't always experienced within familiar communities in my own home town. Always willing to help and doing so far beyond measure is a common trait among the Irish that warms the heart and touches the soul. Oh, don't get me wrong, the landscape is breathtaking and the architecture captures history like a snapshot in time. However, I think I anticipated my reaction to those aspects of our trip. Yet, the magic of Ireland's people has surprised me beyond anything that I might have expected. (Hannah, August 27, 2013)

Exploring these movements and moments in time, we can discover how an individual will perceive their life story and sense of self. According to McAdams (1996), this process of positioning one's self or "selfing" involves constructing and authoring experience as one's own, as well as appropriating, synthesizing, reflection on and simply observing experiences in such a 
way that it is deemed to be mine. Over time, "selfing" builds up and attempts to build together the Me, or in other words "selfing” over time aids in creating a person's sense of self. As for Goodson (2013), the action is called "re-selfing" and is explained as a life theme that develops a person's sense of self and identity; therefore, providing the narrative resources for the engagement with transitions and critical episodes which we tentatively call "re-selfing" - the "new self." "Re-selfing" occurs when the individual combines both knowledge and agency to change and adapt as their lived experiences transpire.

Open and closed narratives. Through the patterns within a storyline, the usage of the narratives by the storyteller emerges. In other words, it delves into "how the narrative is employed in living and directing a life" (Goodson, 2013, p. 73). The utilization of the narratives can be either "open" or "closed." A "closed" narrative contains characteristics of a predetermined path and little agency. When exposed to a transitional moment in life, this type of individual may seek new strategies; however, they continue within the same script which is how they view their identity (Goodson \& Gill, 2011). Within the context of the Ireland experience, the participants with a "closed" narrative will see no significant change in their life story or their "sense of self." Also, they may have minimal awareness of cultural differences or even minimize these differences in order to maintain their narrative.

On the other hand, an "open" narrative will contain a transformation within the individual. The "open narrative" will demonstrate a significant change during a transitional moment which will form and guide their actions (Goodson \& Gill, 2011). As for the Ireland trip participants with an "open" narrative, these individuals may be more accepting of people from other cultures with a nonjudgmental attitude. An example from our trip to Ireland was the reactions of the participants when they saw families in a pub around 10:00 on a school night. The 
majority of the participants were shocked that parents brought their children to a pub to eat dinner. They also could not believe the children were not in bed yet. Some wondered if it was a holiday. Only a couple of the participants recognized that the pub is a gathering place for the community in Irish culture. It could also be that long naps are included as part of the school day, thus children stay up later than in the U.S. This is an example of how the closed narrative follows a pre-established plan of action; the open narrative is more fluid and responds to the transitions within the life story.

\section{Types of Narrative Storytellers}

From this notion of 'open' and 'closed' narratives, four types of storytellers emerge: scripted describer, multiple describer, armchair elaborator, and focused elaborator. The scripted describer does not move away from the original script, almost the birthright script (Goodson, 2013). For example, "My father was a coal miner, my uncle was a coal miner, my great-uncle was a coal miner, my brother is a coal miner, my cousins and their husbands are coal miners." The scripted describer would say, "I am a coal miner and that's what my family does, what we always do." A similar type to this style is the armchair elaborator. While the armchair elaborators are highly reflexive, they decline the opportunities to change, to become somebody different (Goodson, 2013). Within the same story as above, the armchair elaborator version would be: My father only had a $9^{\text {th }}$ grade education and became a coal miner to provide for his family, like many of his family members. But he wanted a better life for his children, so my four siblings and I all graduated high school and attended college. I graduated with a degree in mechanical engineering and ended up in the coal mines. My brother did too. I was able to become a salary employee and that helped me keep a job during lean coal 
years in the 80's. Now, I wish I had been an accountant or something else instead that was less damaging to my body.

The multiple describer is another type of storyteller. Multiple describers focus their life stories on the description of the movement between pre-scripted societal roles as they adopt (not adapt) identities (Goodson, 2013). The aforementioned story told in this style of narrative would be like this:

My father was a coal miner without a high school diploma, so he expected all five of his children to graduate high school. Since he had not finished school, he thought it was important that we did. So, we did. He wanted us to go to college too. We all went and four of us graduated from there too. I tried to raise my kids the same way. I wanted both of them to get good grades and graduate from college. My son decided college wasn't for him. At one point, he asked me to get him a job in the mines. Thankfully, a government job came through before I talked to anyone.

While multiple describers focus on society's pre-scribed roles, the focused elaborators look at how to break away from these established patterns (Goodson, 2013). They often disturb existing family narratives. The focused elaborator description of our above story would be as follows. My father was a coal miner with a $9^{\text {th }}$ grade education. He wanted more for his children and college was meant to be that pathway. I graduated with a degree in mechanical engineering and I applied to three places, two were coal mines. I didn't want to work in the mines, but it was a good job that paid well. I got hired at the mines with the union and two years later was offered the opportunity to become a salary employee. Out of all my family that were coal miners, only one other relative was salary. We're a pro-union family. But I took the position because it meant more stability for my family. I'm glad I 
did because I probably would have been laid off within nine years and would have been laid off at least five times. Being salary was no piece of cake though. With each lay off, I was moved to a different mine, then would come back to my first mine. In 36 years, I worked in five different mines. It took a big toll on my body, my knees are shot and I can't hear certain tones. I never did really want to go to the mines and I wish I had done something different, like accounting. I always did like math and I think I would have been a good accountant or financial planner.

Figure 4 below shows the spectrum of narrative character that illustrates the notion of these four types of storytellers in narrative theory (Goodson \& Gill, 2011). Storyteller A would be the armchair elaborator, Storyteller B would be the scripted describer, Storyteller C would be the multiple describer, and Storyteller D would be the focused elaborator.

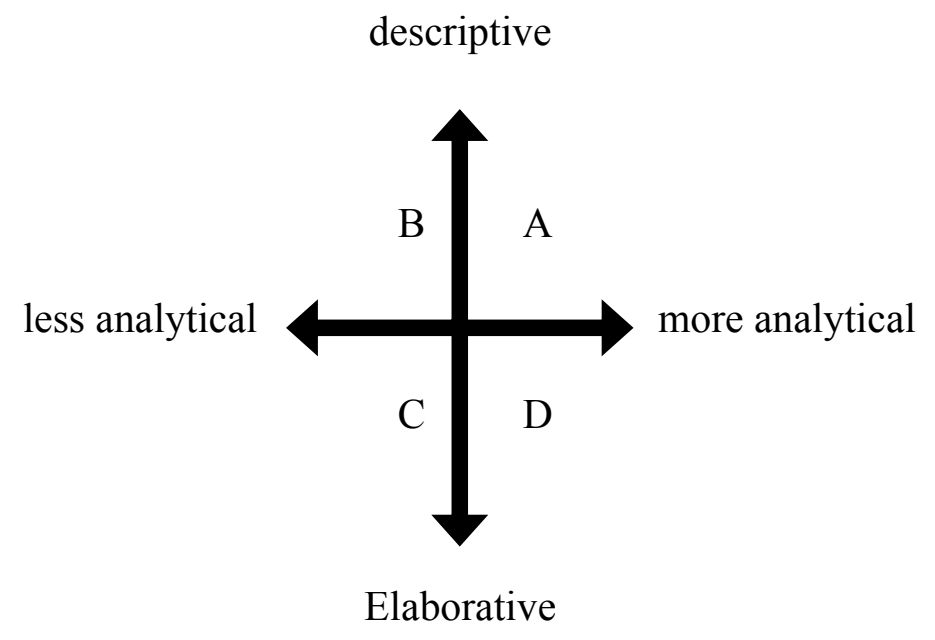

Figure 4: The spectrum of narrative character

By utilizing these four types of storytellers, the participant and the audience possess the opportunity to learn from the experiences and the manner in which the stories are told, such that: ... Narrative learning enhances understanding about oneself and the other, one's lived experience as a person over time, one's position in the world, and how histories, cultures and socio-political forces have helped shape who we, as human beings were, who we are 
now, and the journey we have travelled so far and the journey we are to travel together.

(Goodson \& Gill, 2011, p. 117)

The narrative life stories provide the mechanism through which the reader and the participant are able to gain a level of self-understanding in addition to a better comprehension of the impact of context within one's life.

The narrative life story approach to learning provides society with a profound reflection and interpretive framework for holding together lived experiences, tensions, shifts, and continuity (Goodson \& Gill, 2011). While other approaches could also be utilized, narrative inquiry connects to adult learning as it incorporates the life of the participant and the historical, social, and political context in which they have lived. The next section will further discuss the connection to adult learning.

\section{Narrative, Learning, and the Adult Learner}

Learning is a concept that is often related to formal education and the school system (Dewey, 1944). However, that is a very narrow meaning of education and it does not take into consideration the other approaches in which a person learns throughout their lifetime. According to Rogoff (2003), learning is an aspect of the transformation of people's participation in sociocultural activities. Gill and Thomson (2009) argue that learning involves the cultivation or strengthening of the personal qualities that are necessary for a flourishing life. As it pertains to this dissertation, learning is defined as "individuals changing their ways of understanding, perceiving, noticing, thinking, remembering, classifying, reflecting, problem setting and solving, planning, and so on - in shared endeavors with other people” (Rogoff, 2003, p. 237). Through this definition, learning opportunities are available through a myriad of techniques. In the context 
of this study, I will focus on learning as it relates to these concepts: rural, from Appalachia, women, and age. These various aspects are commonalities for most of the participants in this study and are a part of the cultural practices that impact the manner in which they learn.

The four aforementioned narrative types are connected to adult learning through the manner in which they recall and remember their experiences. Some may possess agency that will provide the potential for change, others may reflect on their experience, and some may simply describe the details of the trip as they remember it. From an educational perspective, the goal is for growth to transpire, no matter which narrative style the participant uses. Furthermore, as each person possesses a different starting point, their level of growth will differ as well, especially those related to diversity and cultural understanding. Goodson's (2013) four narrative types also take into consideration how these individuals view themselves and their own concept of learning. When engaging in this work that encompasses progressive, multicultural, and intercultural views, I noticed that individuals would often place their own learning into fixed or dynamic frames (Johnston, 2012). According to Johnston (2012), people with a dynamic frame of learning explain behaviors in terms of context and mental processes, thus they try to understand the behavior and educate others on new ways of thinking or doing. One of the Ireland experience participants articulated feeling inspired after a visit with an Irish native over this host national's commitment to her familial home and all the work and effort it took to maintain a 350-year-old home, which was counter to her first impression of, "Oh, just another old house."

As for a fixed-learning frame, these individuals see behaviors in terms of permanent traits and view their learning as something over which they have no control (Johnston, 2012). One participant on the Ireland trip would often ask for assistance on tasks she felt she was unable to learn. An example would be any time a currency exchange transaction was needed, she would 
ask someone close by to help her determine the amount of money needed often saying, "Well, I just can't do that." She was always appreciative of the assistance of others with the task she felt she could not learn. Both of these examples illustrate how learning connects to both Goodson's (2013) narrative character types and Johnston's (2012) frames of learning.

\section{Contexts Surrounding Life Stories}

As we have discussed with the narrative life stories, lived experiences are a method through which a person may learn. Life experience plays a major role in shaping their knowledge and new knowledge will fit into that prior knowledge (Sohn, 2006). With this study, the participants have varying levels of education and socio-economic status, but have grown up in a predominately monocultural area of rural Appalachia. Through their past experiences, the participants make meaning of these new events and knowledge. One person had never been outside of the U.S. before, while one had visited another country and traveled extensively within the United States. Bennett (2004) explains that individuals who have primarily experienced a monocultural society have not been exposed to experiences that include the differences between their own perception and that of people who are culturally different. Yet, even in a trip to an English-speaking country with similar cultural characteristics, intercultural factors exist. For example, during the Ireland trip, the individual who had never been outside of the country was quite open to a variety of new experiences and intercultural communications. On the other hand, the participant who had traveled extensively was the oldest participant on the trip and used the phrase "everybody is different" on many occasions, but did not acknowledge the differences in her interactions. For this participant, "everybody is different" was a way to explain what she did not understand or with which she did not agree. The past and present are all a part of the life stories and are indicative of experiences and learning. In the broadest sense, life stories only 
conclude with death; therefore, individuals are always enroute in the temporal plane. Josselson (1995) further explains that narrative models of knowing are models of process in process...personal narratives describe the road to the present and point the way to the future. "Life as we know it is a processual matter rather than a product" (Goodson \& Sikes, 2001, p. 42).

Adult learning approaches. The utilization of life experiences is an accepted adult education practice and is the primary schema discussed in this study. Fenick and Tennant's (2004) viewpoints of adult learning are based upon three basic assumptions: 1) no one theory of learning trumps the others; 2) the context of the learner's life is active and dynamic, thus influencing their learning experience; and 3) the positionality of the 'educator' affects how the learners recognize, feel, act, and recall. Experience is a key component in each learning process (2004). Experience is seen as a conduit for effective learning, and as such it is a good but traditional educational practice (Tennant \& Pogson, 1995). Dewey (1963) has a profound view of experience and learning that places the individual at the center of the educational approach, such that "every experience should do something to prepare a person for later experiences of a deeper and more expansive quality. That is the very meaning of growth, continuity, reconstruction of experience" (p. 47). Tennant and Pogson (1995) concur with the purpose, which they state is to relate the present to the past, to ensure continuity in the acquisition of skill and knowledge. The concept that learning has a fluid relationship with experience, falling along the temporal plane, is central to this dissertation.

According to Tennant and Pogson (1995), the basic framework that encourages adults to learn from their experiences include three tasks: first is to get these individuals to talk about their experiences; second is to analyze those experiences individually or collectively; and third is to identify and act on the implications of what is revealed. This structure is similar to Goodson's 
method, where step two is more specific with the inclusion of the historical and cultural context surrounding the individual and the experience. Goodson and Sikes (2001) articulate as to why the context is vital to what and how the adult learns from their experiences:

Not only might our own stories alter depending on the context and what we judge to be appropriate, politic or useful, they differ from other people's stories as a result of the unique combination of experiences we have had and the knowledge we have amassed as we go through life. (p. 42).

The process of narrative learning. The role of context may also aid the individual in remembering events and experience. Everyone, no matter their background, remembers information that is embedded in a structured context; then, they utilize the meaningful relationships as a way to recall the information (Pogson, 2003). This association can be seen with individuals at various ages telling about their personal lives in connection to major historical and cultural moments, such as: "Tell me about how you found out President Kennedy was assassinated," "Describe your reaction to Neil Armstrong walking on the moon and any other details you may remember," or "Tell me about what you remember your day on September 11, 2001." Each of these events recalls memories and emotions from the individual on that particular day. The connection already exists; therefore, it is crucial that the researcher utilizes this linkage within the study.

The use of recall and reflection are a part of how individuals learn from the narrative approach. Goodson and Gill (2011) developed a cyclical process to better explain how learning transpires in this narrative form, which is seen below in Figure 5. 


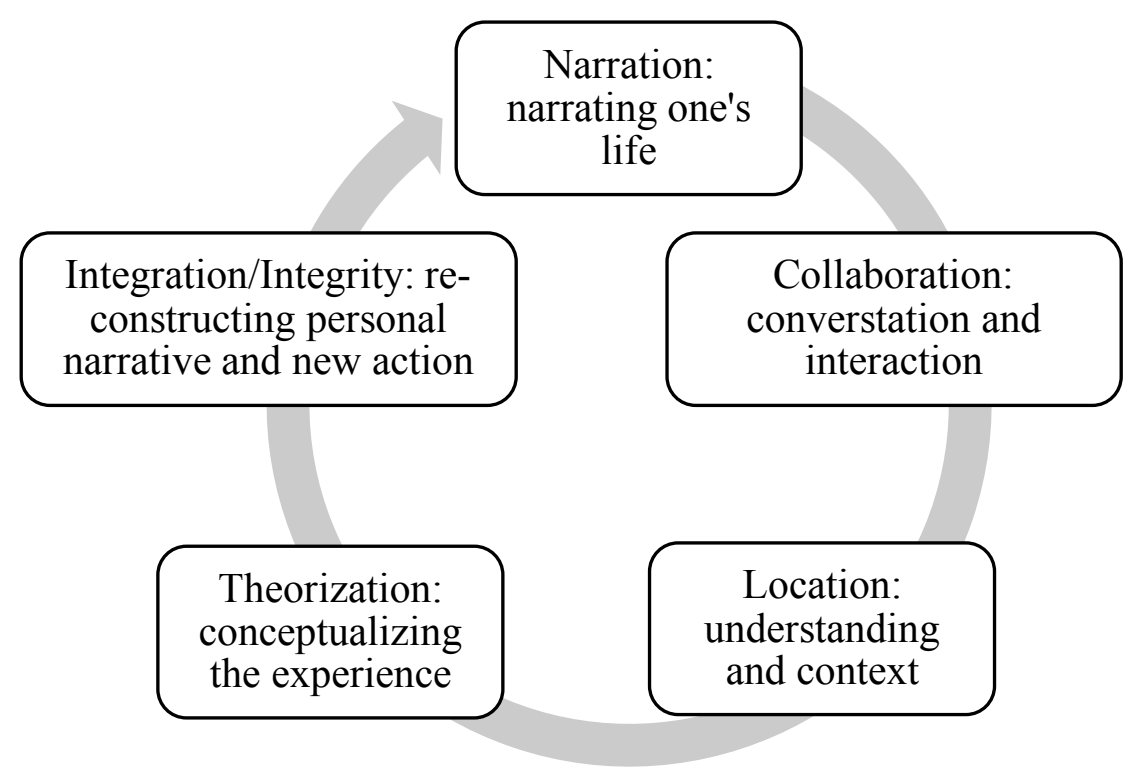

Figure 5: Spiral process of narrative learning (Goodson \& Gill, 2011)

The learning that comes out of life stories is more social and identity related than cognitive learning of information and ideas. A person tells about his or her life and then discusses his or her life with the researcher. Next, the context surrounding the experience is considered before moving to forming complex ideas about the experience. Revising the narrative and taking new action is the following step, which leads the individual into the point where he or she can start the process over again.

This idea of narrative learning does take into account how people view themselves and others as it relates to what they experienced. In the following section, I will explore how narrative life stories are connected to educational concepts.

\section{Relation to Educational Perspectives}

\section{Progressive Educational Connections}

As I argued in the first chapter of this dissertation, perspectives such as progressive education, critical education, and intercultural education are foundational components of this study. When a person listens to understand, not simply listens to respond, a connection is made 
from that action. According to Dewey (1927), "listening-in-question" occurs when two people carry on a conversation together and the action of talking is a transaction. Both parties are concerned about a topic, its results pass between them, from one to the other. Waks (2010) writes that this description of "listening-in-question" provokes an image of electrical currents that connect the two poles in a single circuit. The communication between two individuals is a fluid, back and forth approach where the speaker and the listener both share in the life experiences of the speaker. Dewey (1944) sums it up nicely when he argues:

...to be a recipient of a communication is to have an enlarged and changed experience. One shares in what another has thought and felt and in so far, meagerly or amply, has his own attitude modified. Nor is the one who communicates left unaffected...to formulate requires getting outside of it, seeing it as another would see it. (p. 5)

This connection creates a relationship between the communicator and the listener, which is essential to narrative work. Narrative life stories rely on the emotional closeness to generate shared experience and a powerful unity of outlook that breaks down all social barriers (Goodson \& Gill, 2011). In essence, "listening-in-action" is the foundation work between the storyteller and the researcher that constructs the relationship between these individuals, allowing for learning to occur.

In reference to the experience in Ireland, we would have casual discussions in the evening with members of the group in either the library or the parlor. It was not something that we scheduled as a whole group activity, but it was something in which a large number of the group would participate as those were gathering spots during our stay. At times, the schedule was too full for any dialogue to occur. These discussions were short reflections on the day or the activities. As the organizers, our two main goals were: (1) to have the participants further their 
learning and understanding through contemplation; and (2) to determine the aspects of the program that were the most impactful in addition to being well received by the participants. We did not write down any of their thoughts or ruminations, but looked at the overall message conveyed. In relation to the first goal, we can ascertain the connections the participants made from an intercultural standpoint through comments made while in Ireland and from the three subsequent evaluations. As for the second goal, we consider their statements as we plan subsequent trips to Ireland.

Dewey (1944) explains that learning, or the educational process, has no end and it is a process of "continual reorganizing, reconstructing, transforming" (p. 50). The educational process is a continuum that links the present to the past and to the future, where learning occurs across all three spatial entities through their connection. Thus, part of the educational process is learning from experiences. "To 'learn from experience' is to make a backward and forward connection between what we do to things and what we enjoy or suffer from things in consequence" (p.140). Dewey (1944) also argues that experience is an active-passive affair, or simply just because a person completes an activity does not equate an experience. Experience occurs when an individual learns from the consequences, positive or negative, of an action or an activity. Goodson and Gill's (2011) definition of narrative learning correlates with that of Dewey. They argue that a definition of learning is far more than the current perception as the acquisition of knowledge and skills, but that the narrative is entwined with both the individual and the life lived through their narrative. The connections between communication, experience, and learning are not only seen within the progressive education perspective, but also through the critical perspective. 


\section{Critical Educational Connections}

One connection to Freire's (1970) critical theory is seen with one of the class options of the trip. While the majority of the Ireland experience participants were in the Digital Photography class, the rest had chosen the cookery/gardening/rambling workshop. Each day was spent with a different instructor and all three components of the workshop was very instructorled. The gardening class had one small part where the participant planted roughly a dozen plants in a small plot; however, the cookery class was a demonstration and the rambling (walking class) contained historical information and visits. Each instructor was seen as the 'expert' and thus controlled the power within the relationship. In the cookery class, the recipes were written with Irish food terminology, cooking, and measurement directions. It was reminiscent of trying to read in a foreign language and needing a translator to understand the message. He would often say "in America, I believe you call this cilantro, while we call it coriander" or " $176^{\circ}$ Celsius would be $350^{\circ}$ Fahrenheit." This could have been a difficult situation as the power of understanding this learning opportunity laid with the chef who could interpret the recipes. However, the older, white women maintained their privilege and their linguocentrism as the chef catered to their gender and age, providing them all the information requested and needed.

Communication in critical education. Another aspect in common is the importance of communication. Freire (1970) articulates that "without dialogue there is no communication, and without communication there can be no true education" (p. 93). He also argued that authentic thinking takes places in communication and deals in reality (Freire, 1970). Thus, the discussion between the educator/researcher and the learner/participant allows for the active participation of the learner/participant in the educational process. This fluid association between the researcher and the participant is similar to Dewey's “listening-in-action" as well as Goodson \& Gill's 
narrative component of creating an emotional closeness between the two individuals.

Additionally, the dialogue aids the learner in recognizing not only how they connect to the world in which they live but to be cognizant of reality as a process not a stagnant arrival (Freire, 1970). The communication and dialogue between the educator and the learner create the environment where both individuals reflect in order to learn about themselves and the world.

For our experience in Ireland, we held a pre-trip informational meeting with the attendees to explain information on traveling abroad as well as to answer any questions they had before going to Ireland. As previously stated, we met informally on a regular basis throughout the experience so that we could discuss the activities, their feelings and thoughts as well as any concerns. Upon our return, we asked the participants to switch roles, in essence, and to share their experience with others. This was done both informally with family and friends and formally with presentations to local clubs and West Virginia CEOS members at their annual state conference. The participants often spoke of what the experience meant to them, what they did and learned, and what was their favorite part of the trip (and why).

The role of the learner in critical education. Another aspect relates to the role of the participant or the learner within Freire's (1970) “problem-posing system.” The learner/participant becomes a critical co-investigator with the educator/researcher. In this system, the individual has an equal role to the researcher; there is no dominance of power over one another. Goodson and Gill (2011) agree with Freire's “problem-posing system” as they define narrative pedagogy as the facilitation of an educational journey that involves profound encounters, meaning-making, deep dialogue and exchange. In other words, it is a shared experience that incorporates mutual trust and respect between the learner and the educator that leads to knowledge. The learner has a very active role in their educational process as reflection 
within one's context occurs. Freire (1970) maintained that "authentic reflection considers neither abstract man nor the world without people, but people in their relations with the world" (p. 81). Thus, the context that surrounds the learner, or the participant, must be considered during the learning process as it is a part of his or her reality. The context is not only important for the learner/participant as they make connections within their reality, it is also essential in narrative life stories. Without contextual commentary on issues of time and space, life stories remain uncoupled from the conditions of their social construction (Goodson \& Sikes, 2001). Narratives are embedded within a social, historical, and political context and to remove the situational perspective hinders authentic reflection from happening.

The Ireland experience did include a number of opportunities for personal reflection connected to learning. Yet, we were not intentional in including the contextual aspect into the reflections. The contextual information that is gleaned from the participants' comments stem from their individual perspectives solely. Additionally, the power relationship between the organizers and the attendees mainly stayed with the attendees possessing the power and control, particularly with the itinerary. We adapted the schedule frequently due to the various requests made by the participants. For example, on the outbound trip the organizers arranged for wheelchairs for two individuals with mobility issues. However, during the return trip to the U.S., three additional individuals requested assistance while in the airport. One person simply sat down in another participant's wheelchair, which led the organizers to arrange for more assistance from the airline. If a participant felt a situation was outside of his or her "comfort zone" and saw that age or gender could be utilized advantageously, then the person would manipulate the situation to gain what he or she desired, i.e. control. 


\section{Intercultural Educational Connections}

The CEOS to Ireland experience provided a variety of cultural contexts to the participants and demonstrated the need to learn how to interact with people from different places. This is because rural areas, like Appalachia, are often quite culturally homogenous; and globalization affects these regions just as it impacts urban locales (Louisy, 2001). A supposition exists that contact with cultural differences generates pressure for change in one's worldview (Bennett, 2004). With the trip to Ireland, the change in perspective could occur with the participants from Appalachia and/or with the host nationals. According to Lash (2016), knowledge, contact, and/or language learning alone do not lead to intercultural competency. Therefore, a multi-faceted approach must be utilized in order for intercultural awareness to occur. One aspect was to offer a multitude of opportunities to communicate with numerous individuals while abroad. Even though the host nationals spoke the same language as our participants, differences existed in terminology, pronunciation, accents, etc. By providing instances in which the participants could communicate with various Irish citizens, the participants began to note the following differences in Table 2.

Table 2

Language differences between Ireland and the U.S.

\begin{tabular}{|l|l|}
\hline \multicolumn{1}{|c|}{ Ireland } & \multicolumn{1}{c|}{ United States } \\
\hline biscuits & cookies \\
\hline coriander & cilantro \\
\hline aubergine & eggplant \\
\hline bin & trash can \\
\hline courgette & zucchini \\
\hline crisps & potato chips \\
\hline
\end{tabular}

Cilantro, zucchini, and eggplant were all part of the cookery class discussion with the Irish chef. Biscuits, bin, and crisps were noticed by participants throughout the experience. 
Another prong was to provide opportunities for cultural knowledge. Appendix A is the itinerary of the CEOS Trip to Ireland and contains various excursions related to the history and culture of Ireland. Participants visited Newgrange, a Stone Age Passage Tomb and explored the Beaulieu House that is passed to each generation through the women in the family. The residents of Appalachia also saw the Shrine to Saint Oliver Plunkett in Drogheda as well as other historical sites in the Boyne Valley. The group spent one day in Belfast, visiting the Peace Wall and the Titanic Museum. Additionally, they took a trip to Dublin, going to the Trinity College to see the Book of Kells in addition to a visit to the Temple Bar area. These are just a few of the excursions and visits of the Ireland experience, yet they show the range of activities that allowed the participants to learn more about their host country and its culture.

A third component was contact with host nationals, not just for learning new language phrases, but also to interact with Irish citizens. The myriad of places visited by the group permitted the participants to intermingle with individuals from a wide range of backgrounds and classes. The participants often mention the friendliness and welcoming nature of those individuals they met during their time in Ireland. It was only during the time in Belfast/Northern Ireland did the participants not feel the host nationals were as pleasant as in other places. Even though a passport was stolen from a participant in Dublin, the group as a whole felt Belfast was a more dangerous city.

An essential component to each of the three aforementioned items is the reflections. As previously mentioned, informal reflections occurred almost daily during the trip, blog entries were utilized as a reflection tool, and formal reflections were a part of the three post-trip evaluations. The overall experience was for the participants to learn and then ruminate on the learning. Lash (2016) argues that experience with the cultural differences and subsequent guided 
reflections are essential for effective intercultural learning to occur. Participants from Appalachia should be encouraged to pay attention to diverse people and places as their lives and identities will intersect over time with their experiences due to various facets of globalization (Luke \& Tuathail, 1998; Urry, 1995). This again demonstrates the necessity of intercultural education as it aids in maneuvering social relations across cultural boundaries (Bennett, 2004).

Through these educational perspectives (critical, progressive, and intercultural), an individual's life story can be shaped through the additional lens that is brought into the picture. Whether it is through Dewey's (1944) outlook on fluidity between reflection of past experiences and current learning or Freire's (1970) view of the role of the learner and power relations in educational settings, individuals have control over their own learning and possess the ability to affect change. Additionally, intercultural education is a key factor since nations are no longer as homogeneous as they have been in the past, as interdependency has become a guiding concept to examine the plethora of national conditions that have become transnational dilemmas (Roberts, 2007). Both learning from experiences or opening one's eyes to a new perspective allow an individual to gain a different vantage point. Goodson (2013) sums up it up best in the following statement:

Our 'narrative capital' needs to be employed and deployed to link our personal narratives to narratives of wider social purpose. Moreover, our narrative capital will need to be deployed in the recurrent 're-selfing' that the new flexible economics will demand. In the new social future, our narrative capacities hold one of the keys to the shape our world will take. (p. 129) 
Being able to utilize our "narrative capital" for a wider social purpose connects to both Dewey's and Freire's work. As mentioned previously, both men were advocates for the use of communication in learning and this is the same premise with narrative life stories. In order to learn from our experiences, we must openly discuss and reflect with an active listener so that we can ascertain the influences in our lives and who we want to be in the future. Moreover, narrative learning allows for Bennett's (2004) model on intercultural sensitivity. A person may live in either an urban setting or in a rural locale, but needs to understand the relationships that exist between the countries of the world and more so, their cultures. Once the person looks outside "the window" into another culture, what they see in their "mirror" when observing themselves may transform or strengthen them. The self in effect stands in a dialectical relationship to experience, both forming and being formed by the experience it encounters (Tennant \& Pogson, 1995). It is this residual effect on life stories that include experiences relating to both Appalachia and Ireland that will be explored in greater detail in this study.

\section{Limitations}

The 2013 CEOS Trip to Ireland had a foundation from the educational perspectives outlined above; however, what occurred differed in some parts of the experience. In planning the trip, one limitation was our ability to effectively communicate with the attendees. As the individuals lived in areas all around the state, we primarily communicated through written letters. Also, the majority were an older audience who felt more comfortable with face-to-face interactions than an online format. Therefore, we held a meeting to go over important details and tried to meet at a primarily central location. Thankfully, we were successful in this piece and all were able to attend. However, we only scheduled one meeting, where multiple sessions could have been arranged if the individuals lived in a closer proximity. 
During the trip, one limitation was how the planners at the host organization interpreted our requests. When we asked for a cooking class, it was not a hands-on cooking class, but a cookery demonstration by a well-known television chef reminiscent of the "banking method" of education. This decreased the likelihood the participants would feel comfortable in recreating the recipes that were provided to the class attendees. Another example was with the request to include a brief genealogical search for interested participants. This resulted in providing information to the host organization on the family names and areas from which they came (if known) prior to the trip. While in Ireland, the interested participants met with a local genealogical and history expert that gave a short explanation on when and why diasporas occurred in Ireland, from which he based the familial connections and their Irish locations. Both of these examples illustrate how our expectations were different than the actual experiences provided to participants. These examples taught us to be very explicit in our communication with all parties involved in the experience so that little is left to interpretation.

\section{Conclusion}

The intensions of non-formal educational international experiences are to expose the participants to substantive learning, a deep understanding of the host culture, and communicating within that culture because the experience is not isolated from the social and physical context (Pagano \& Roselle, 2009). As for the participants from Appalachia, these experiences might yield increased knowledge of the host nation's culture and history, an increased ability or comfort level to interact within another culture, further understanding of people, and/or knowledge and ability to travel internationally. Through using narrative life stories, this study is able to glean the learning occurred in addition to the influences the non-formal educational international had on the lives of the participants. Our narrative life stories not only create 
memories to recall, but also allow us to use those accounts to react to events that happen in our lives as well as choose our future actions. We do and we will interact with people from various cultures, so we must learn to better navigate this aspect of life, wherever we happen to choose to live.

The following chapter will outline the methodological approaches of this study. It will detail its purpose and the research questions that drive the study. Additionally, I will discuss my epistemological stance that informs my research's theoretical framework. Limitations of the study as well as contextual information are also explored. 


\section{Chapter 3: Methodology}

Stories are far and away the most important feature of our everyday existence.

(Booker, 2004)

In this chapter, I outline why narrative inquiry is an ideal method to study how adult participants from Appalachia are affected by non-formal, educational programs in an international setting. First, I explain my personal connection to this work as it is crucial in understanding my choices in methodology. Also, I include limitations to this approach in order to recognize where potential risks lie within this research study. Lastly, I describe the methods that I used to examine the multiple contexts of the participants, thus the effect of the experience both individually and collectively.

\section{Purpose of the Study}

The purpose of this study is to understand how non-formal educational experiences in an international setting affect the lives of participants. First, I want to understand how non-formal educational experiences in Ireland influenced participants from Appalachia both when they were abroad and when they returned from the experience. Within this research, I want to understand the ways in which the viewpoints of these participants from Appalachia were shaped, created, reflected and/or formed in relation to the international education experience as they perceived it. I especially want to understand the ways in which the participants' Appalachian cultural identities shaped and are shaped by their international experiences. This research will not be a full assessment of all participants from non-formal educational international programs, but rather it is one that focused on how the participants from Appalachia perceived their experiences in order to better understand their influences. My goal is to add to the body of current research in the area of non-formal educational experiences in international settings. 


\section{Research Questions}

My specific research questions for this study are:

- How have non-formal educational experiences in Ireland influenced participants from Appalachia both during the time abroad and after their return?

- How are these experiences viewed within the life stories of the participants?

\section{Epistemology and Theoretical Framework}

\section{Epistemology}

The philosophy of knowledge that I use to consider my research questions through this study is social constructivism because I believe that there is not an absolute value for knowledge. I believe that a person interprets and constructs his/her reality through experiences and interactions. I do not think the context can be taken out of knowledge; it is an essential part of one's reality. Moreover, as these concepts relate to culture and society, a social constructivist perspective is fitting for this study. This is because social constructivism is all-encompassing and it "emphasizes the idea that society is actively and creatively produced by "human beings," and social worlds being 'interpretive nets woven by individuals and groups"” (Crotty, 2013, p. 54). In other words, since all meaningful reality is constructed socially, the focus is on an individual's learning that takes place within the interactions in group settings. As for how culture factors into this perspective, "culture is best seen as the source rather than the result of human thought and behavior" (p. 53). Therefore, culture is not the action(s) of an individual or a group, but instead the impetus for that/those action(s). From this social constructivist viewpoint, culture is the first lens one uses as he or she learns to view the world and is what brings some aspects into focus and keeps other features at the periphery. 
Using the social constructivist/interpretivist framework, I believe that it would be essential to articulate my own perspectives as they related to this study. I am a female resident of Appalachia, born and raised in West Virginia, and I am in my mid-thirties. I am white, middle class, and live in a rural setting. Both of my paternal grandparents and my maternal grandmother grew up in low socioeconomic areas. While my grandparents moved their status to middle-class, some of my extended family members are in the lower socioeconomic class. Education and learning have been very important to the paternal side of my family. Neither of my father's parents graduated from high school, but all five of their children did and all went on to college. Four of the five graduated with degrees ranging from associate's to master's. This is the foundation on which my lens related to learning is based. Traditionally in Appalachian culture, women were the primary caretakers of the home and the children, while the men were the breadwinners with my family being no different (Latimer \& Oberhauser, 2004). As society has moved towards families needing two incomes, my family is no different as well. Most of my aunts and female cousins work outside the home, at least part-time, with the exception of one aunt and my mother. As for my personal experiences combined with my age and educational background, these aspects have affected my life and caused me to regard gender roles and life choices in ways that typically have conflicted with my family's traditional viewpoints from their Appalachian outlook.

My desire to learn more about the impact of non-formal educational experiences in an international setting has stemmed from my own involvement in formal and non-formal educational programs of this type. I studied abroad in Spain for a semester while I was an undergraduate. I also served as a graduate assistant to a summer experience to that same locale. Through my current position with the West Virginia University Extension Service, I have been a 
faculty leader on numerous trips to four countries. I was the co-lead faculty member on the Ireland trip and was involved in planning, facilitating and evaluating the different stages of the program. I have realized that my involvement in creating the experience as part of my employment has led me towards particular biases; however, the design of the study built in validity checks and space for researcher reflexivity to address this issue.

Since I am a resident of Appalachia and have had my own non-formal educational international experiences, I feel it is important for Appalachia to be a part of the context of this study. Given these motives, I believe it was necessary to utilize my own personal lens within the context of this study in order to address my subjectivity because "in narrative thinking, context is ever present...context is necessary for making sense of any person, event, or thing" (Clandinin \& Connelly, 2000, p. 32). Interconnectedness exists between this research study and my own personal life narrative and therefore, I feel it necessary to embrace this aspect of my lens in lieu of trying to fight against it. With that notion in mind, it is also imperative that the design of this study include mechanisms to confront potential biases, such as member checking and triangulation.

\section{Theoretical Framework}

Researchers using the constructivist perspective believe that meaning and values can differ for every individual. This led me to choose an interpretivist theoretical framework. The notion of culture as the social reality is the interpretivist theoretical perspective, which looks for culturally derived and historically situated interpretations of the social life-world (Crotty, 2013, p. 5). Interpretivism takes into consideration the individual and their personal context of where the experience happens and as it occurs in a specific moment in time. This type of viewpoint emphasizes the subjectivity of people's behaviors and realizes that people's interpretations are 
based on everyday experiences that have meaning for them (Ferranto, 2013). Thus, as the individual is engaging in the world, they are interpreting experience from their own standpoint, and constructing meaning of their world that is based upon a blending of their perceptions and knowledge gained.

\section{Method: Narrative Inquiry}

The method that I chose for my investigation is narrative inquiry. In this section, I have situated narrative inquiry within qualitative research. I define narrative inquiry and explain how specifically I used the method to answer my research questions.

A qualitative approach will help me to gather information about the participants' experiences. Qualitative research is comprised of many different methods. Denzin and Lincoln (1998) detail the characteristics of qualitative research in the following excerpt:

Qualitative research is an interdisciplinary, transdisciplinary, and sometimes counter disciplinary field. It crosscuts the humanities, and the social and physical sciences. Qualitative research is many things at the same time. It is multi-paradigmatic in focus. Its practitioners are sensitive to the value of the multi-method approach. They are committed to the naturalistic perspective, and to the interpretive understanding of the human experience. At the same time, the field is inherently political and shaped by multiple ethical and political positions. (p. 6)

As these qualitative research scholars indicate, qualitative methodologies take into consideration the various contexts involved with human research. Specifically, the context includes the individual's background, morals, values, and beliefs in their natural setting. This type of research looks at how the different components of context interact with one another to construct the 
whole. This relates to my project because the Appalachian culture of my participants and the (in)congruous Irish culture in which they were immersed. Their international experiences inform the processes of which I am interested.

From the perspective of this study relating to individuals, their contexts, and their experiences, narrative inquiry is the most appropriate methodology because it is connected to both the educational frameworks of the experience as well as the culture of the participants. Narrative methods are also applicable to my participants and context because storytelling has long been a part of the Appalachian culture and utilizing narrative inquiry that focused on both the context of the experience as well as the story of the participant was a natural pairing. Additionally, the foundation of narrative inquiry incorporates experiences as a mode of learning across the lifespan.

Narrative researchers are able to explore the personal and the social aspects of learning (Riessman, 2008). They delve into both the individual's learning as well as the shared environment where the learning takes place (Clandinin \& Connelly, 2000). This allows the researcher to obtain a more comprehensive view of the learning. Narratives are a mode through which individuals can make sense of their past, in a context of time and memory (Riessman, 2008). Additionally, the narrative method recognizes the constant change that occurs in learning. Narrative inquiry requires cognizance of a history, a present, and a future within the individual and the context.

According to Clandinin and Connelly (2000), narrative inquiry allows the researcher to view the experience in question on several levels. Not only is the investigator able to delve into the context of the experience, but is striving to look for growth within the life story as well. Living a life and telling a story are iterative processes. As Clandinin and Connelly (2000) state, 
"there is a reflexive relationship between living a life story, telling a life story, retelling a life story, and reliving a life story" (p. 71). This cycle is reminiscent of Dewey's notion of experience in education as a backward and forward movement that weaves together experiences and reflection upon those experiences (Dewey, 1944). Thus, the intertwining of life and story is productive of education and it is that educative narrative on which I will focus in my study. The aspect of narrative inquiry that is most beneficial to this study is how it allowed for layering of narratives in order to study the history of the participants as well as explore what is yet to come. Narrative inquiry connects to the constructivist epistemological stance as it looks at how people create meaning in their lives through their stories that are lived and told (Clandinin, 2006). From the interpretivist theoretical framework, it is these stories that contain both cultural and historical settings that are just as important in understanding the event or the experience as the words the individual uses:

People shape their daily lives by stories of who they and others are and as they interpret their past in terms of these stories. Story, in the current idiom, is a portal through which a person enters the world and by which their experience of the world is interpreted and made personally meaningful. Narrative inquiry, the study of experience as story, then, is first and foremost a way of thinking about experience. (Clandinin, 2006, p. 45)

Storytelling has a long history as an oral method of sharing a part of one's self and their life, especially in Appalachia. As Geiger and Sorber (2013) have noted, "When we narrate something, even in telling our very own story, it is (again in the normal course of events) the voice of our culture - its many voices, in fact — that is heard in what we say" (p. 64). 
The use of narrative inquiry provides my participants from Appalachia with the opportunity to explain their experiences in their own words and also to expand their knowledge base. Knowledge grows by telling stories because narratives "motivate and explain our actions, the stories we tell change the way we act in the world" (Geiger \& Sorber, 2013, p. 349). This narrative telling could lead the participants to view their experiences in a new or different light as they grow and change over time. The internal and individual representations about this experience can vary, which would allow the same person to tell different stories about the same experience based upon the circumstances in which one has lived (Andrew, Squire, \& Tamboukou, 2013). For example, consider the story of a life-long New Yorker with young children who was interviewed shortly after the September 11, 2001 attacks that she witnessed. Likely, her story would be shaped by her multiple identities — as a mother, as a local resident, as a nurse, as an activist, as a global citizen. The story would very likely be emotional.

Now, consider how the 9/11 story may be different when conducting an interview 13 years later. The woman's son is now in the military and is currently deployed. Her emotion; her phrasing; her story grammar; her emphasis on various heroes, villains and victims; her attention to place, politics, and her position within all of this would change due to the contexts of time and memory. Her viewpoint on international issues may be different than before now that her son is in another country.

I will use the narrative inquiry method in order to weave together the epistemology, the theoretical perspective, and the concepts of "culture" and "Appalachia" in order to understand the learning that has occurred with the participants on individual and societal levels. This approach, however, is not without its limitations. 


\section{Limitations of the Narrative Approach}

Clandinin and Connelly (2000) also address the concerns that exist when utilizing narrative inquiry. The first critique is the subjectivity of the approach, which is central to the method, but that causes the researcher to lose their authoritative perspective when writing. A second critique of narrative inquiry is the notion of "narrative smoothing," in which the participants tell and/or the researcher analyzes and writes so that everything works out in the end. This idea of a happy ending does not include the stories that were not told. However, as a researcher I need to be as cognizant of those silent possibilities as I am of the stories the participants tell. Another concern is that while the narrative is meant to focus on experiences and life, it could result in fiction instead of truth. This could be seen with both fabricated data by the participants as well as the researcher using that data to mislead their audience. Each of these critiques revolves around the question of validity and reliability with this approach. The key components that are found at the core of narrative inquiry are also the concerns, as each facet contains a potential "dark side” (Riessman, 2008, p. 199). Being aware of the possible risks involved as well as receiving feedback from a community of researchers are two primary ways that I will address the critiques of narrative inquiry.

\section{Context, Participants and Data Collection}

Time and place are essential aspects of narrative inquiry as both speak to the development of the stories of the participants. A person carries their context with them, affecting not only the present, but also how they perceive their past in addition to envision their future. With that idea in mind, context was a key to this research. The Appalachian region (primarily West Virginia) and Ireland are being selected as the contexts for a number of reasons. One rationale was my current position as a faculty member with the WVU Extension Service. By 
selecting Appalachia as the context, it allows me access to a number of potential participants for this study through my connection with this organization. Furthermore, I was involved with a number of international programs sponsored by the WVU Extension Service and have already gained entre with the individuals who participated in the programs. This again speaks to admittance to research participants.

A second motive for choosing Appalachia is because of the potential contribution to the research of this region. The stereotypes that exist about residents of Appalachia indicate that they are poor, backward individuals and lack intelligence due to their rural setting (Shapiro, 1978). As mentioned in previous chapters, class and sex of the participants are relevant topics when investigating Appalachian research. As both facets will play a role in this study, I anticipate the findings to add to current research.

As for the rationale in selecting Ireland, I was one of the lead faculty members on this trip in 2013, which again speaks to my ability to access the individuals who participated in the excursion. Both the individual narratives and the group story give a sense of a whole, which "is built from a rich data source with a focus on the concrete particularities of life that create powerful narrative tellings" (Clandinin \& Connelly, 1990, p. 7). In order to offer a comprehensive viewpoint, it is advantageous to look at an experience before it occurred, during, and afterwards. This type of perspective is possible with the Community Educational Outreach Service (CEOS) Trip to Ireland due to my role with the program.

Choosing Ireland as a context is also due to the rural location in which the trip took place. The town of Termonfeckin, population 600 , served as the home base. The participants visited three cities as a part of the experience, but the majority of the time was spent in a rural setting. As 40\% of residents of Appalachia live in rural areas (ARC, 2014), it was important to select an 
international experience that also took place in a rural setting. Not to mention, there is a historical connection that exists between Ireland and Appalachia. During the Irish Diaspora in the mid-1800s, a number of Irish immigrants found their way to the United States, settling in the east coast and inland. 34.7 million U.S. residents claim Irish ancestry and the Irish influence is visible in Appalachian music and dance as well as the prominence of quilting in this region (Tritz, Dransfield, \& Scott, 2012). Due to this connection between Appalachia and Ireland, it was interesting to examine the commonalities between the cultures and how this sameness influenced the participants' perceptions.

\section{Participants}

The participants were adult members of WVU Extension programs. This study focused on the CEOS trip to Ireland that was conducted in 2013. There were 22 individuals from which I selected the five participants. The sample size of five allowed for variation within the identities of the participants from Appalachia in terms of their age, sex, marital status, and educational background. The sample size of five participants was also reasonable in terms of my available time given the distance at which some of the participants were located. Given the narrative method, I allowed significant time for the interviewing process to unfold, as well as time for multiple interviews with each participant, therefore, I conducted two in-depth interviews with each participant.

I began the participant selection by contacting the individuals who participated in the 2013 CEOS Trip to Ireland. As I am a current employee of the Extension Service and was one of the lead faculty members of the trip, I had already established a relationship with the participants. I solicited involvement by sending letters to the participants in order to gain permission to utilize the observations and blog entries that have already been collected. I 
provided contact information through all correspondence on how I can be reached. The participants met the following criteria to participate in this study:

- Is a resident of Appalachia

- Self-identifies as rural or semi-rural

- Currently resides in West Virginia

- Participated in the 2013 CEOS Trip to Ireland

The trip members who were interested in participating agreed with implied consent using an IRB cover letter. This cover letter made them aware that they could drop out at any time that they chose. I selected five individuals from the initial list of 22 trip participants, removing anyone who chose not to be involved in the study. I conducted two interviews per participant, for a total of ten interviews. A time limit for these interviews was not set as follow up questions to participant comments could have lengthened the initial set of questions. Below is Table 3 that includes demographic information on the participants of this study. It is important to note that Martha passed away in January 2017, while the second round of interviews was being transcribed.

Table 3

Demographic Information of Participants

\begin{tabular}{|l|l|l|l|l|l|}
\hline \multicolumn{1}{|c|}{ Name } & \multicolumn{1}{|c|}{ Age } & \multicolumn{1}{c|}{ Race } & \multicolumn{1}{c|}{ Gender } & Marital Status & \multicolumn{1}{c|}{ Education Level } \\
\hline Martha & 79 & White & Female & Widow & High school graduate \\
\hline Ruth & 78 & White & Female & Widow & College graduate \\
\hline Rebekah & 63 & White & Female & Married & High school graduate \\
\hline Hannah & 40 & White & Female & Married & College + masters graduate \\
\hline David & 31 & White & Male & Single & College + masters graduate \\
\hline
\end{tabular}




\section{Data Sources}

The primary data source that I used to support the narrative inquiry and answer the research questions was in-depth interviewing; two individual interviews with each participant. In the first interview, we discussed the life story of the individual as the "qualitative research interview has a unique potential for obtaining access to describing the lived everyday world" (Kvale \& Brinkman, 2009, p. 29). The second interview allowed both the researcher and the participant the opportunity to discuss the CEOS Trip to Ireland as well as any remaining questions that came about after analysis of the initial interview, and provided the opportunity for member checking. Kvale \& Brinkmann (2009) said that "interviewing is an active process where interviewer and interviewee through their relationship produce knowledge" (p. 17). Through this active co-construction of knowledge, I strived to explore in depth certain aspects of their international experience especially as it related to Appalachian culture, identity, and notions of the rural.

The first field text consisted of personal artifacts of the participants, such as photographs, memorabilia, souvenirs, etc. During the first interview, I asked the participants to bring three items that represent what is most important to them in life. This was to aid in beginning the conversation between the participant and me. Additionally, the individuals could have brought something that connected to their trip to Ireland without specifically being asked. More so, these items were utilized as a medium through which to elicit stories. "It is these artifacts, collected in our lives that provide a rich source of memories" (Clandinin \& Connelly, 2000, p. 114). By utilizing these personal items, I hoped to trigger memories that will lead to sharing stories that have impacted their lives. While this approach did trigger memories, most of the participants did 
not remember to bring the personal artifacts with them and simply shared with me verbally the items that they chose to represent what is most important to them in life.

The other complementary data source was blog entries that were written during the original members of the international experience. Utilizing blogs as a reflection tool for this research project is beneficial because it naturally connects to the narrative approach and storytelling. "By virtue of its own very nature, blogging incorporates many elements of good autobiographical storytelling. Blogs tend to be personal and introspective... and their multimedia nature encourages students to share both their reflections as well as primary evidence of their experiences as a form of experience-based learning” (Downy \& Gray, 2012, p. 2). Members of the CEOS Trip to Ireland were encouraged to blog about their trip in order to share their daily activities with those back home as well as to reflect on what they were observing and experiencing. Both types of commentaries can be found in the blog entries from these individuals. "The researcher who establishes intimate participate relations can become so focused on the relationship that the flow of documents that help contextualize the work goes unnoticed" (Clandinin \& Connelly, 2000, p.114). This cautionary advice was beneficial as I had an existing relationship with these participants. Utilizing both corresponding sources assisted me in keeping the focus on the context of the experience.

\section{Data Collection Plan}

Phase I consisted of reviewing the existing blog entries from summer 2013, which were included as archival documents in the IRB proposal for this study. Data from those who request to be removed from the study were not utilized. I analyzed these documents first in case a significant aspect arose out of the existing information that would have been essential to obtain more details during the interviews. The aspects that elicited further detail during the interviews 
were: first time traveling internationally; cultural similarities between Ireland and Appalachia; building relationships; and reconnecting to "home."

Upon analysis of the blog entries, the first round of individual in-depth face-to-face interviews was scheduled with five participants. The individual interviews lasted less than two hours each and were about the life story and international experience of the participant in order to see if there are any intersecting stories between the two. They were conducted in settings that were private in order to foster a trusting environment to share their stories. As I traveled around the state conducting these interviews, I asked the participants to select the location to meet and offered to conduct the interviews in their homes, such as their living room or dining room. The interviews were conducted in a quiet, semi-private location and I audio recorded the interviews so my attention was on the participant. Please see Appendix A for the protocols for both interviews: Life Story and Ireland Experience.

All of the interviews were recorded on a digital handheld device, then all files were transferred to a jump drive and stored in a locked filing cabinet in my office. I had all relevant content within the interviews professionally transcribed. I utilized pseudonyms as well as other masking techniques for increased confidentiality. One of the participants was a family member and the oldest individual on the CEOS Trip to Ireland experience. As this person was related to me, it was difficult to speak to her experience and life story without including myself and still maintaining confidentiality. Additionally, the blog entries were public documents, which increased the difficulty in maintaining confidentiality.

Phase III consisted of the second round interviews that focused on the international experience to Ireland and allowed for member checking of the first life story interview. The safety parameters indicated in the description of the first interview as well as the location of the 
stored data and ability to maintain confidentiality as the individual permits was the same for

Phase II. Table 4 consists of the timeline of the data collection plan and is provided below.

Table 4

\section{Data Collection Plan}

\begin{tabular}{|l|l|}
\hline \multicolumn{2}{|c|}{ PHASE I } \\
\hline November 2015 & Existing Document Analysis \\
\hline December 2015 - January 2016 & First Round Interviews \\
\hline $\begin{array}{l}\text { February 2016 - } \\
\text { July 2016 }\end{array}$ & Data Analysis of First Round Interviews \\
\hline & \multicolumn{1}{|c|}{ PHASE II } \\
\hline August - September 2016 & $\begin{array}{l}\text { Second Round Interviews and Member } \\
\text { Checking }\end{array}$ \\
\hline October - February 2017 & $\begin{array}{l}\text { Data Analysis of Second Round } \\
\text { Interviews }\end{array}$ \\
\hline \multicolumn{2}{|c|}{ PHASE III } \\
\hline March - April 2017 & Reporting of Findings \\
\hline
\end{tabular}

\section{Data Analysis}

Life stories is a narrative theory approach, where our stories and storylines are understood (Goodson, 2013). In order to form these storylines, I began my data analysis by constructing timelines of each participant. I organized the data from the interviews into five time periods: childhood, adolescence and early adulthood, adulthood, the Ireland experience (anything relating to before, during, or after), and future plans. Please see Appendices E-I for each participant's timeline. Using timelines alert the researcher to experiences and phases of life to explore (Goodson \& Sikes, 2001). Additionally, timelines can be expanded as the analysis stage progresses. Through these timelines, I could identify events from within the interview data as well as it provided a holistic view of the life stories of the participants.

Next, I used a critical events approach with textual analysis. A critical event analysis reveals a change of understanding or worldview by the storyteller. Critical does not mean 
something traumatic or excessive, but rather is called that because of the effect on the storyteller (Bohl, 1995). Since critical events are identified through the impact on the storyteller, the analysis derives from open-ended questions that engage the participant in storytelling (Webster \& Mertova, 2007). Moreover, Clandinin and Connelly’s (2000) professional knowledge landscape research is included in this method as it recognizes that the stories of the researcher will be evident as the research texts are composed. The use of the critical event approach to these life stories allowed the participants to distill events that were most important to them (Webster \& Mertova, 2007). A benefit of this approach for this study is that a critical event as told in a story reveals a change of understanding or worldview by the storyteller (2007).

Reighart and Loadman (1983) developed a system for analyzing the content of narrative reports of critical events that occur during an experience. Their content analysis system has each event classified with type of experience, type of event, category of event, and effect of event. I added columns for impact to the life story, memoing, and any other notes to consider. With each event, I categorized them by the educational theory, life story, and post experience. From here, I could see what influences were most predominant in their stories. Appendices J-L are examples of this approach and the collective results. The main reason I selected these approaches was due to the importance that context plays within them because "stories are social artifacts, telling us as much about society and culture as they do about a person or a group" (Riessman, 2008, p. 105).

Once the data was gathered through the narrative theory method, the next step was "bathing in the data," as Goodson (2013) explains. This entailed reading through the transcripts slowly so that the main emergent themes can be recorded in a notebook as well as on the transcript pages, gauging when some themes have become saturated. Within "bathing in the data" includes the critical event approach which is Reighart and Loadman's (1984) system of 
analysis. Each event is classified in the following manner: type of experience, type of event, category of event, and effect of event (1984). I used the most thematically dense life stories and presented them in the form of a detailed individual portrait of a life narrative (Goodson, 2013).

As the participants tell their life stories, they tend to fall into a set of narrative character styles (Goodson, 2013). A body of research to support the usage of narrative character styles exists and demonstrates how these narrative forms are present in Western culture. However, variation, nuance, and complexity in the narrative stories is also an important consideration so that the participants are not simply placed into a box. These narrative character styles are listed below with excerpts taken from my diary during my first international experience in Spain to serve as examples. It is important to note that participants' length of utterance at times is very brief as these excerpts were originally written in Spanish in an effort to be fully immersed in the culture.

- Focused elaborators are individuals who strive to break away from inherited scripts or established patterns of socialization. They have a high narrative intensity and reflect often, carving out a new original script.

- Here is an example of a focused elaborator story: Today is the Day of Resurrection. In English, it is called Easter. It is the first holiday that I have ever spent away from my family, in my entire life. Never have I been this far away from my family during the holidays. It is something that I don't like because it is the reason for the holidays, to spend time with your family and friends. But 21 days more. 3 weeks. I like Spain, but I want to go home. Until tomorrow (April $15,2001)$. 
- Armchair elaborators also have a high narrative intensity, but possess a lack of agency; thus, are unable to delineate courses of action. While they desire to "re-self," they do not have the capacity to implement a new narrative identity.

- We can see the armchair elaborator in this example: I want to return to the U.S., to my state, to my home, to my family, to my parents. At times, I am very lonely. I wish to have a good friend to do things with, but I don't think that is in my future, but I don't know. I want to stop crying but I can’t. All my life, after meeting Natalie, she has said "Santander is this and Spain is that," and so on and so on. And now I'm here, finally, and Natalie isn't here. She is in the U.S. and I don't know when she will come back to Spain, but it doesn't matter to me anymore. It's very late at night and I am a little tired. I finished my homework and I want to sleep but I can't. I can't sleep here. I don't know the reason but I wish I could go to sleep soon. Tomorrow, my class is going to the library and the house of Menéndez Pelayo. I hope they tell us who Menéndez Pelayo is because I don’t know. Every Friday, my class will go on a visit around Santander. I don't know what the visit will be next week. Well, I'm going to the bathroom and then I'm going to bed. Until tomorrow (January 11, 2001).

- Multiple describers do not spend much time in reflection, but describe their lives in a short, detailed manner. They have low to middle narrative intensity and their personal vision can be individualized, a committed vocation, or a vision of family life.

- In the following excerpt, we can see an example of a multiple describer: Today is my fourth day in Spain. It is my first day at UIMP (Universidad de Menéndez Pelayo) also. I like the Cagigas family and my room, which is like my room in my 
house. I miss my parents and I cry when I think about my family. But I believe it is because I don't have any friends here. My classmates from UIMP are very nice. My birthday is Wednesday. I will be 22 years old. I think that is very old because my younger cousins are in high school. The food here is good, but at times, I am worried because I don't know what I'm eating. But it's all good. The coffee is very strong and I couldn't sleep at night for two days. I hope that it doesn't happen again tonight. I think that if I have one cup in the morning, only, then I will be fine, but I don't know. I want to call Sarah tomorrow. She is in Arizona and its eight hours behind Spain now. Well, until tomorrow (January 8, 2001)

- Scripted describers have low narrative intensity and are unaccustomed to talking about or even thinking about their lives. Their narrative is more about ordering the experiences and describing the experience accurately, not making sense of a life.

- A scripted describer example is: Today, at 5:30 pm, my class went to the "Celtic Tavern" again. I had fun. My classmate, Sharon, lives very close to me. I live in Chalet \#60 and she lives in \#49. Now it is $11: 30$ pm and I have more homework to do. After class, I came home and ate "la comida." Then I took a nap. At 5:00 pm, I left the house, took a bus to the center/Celtic Tavern. Afterwards, Sharon and I took the bus to go to the Chalets. But we went to Lupo, a supermarket before you go into the Chalets. I bought gum, yogurt, Febreeze, and a bottle of Sunny D. I didn't have time to look at my emails. I hope that I have time tomorrow. Well, I have to have time because I have to talk to my parents. Also, I have to go to the tobacco store to buy stamps to send my letters that I wrote this past week to Sarah, Megan, Amanda, and Joshua. Also, I have to go to the store 
called "Estudio.. It's a book store. But it's not as important as going to "Cibercec" (cyber café). Until tomorrow (January 15, 2001).

Again, these are the dominant styles most people adopt to tell their life stories. However, as I have illustrated with my own multiple narrative styles, all people move somewhat between these narrative forms as none are totally pure (Goodson, 2013).

One key aspect of this analysis that benefited this study is that the voice of the researcher was active not passive. Again, this approach focused on the contextual features that shape the construction of narratives in addition to how the meaning was collaboratively created through interaction between storytellers and listeners (Frost, 2011). Due to my connection with the contexts of this study, I did find myself included in the data. This is especially noticeable with the life narrative of Martha, who was also my maternal grandmother. Martha passed away in late January 2017, while the second round of interviews were being transcribed. This played an emotional toll on me while analyzing her life story and it continues to be difficult when I am confronted with her death.

A benefit of having an active voice is that it allowed me to recognize my participation in the trip. However, I strove to be cognizant of my voice so that it did not overwhelm the narrative. Riessman (2008) cautions narrative researchers on their need to pay close attention to their chosen method for data analysis in order to ethically arrive at valid interpretations and findings. While it can be advantageous to include the investigator's voice, it could also be detrimental to the trustworthiness of the research. The question of validity and reliability in qualitative studies has never fully faded away, which makes it imperative to consider these concerns when analyzing the data. One way these issues were addressed in this study was with the incorporation of member checking in the design so that bias was less likely to occur. During the data analysis 
process, I sent copies of the interpretations to each participant in order to determine if my understanding of their statements were adequately represented. Information from the initial interviews only slightly shaped the contents of the second interview.

Another form of triangulation that was used was incorporating document analysis. There were blog entries from the CEOS Trip to Ireland. These documents demonstrated the sequence of the experience and through their exploration, I also considered how the fluidity of time impacted the perceptions of the participants. Past experiences impact the views of the present just as the present affects how we see the past. Both the past and the present form an individual's frame regarding the future. By utilizing both pre-existing documents and interviews, I was able to consider the different temporal perceptions that factored into this non-formal international education experience.

All of these facets were interpreted in order to arrive at a holistic understanding of the narrative. Wertz et al. (2011) stated that data are read multiple times in a hermeneutic circle, considering how the whole illuminates the parts, and how the parts in turn offer a fuller and more complex picture of the whole, which then leads to a better understanding of the parts, etc.

Comprehending the components, while looking at the experience as a whole spoke to the likelihood of transferability of the experience to future participants. Above all, the goal of this study was to offer credible and dependable findings that add to the body of current research in the area of non-formal educational experiences in an international setting.

\section{Writing}

In completing the remaining chapters of this study, I anticipated emerging content for Chapter Four, that details the data for this research. This data chapter incorporated a narrative design in the writing style. In order to adequately capture the essence the participants share, I 
incorporated large, verbatim portions of the interview data within the analysis chapter. The first part of the chapter concentrated on the individual life stories of the participants. The themes included are childhood and life events, their rationales for choosing the trip, and post-trip life events. Photographs pertaining to their individual stories were included in this chapter as well. The other portion of the chapter centered on the collective group story. This included comfort zones and fears, looking at the unfamiliar, and group dynamics. Lastly, there is a conclusion that shares the implications of this study.

\section{Limitations}

When it comes to the limitations of this approach, a main critique is the relationship between the researcher and the participants (Goodson \& Gill, 2011). As mentioned previously, a relationship that fosters mutual respect and communication is key in narrative life stories. Within this approach, the researcher engages actively with the participants and connects closely with them both on a personal level and within the research domain. Part of this limitation is explained by Hatch \& Wisniewski (1995), who are concerned about the authorship, ownership, and voice of both the participant and the researcher. These notions of power, control, and privacy need to be kept in the forefront of the study in order to not trivialize the participants as a means to an end. Using Freire's "problem-posing” approach as part of the foundation for the study aided in addressing the concerns of voice, ownership, and authorship. The design also assisted in counteracting this critique as well.

In discussing the research design, many feel that a challenge lies in being able to achieve both representativeness and generalization (Goodson \& Gill, 2011). This directly relates to the validity of the research as the study is composed of connecting individualized stories to a larger audience. One approach is to balance "the story of the individual in all of its uniqueness with the 
larger social, political, economic contexts which frame it, and are, in turn, reinforced and challenged by the individual's action and responses" (Hatch \& Wisniewski, 1995, p. 120). Goodson and Gill (2011) argue that the issue is not necessarily between the individual story and the social, but it is a question of structure and agency. The research design recognized the inclusion of the contexts surrounding the individual life stories, thus gaining a larger perspective for meaningful understanding amongst a larger audience.

The third challenge involved both the researcher and the participant. There is a concern that researchers are not always aware of the possible effect life story research may have on the participants (Riessman, 2005). Life story researchers are confronted on an ongoing basis due to both the nature of the research relationships, as previously mentioned, as well as the processes that the researcher and the participant go through together (Goodson \& Gill, 2011). Even though the structure of narrative life stories allows for self-reflection and opportunities for change, it does not take into consideration how drastic the changes may be nor what negative selfperception may come from reflecting on one's life. Goodson and Sikes (2001) state the difficulty in determining the effects any research may have on the participants and the researcher; it could be "insignificant" to "life altering" or from "local" to "global." This is a relevant aspect to keep in mind throughout the study. Additionally, Riessman (2005) believes that a "give and take" approach to the research relationships in life story and narrative work. In order to address this concern, the researcher was cognizant that each participant brought along their own personality and emotions and looked for ways in which these feelings were honored and addressed during the study. Within this project, it was important to be aware of the possible risks involved as well as receiving feedback from a community of researchers, which were two additional ways to address the critiques of narrative theory. The limitations of this approach related to both ensuring 
the emotional safety of the participants and the validity of the findings. These concerns were mitigated, as best as possible, through the development of the research project; however, issues relating to events in the life of a participant could have arose unintentionally as the life story was obtained. That being said, narrative life stories should not be overlooked due to these concerns since the overall impact of the approach has high potential for learning and education.

\section{Ethical Considerations}

For me, the basis of this study was to highlight the influences of international experiences on the life stories of the participants from Appalachia. While providing the conduit for their stories and voices, I put the participants' social, emotional, and cognitive well-being ahead of the needs of the study at all times. As all the participants were residents of Appalachia and most of them were women, they came from marginalized positions and that aspect was always taken into account. Also, I kept in mind that as the researcher and the co-lead faculty member of the experience, I had more power than the participants, by default.

I adhered to the proper process to gain the consent of the participants and access to preexisting documents. Additionally, I worked to inform the members of the trip to Ireland of the purpose of the study and what was expected if they chose for their blog entries to be included. As for the participants, I also went through the formal process of consent for the rest of the study. I informed all the members of the trip, including the five participants, that they could have removed themselves from the study at any time with no reason needed. Additionally, there were no negative consequences for consenting to participate or choosing to withdraw from the study.

\section{Moving Forward}

This chapter began by illustrating why narrative inquiry is the ideal methodology for this study. My constructivist perspective naturally connects to my choice of narrative inquiry. Being 
cognizant of the limitations to this approach allowed me to recognize the potential risks in this study in order to plan accordingly and work through any issues. The methods that I used to examine the multiple contexts of the participants demonstrate how adult participants from Appalachia were impacted by non-formal, educational programs in an international setting. In the next chapter, I present the study findings. 


\section{Chapter 4: Findings}

To speak a true word is to transform the world.

(Freire, 1970)

Narratives are useful in research precisely because storytellers interpret the past rather than reproduce it as it was (Riessman, 2003). Since our experiences and our knowledge are informed by the lenses (i.e., parent, teacher, spouse, employee) in which we view the events, different interpretations of our stories are inevitable (Goodson \& Sikes, 2001). These narrative accounts shift between the past, present, and future through the connections they make; and they offer storytellers a way to re-imagine their lives (Riessman, 2003). Utilizing narrative life stories, this researcher gained insight into the effects of various events on the lives of the participants as well as the patterns within the storytelling. More so, the use of narrative interviews of a constructionist vein are viewed as "dialogical performances, social meaning-making acts, and co-facilitated knowledge exchanges" (Koro-Ljungberg, 2007, p. 430). At times, my own voice is a part of the narrative stories, which demonstrates the constructivist perspective. It will also aid this approach to social research that gives a voice to the silence and bridge the lived world with the intellectual world (Goodson \& Gill, 2011).

The overarching research question of this study was, "How do non-formal educational experiences in an international setting affect the lives of participants?" The data analysis is broken into the following two sections: Participants' Life Stories and Shared Group Story. Each of the participants had a story to share about his or her experience in Ireland and his or her life overall, which are the first parts of this chapter. The analysis section begins with the exploration of the life stories of the five participants with the emphasis on their experiences in Ireland. Since this study is to consider what influences (if any) the Ireland trip had on the participants, it was 
important to include questions on their life prior to and after their time abroad. The individual life stories and the latter collective story stem from a constructed dialogue between the participants and myself that allowed for subjective interpretations on both levels (KoroLjungberg, 2007).

Next, I delve into the shared group story that was derived from the analysis of the individual interviews. I ascertained the following aspects that arose from the participants' experiences in Ireland in 2013. The first facet that emerged was the comfort level of the participants and how they dealt with activities that worked within and outside of these comfort levels. The second component was the cultural comparisons and how these similarities and differences came into play in their stories. The third aspect is the intergenerational characteristic of the experience, which includes the connections and relationships of the participants and all the members of the 2013 group. I will look at these three themes and how different stories are included within these characteristics. Additionally, there is also overlap between these three aspects due to the fluidity of the narrative stories, as this research is set to explore how nonformal educational international experiences were viewed within the life stories of the participants. It is through narrative life stories that give us, as humans, profound reflective and interpretive framework for holding together lived experiences, tensions, shifts and continuity (Goodson \& Gill, 2011).

\section{Participants Life Stories}

The first section of this chapter looks at the life stories of the participants and how they connect with one another. The participants of this research study cover a wide age range from 31 to 79 years. Martha was the oldest member of the group, turning 79 years old while in Ireland. Of the remaining participants, Ruth was 78 years old, Rebekah was 63 years old, Hannah was 40 
years old, and David was 31 years old at the time of this experience. The first participant story is Martha's. Second, we will look at David's; he was the youngest participant of this study and next to youngest member of the CEOS Trip to Ireland. Then comes the life story of Ruth, who is the next to oldest participant of this study. The next participant story is Hannah's, who is also one of the younger members of the CEOS Trip to Ireland. Lastly, we will look at Rebekah's life story and she is between the ages of the older two and younger two participants. The next subsection will look at Martha's life, her experience in Ireland, and its influences on her life.

\section{Martha's Story}

Martha was born in 1934 in her grandmother's home in Morganville, which is the county seat in Newton County, West Virginia. Newton County is part rural, part urban and is in the northern region of the state (close to the Pennsylvania and Maryland borders). Living in the same county all her life, she was in her early eighties at the time of the interview. She was a CEOS member for many years. Additionally, Martha was my maternal grandmother and as she was a close relative, I do know more about her life story than any of the other four participants. Looking back at her childhood, Martha lived on the street where she was born for the first five to six years of her life, which was close to her paternal family. Then her family began to move around Newton County quite a bit, living in 20 different homes in 12 years. These homes differed in location, some being rural and some urban. No matter where the home was, the main form of travel and transportation was walking as her family did not frequently own a car. "When I was little, like on Main Street or these streets, you could walk those places sometimes with my mother or my grandmother. My other grandmother or you know, then you walked wherever you went. You didn't have any way to get anywhere except walking” (Martha, November 21, 2015). 
Walking and exploring were ingrained into Martha's lifestyle as a child and continued throughout her life. When discussing her experience in Ireland, Martha mentioned most often getting to walk around and explore. Her inquisitive nature led her to explore and travel, both with groups and individually. As for the Ireland experience, she shared a story about an excursion to the Port of Clogherhead, which is a fishing port on the east side of Ireland and is approximately 2.4 miles from the town of Termonfeckin, where the group stayed.

When we, on that, it was always water and was on it by this hill, a big hill, and where they had the cows up on the hill. I forget what that was called there...well somebody was up on the hill, I couldn't see who it was but I knew it was somebody up there and I thought well I'm gonna walk up there up on the hill and see what is going on up there. And I didn't realize how sharp it was coming over the hill but that's why somebody helped me get over but when I came back there wasn't anyone but that's alright I managed to get back down. (Martha, November 21, 2015)

Martha was interested in what was going on up the hill, so she simply went to see; she was the type of individual who once she put her mind to something, nothing could stand in her way.

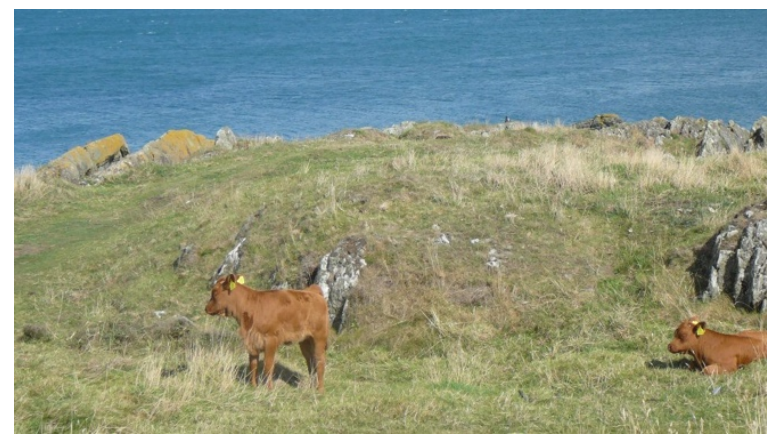

Figure 6: Cows Grazing, Port Oriel, Clogherhead 


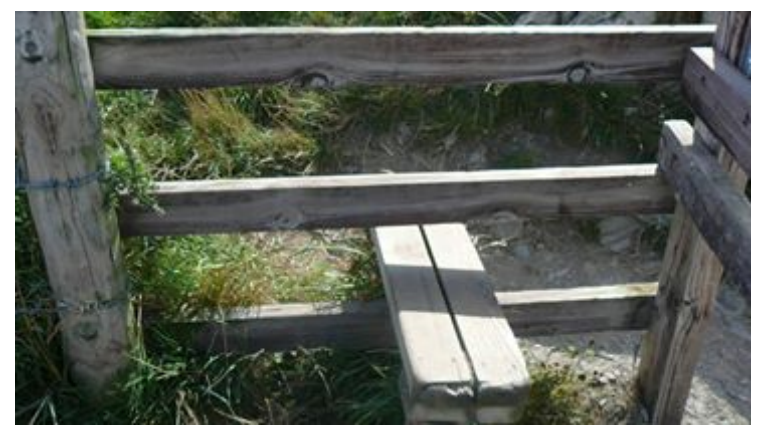

Figure 7: Fence crossing

Martha stepped over a wooden fence (with help) to walk with the youngest member of the group on the side of the cliffs, among the grazing cattle. This researcher took the above photos with the above left photo is of the cattle grazing at the Port of Clogherhead and the above right photo is the step used to climb over the fence to enter into the cattle grazing area. Even though she was the oldest person on the trip, she was also one of the most active. I always said my grandmother had two speeds: stop and go. This excursion was part of our Rambling class (rambling means walking around/exploring), which we had to modify due to mobility issues of some of the members. Her walk among the cliffs demonstrated part of an intergenerational connection that is also seen in each of the other participants' stories. Martha was more interested in being around the younger members of the group because they took walks into town and were more active than the individuals on the trip that were her age.

Martha described Ireland as "someplace I always would love to go" (Martha, July 23, 2016). She spoke of finding the Ireland experience very enjoyable. She specifically mentioned how the Titanic Museum in Belfast was very interesting, seeing the process of the ship being built from start to finish. She also talked about walking down to the local store in Termonfeckin, "I enjoyed walking and up to the grocery store; it was a good little walk" (Martha, November 21, 2015). As a scripted describer, Martha included the places she visited, but offered little insight to why she enjoyed the experience or found an excursion interesting. Her responses contained 
minimal reflection; however, she did have agency throughout her adult life. The fact that a 79year-old West Virginian native hiked up the hillside at Clogherhead, thousands of miles from home demonstrates her agency. It is highly probable that the rural, hilly landscape with cattle grazing in some ways reminded her of home. This could especially be the case for two reasons: Martha's neighbor has cattle right behind her house, and her daughter's house is located beside a family farm (with beef cattle), which she visited often.

Martha made one reflective comment related to the photography class, which was not the class she took in Ireland. "My camera doesn't do like the young people today, I wish I would have had, at that time, just to have one to do that but I don't know if I could have learned that quick anyhow. So, I didn’t get to take very many pictures for that reason” (Martha, November 21, 2015). Martha was not well versed in technology, so she chose to take the Gardening, Cookery, and Rambling course instead of the Digital Photography course. As much as she liked to take pictures, her camera was a $35 \mathrm{~mm}$ and she had trouble with using it at times, such as putting her knuckle over the flash or pressing the wrong button in her attempt to take a photo. However, Martha loved having photos of her family, friends, and events of her life. She would have preferred to have taken the Digital Photography course, but knew she did not have the correct camera or did not think she would have been able to learn as quickly as needed for the class.

However, there were skills common to her generation that Martha possessed that are not as present in today's younger generation, such as "I used to quilt, I can't do it anymore 'cause I always needed somebody just to help me turn it or so on. Umm, I used to make Afghans and I made them where you made the little things and then knit them together" (Martha, July 23, 2016). Additionally, when asked how Appalachia influenced her learning, Martha said, "So, I 
wish I could, I wish I knew how to do wood and you know, there's always things that need fixin' and so on and you hate to ask son-in-laws to do so many things that need to be done" (Martha, July 23, 2016). According to Fenick and Tennant (2004), the lens where learning is viewed as acquisition sees knowledge as something obtained through learning experiences. Martha wanting to learn new skills involving her home would fall into this perspective of adult learning. The premise behind acquisitional learning is that an individual would not just learn new content, but also "have strategies to develop new knowledge or cope with unfamiliar situations" (2004). In theory, if Martha had learned these other skills mentioned above, she should have been able to transfer this knowledge to other similar areas. In the Experiential Learning Model, generalizing the knowledge learned is a part of the "reflect" stage that connects to being able to "apply" the knowledge to new areas.

Martha's learning and education was very much influenced by traditional gender roles. Her desire to know how, to know more, and fix things is linked to her agency and to not be reliant on others. It is not connected to resisting gender roles because she would comment on mothers not cooking and cleaning like they should, or "girls" (i.e., this researcher) not being taught sewing in school. Her interactions with men during the trip to Ireland also indicated her acceptance of traditional gender roles. For example, there was a handyman at the facility where our group stayed. He carried the luggage up the grand staircase to the rooms for the members of the group on the first and last days. Martha felt that it was quite appropriate that he took care of the baggage for our group because that was what a gentleman should do and what was expected. However, this researcher was taught to be independent by her father (Martha's son-in-law), including to only travel with what one can carry. Therefore, I carried both Martha's and my own 
luggage up the staircase to our room. While Martha was content to accept this stereotypical gender role, this author felt differently.

Martha also expressed that Appalachia created a barrier to learning. In some sense, it seems as though she wished she had more opportunities to learn in school when she was younger. It also seems that she experienced some mourning and regret for not having been able to even be "wide awake" enough to have the desire to go to college when she was younger because the desire was completely closed off for young women like herself, saying, "I think I wish I had learned more. I had no desire to go on to college, we couldn't have done that anyhow back then, but umm, I do sometimes I wish that I knew more” (Martha, July 23, 2016). Martha's comments connect to Tennant and Pogson's (1995) adult learning framework as she talks about her learning experiences and analyzed those experiences. The only part missing from Tennant and Pogson's (1995) approach is the third step, identify and act on the implications of what is revealed, which did not occur. That could have been due to her being 83 years old at the time of this interview. Martha did not like being unable to accomplish a task, which would lead to frustration and her feeling stupid. This was the first time ever that this researcher had heard her say she wished she had learned more, or heard her reflect on her life this way. It is possible that she was ill during the time of this interview, which caused her to see aspects of her experiences in a different light.

Martha was a product of the Great Depression and had lived through World War II, with these events shaping her life. For individuals who lived through the Depression Era and have come from working class and poor backgrounds, money can be especially precious. Also, making purchases can be an emotional act. During the trip to Ireland, Martha only made a few purchases and discussed her trepidation about her first purchase. The novelty of the euros and her 
discomfort with mental tasks made her wary of being taken advantage of by a store clerk; it brought on a fear on giving too much away. However, I felt that she could learn how to purchase with foreign currency and it was more of a comfort issue than an ability issue. Therefore, I stood behind some shelves so that I could be close by, just in case, but allowed her to gain the confidence to work through the learning experience. Tennant and Pogson (1995) argue that experience is a conduit for effective adult learning; therefore, Martha making a purchase with foreign currency provided her with an opportunity to effectively learn this skill. Martha tells of learning to use foreign currency, "I wanted to get (panty)hose because I must have not had enough or something and I, but I did, I had to get them myself 'cause you didn't want me, you wanted me to do it myself" (Martha, November 21, 2015). She was the center of the learning experience and the goal of Martha purchasing pantyhose by herself was to prepare oneself for a later experience of a deeper and more expansive quality (Dewey, 1963). Martha's response "but I did" is very telling in that she was able to use foreign currency and was successful in this learning opportunity. This approach to learning by experiencing I have utilized with other international travel groups with WVUES and it tends to work quite well.

Although it may seem that older individuals from Appalachia would be geographically isolated and ill at ease outside the U.S., let alone the ubiquitous holler, this was not the case with Martha. The CEOS Trip to Ireland was one of Martha's many travel experiences. Martha's sister lived in Washington, D.C., which allowed her to visit regularly with her family. Domestically, she traveled significantly: Niagara Falls, Boston, Florida, and a 23-day trip from West Virginia to a northern U.S. route to California, then down to the southern part of the U.S. and back to West Virginia. She traveled to Hawaii on a 10-day trip with her oldest daughter in the mid-1980s and to California with her middle daughter in 2000 to see her grandson perform in the Rose 
Bowl parade with his high school band. Her first international trip was in the early 1980s with her youngest daughter. They went to Spain with her daughter's high school Spanish Club and "I wouldn't have let her go to Spain all by herself. I mean other people do, but I wouldn't have let that happen” (Martha, November 21, 2015). As she had been her entire life, Martha's wish for her future was to still be able to travel and be active.

Martha never indicated any changes that occurred from her experience in Ireland. Martha simply sees it as another place to which she traveled and activity in which she participated. She mentioned how much she enjoyed the trip and how nice everyone was. She did not do anything differently upon her return or view the world differently. During the interview process, Martha was intent on providing accurate dates and places; she had a unique interview style. For example, when she was asked a question about what she learned in Ireland, Martha responded with "Oh Lord, I need my little paper where I went” (Martha, November 21, 2015). Martha had a brain aneurysm at age 37, which led her to re-learn most tasks, including talking and writing. With her desire to be precise, she kept a paper of the places she had visited in Ireland so she could correctly share it with others. Martha also kept written reminders of other information as well in order to allow her to share details exactly. She still had difficulty describing in detail her experience and her life, but this was very important to her. In part, this was because she was a strong Christian and believed in telling the truth, as had been taught to her whole life through church, the Bible, school, and her family. But I also believe that because I was her granddaughter, and she could see that I had so much invested in this project and degree, she did not want me to "get it wrong" on her account. She wanted my success. And so, although Martha tried her darndest to be a scripted describer of the kind that Goodson (2013) describes in his work (and her health issue intensified this), her spirit and agency kept leaking out in, around, and 
through the "truths" she told. She was indeed a complicated storyteller and a unique, complex individual.

Martha saw her role in life through familial connections, as is typical among residents of Appalachia. First as a daughter and now as a mother, she looked back through occurrences and relates the details to her own positionality and roles. Martha's lens of family deepened with this trip as it was something she shared with her granddaughter. Not only did she travel to Ireland with her granddaughter, but they roomed together, took the same 3-day course, and the excursions. It is possible that Martha saw the trip to Ireland more as a familial bonding experience than an educational one. She included the role of family throughout her story and this is seen with what she chooses to mention during the interviews as well as when discussing important things in life. The three most important things in her life, Martha said, were: 1) her Lord (faith); 2) her husband, mother, and children (family); and 3) honesty. Her rationale was that these are the three things she thinks about most, which confirmed much about how and why she framed her narratives in the way she did and, as mentioned above, why the scripted descriptor identity resonates.

Martha was not the type of individual to explore the similarities or differences of a culture without someone leading her down that road. She was in the denial stage of Bennett's (2004) DMIS. Bennett (2004) states that the denial stage "is not a refusal to "confront the facts," but is instead an inability to make the perceptual distinctions that allow cultural facts to be recognized." Martha often would say we are all just different and used that rationale to explain anything she did not understand about others. As stated above, faith was an important aspect in her life. However, she did not make any inferences relating to religion or faith about the CEOS Trip to Ireland, even though there was an optional excursion to a local church service and the 
Belfast visit included a discussion of "The Troubles." This could be because she was Methodist and Ireland is predominately Catholic; Martha was one who needed clear connections in order to recognize correlations. Again, this speaks to the Denial Stage as she was unable to make distinctions related to cultures.

It also speaks to the missing connections to learning approaches and Appalachia that I was expecting as Martha had very little authentic reflection in her interviews. According to Freire (1970), authentic reflection focuses on people and their relationships with the world. Martha seemed to avoid talking about relationships with other people, but concentrated more on others" activities. She looked at the "what they did" and not the "how they felt" or "why they did.” More so, she saw learning and education as accomplishing a task, not as a fostering, nurturing, and cultivating process (Dewey, 1944). Martha was the type of person who equated education to a check list. For example, her desire to graduate high school was so that she could marry; one task had to be completed before the other. Martha died on January 27, 2017 and was unable to complete the member check portion of this study. However, the clear-mindedness and consistency with which Martha repeated themes in her narrative and enacted them, as well as my life-long relationship with Martha and confirmation of family members who have known Martha for generations, gives me confidence in this interpretation of Martha's story.

Martha's story gives us a perspective from the oldest member of the group who traveled to Ireland in addition to the oldest participant of this study. The next story is David's. David is the youngest participant and the second youngest member of the trip. The similarities between David and Martha's stories are evident in the relationships that were built upon the trip to Ireland. 


\section{David's Story}

David was born in 1982 at a local city hospital near Lee County, West Virginia, where he has lived his entire life. This county is very rural and is close to the border between West Virginia and Ohio. David was 31 years old during the CEOS Trip to Ireland and was the youngest member of the group. He is a first-generation college graduate, having attended a local university close to his home. However, he took a hiatus from his master's work to take care of his grandmother. David was employed by this local university and did complete his master's degree after the death of his grandmother, while still living in his hometown. A lot of changes came in his life after the Ireland experience; however, both the role of family and career are present throughout David's story.

David is not a CEOS member; however, he does have ties to WVU Extension through his involvement with 4-H as a child as well as other Extension Service Groups in his local area. After seeing about the Ireland trip on social media, David explained his decision to go to Ireland.

I decided to go after I had a colleague who I told about the trip and they decided to go as well so I actually funded the trip by taking money out of my retirement [account] because I felt at my age that I would probably be working until I was in my eighties anyways so why not live it up while I can in my thirties? (November 20, 2015)

While this financial maneuver might seem radical as David positions himself as one living in the moment (and perhaps not trusting the future of the Social Security system in the U.S. or scoffing at the very notion of retirement, it is unclear exactly what he believes), he also connects travel 
abroad to what he knows, what was near and dear to him in his community and childhood, and that is involvement in 4-H. As he states:

So, that's pretty much, seeing the opportunity and I grew up and 4-H was a part of growing up. Being involved, I have a cousin that is about a year older than me and he was involved in 4-H which in turn helped get me involved and I grew up near the Extension Office in Lee County so I knew 4-H, I knew the programs, I knew what they did and getting involved in this trip just seemed like a natural fit because I also knew one of the people planning the trip, and that helped. That helped ease any fears because there was somebody to kind of lean on who had already been there. Who had kind of dealt and knew what we would have to go through and it was a trusted resource to use. (David, November 20, 2015)

As this was his first international experience, his concerns were allayed by traveling with a group and knowing one of the faculty members planning the trip, someone from his home town that he knew on a first-name basis. On one hand, David chose to participate in this experience because of the familiarity and trust he placed on others, thus allowing him to remain somewhat in his comfort zone. On the other hand, it could also be counterintuitive to multicultural learning since some researchers argue that a feeling of discomfort is a healthy way to generate discussion of how marginalized or minority groups feel (Cruz \& Patterson, 2005).

David is a case in which very active and significant identity ruptures seemed to occur as a direct result of the trip. One of the major changes in David's life occurred after returning from Ireland. Previously, he worked at a local university in a neighboring county and commuted to 
that university from his hometown. Within a year of his return, David had obtained a new job at another higher education institution that is over 90 minutes away from home and moved to a city 60 minutes from his home. Then, three years after the Ireland trip, he began working at another campus and had moved again, now two and a half hours from Lee County. According to David, the experience in Ireland gave him a greater self-understanding that allowed him to feel the selfconfidence and freedom he needed to seek new possibilities for his life, as an individual. As he explained:

I am more capable of accomplishing things in my life than I thought I was before. I was working a job that I was somewhat uncomfortable [with], I was not happy because I lived in the same town that I had been in for thirty years at that point, things didn't change, people were backwards. (November 20, 2015)

While the statement, "people were backwards" may seem harsh and unsympathetic to his own kith and kin, there are some reasons for why David states this position, one that separates him from the people in his homeplace. As he describes in the next quote, David experienced an identity shift while abroad. This connects to Koro-Ljungberg's (2007) notion of how personal transformation is further accelerated by self-reflexivity when a person critically questions his or her own beliefs. Not only did David further question his own personal decisions, he also saw the experience through Slocum's analogy of a window and a mirror (A. Slocum, personal communication, November 12, 2014). David learned from what he saw through the window into this other culture and the mirror into himself and applied what he discovered to his own life. Additionally, he read himself into the globalizing context of the Irish young professionals that he 
met while abroad provoked a new kind of courage as he saw it, to become more fluid and flexible, and leave in search of a better opportunity:

They [the people back home] were afraid of change and because of the trip I had the confidence to start looking for work outside and to move away and seeing so many young Irish people leaving to come to the United State for work or even to go to Australia for work. So being able to almost connect in a way with them [young Irish professionals] and understanding its ok to leave to find work, even though I stayed in West Virginia, having that confidence in myself to know that I'm capable of more than I was before I left. (David, November 20, 2015)

David strategically used an artifact that he himself created as an identity touch-stone of sorts that telescoped between the past, present and future. The photograph that he took in Ireland seemed to encapsulate his experience, and he wanted it with him and to share it with passers-by. It was a form of symbolic capital, also, in that it represented his ability to do things beyond his raisin' so to speak, and also symbolized that he was okay, or more than okay, with this change. Below he discusses the utility of this photo as an artifact:

So that's one reason why I have the job I have now is because I had the confidence to want more, to seek out more and speak to my students about it now. There is a picture hanging in my office of my trip to Ireland and I get to tell them and explain to them and talk to them about international travel and why it is important... (David, January 17, 2017) 
Even with his newfound strength and tangible representations of this, family was an important factor in David's agency, just as it was for Martha. This may be a reflection of rural, Appalachian culture. David particularly respected his father's opinion. His consent and blessing to leave was the "juice" that he needed to push him forward:

Having my father saying its ok if you want to leave. Him supporting that and encouraging me to leave and kind of test the waters outside of Lee County. Because there is that sense of abandonment you know...but being able to leave and not feel bad about it. It took a year of after leaving Lee County to not feel bad about it anymore. (David, November 20, 2015)

There were particular reasons within the family that affected David's emotions and difficulties adjusting to his new setting away from home. Primarily, the sense of responsibility that comes with taking care of one another within the family unit is an issue that is central to who David is. This was demonstrated earlier in his adulthood, when he left his master's program to take care of his grandmother and remained in Lee County to be close to his parents, even though he was unhappy with his career at that time. Family responsibility trumped personal happiness at that time, yet perspective from foreign travel showed him that others lived differently and more with their individual desires and needs at the forefront.

Looking more carefully into David's artifacts and narrations from the Ireland trip provide clues into the exact mechanisms that provoked change within him. While David mentioned various excursions on the trip that were formative. Going to the pub in Termonfeckin was one of his favorite experiences because he felt like it really bonded the group together because "we sat 
around and I think a lot of people learned about each other sitting there...I mean that was the experience I really enjoyed because talk about coming from different backgrounds. Even though we were all from Appalachia, we also came from different backgrounds, religious backgrounds" (David, January 17, 2017). David clearly felt the pub experience was a special one due to the comradery aspect that was fostered in the setting. The other co-faculty lead and I spoke informally to a few of the group members on the role of the pub in a community while we walked to the location. However, we could have turned that excursion into more of a teachable moment and spoke to the group collectively afterwards about the pub and include a reflection component. After all, without dialogue there is no communication, and without communication there can be no true education (Freire, 1970). As a pub is a gathering spot of the community, like town squares and plazas, it is a center for communication. The pub can serve as a conduit for learning as it provides the opportunity in which authentic thinking can take place within communication and reality (Freire, 1970).

This is interesting in that David explicitly notices and discusses Appalachian identity as being (a) visible, yet (b) varied and diverse. This aligns with some of the research mentioned early in this section that painted a polycultural view of Appalachian identity (Lewis, 1999). It is an important insight because it shows the potential pedagogical power of dialogue amongst diverse individuals from Appalachia in order to deconstruct deficit notions of identity that can lead to fear of judgement amidst local and cultural pride. It is the dialogue that allows for communication, which allows for actual education; and communication fosters an environment of authentic thinking (Freire, 1970).

Intergenerational connections made throughout the trip were especially salient to him: 
The different generations on the trip, I think was encouraging just because you would have the older members of our group sharing stories with the younger, but then you would have the younger group sharing how to use their cameras with the older groups and showing them how to take pictures from our photography class. So, you know, we kind of leveled each other out and being able to go to a pub with people in their late $70 \mathrm{~s}$ early 80 s and watching a soccer match and watching them drink Guinness for the first time but obvious things. (David, November 20, 2015)

In this interview excerpt, David explains peer teaching that occurred during the trip to Ireland. This was an educational experience that was unintentional on the part of the organizers; however, the result was very enlightening. The members of the group were influenced by intersectional identities of class, gender, and age; and the individuals aligned with their preconceived roles. Older members took on the role of learner, while younger individuals became the educators. When it came to sharing their life experiences, the younger members of the group became the learners (or the "children"), while the older individuals were the educators (or the "parents"). An educational program that incorporates peer-led learning along with an instructional style that changes or deepens the learning experience is essential when examining one's place in the world (Jehangir, Williams, \& Jeske, 2012). Thus, the combination of peer-led learning with the experiential learning style allows the leaders of such excursions to leverage a power that focuses on self-reflection within a life story.

David connected to progressive learning by his ability to reconstruct his experience, thus adding to the meaning of the experience, and therefore applying his learning to later experiences (Dewey, 1944). It was interesting to see this development as it was not a collective thread in the 
other participants' stories. Even though David brought up class and Appalachian identity during his interviews, he did not discuss either aspect with a critical perspective. He focused on overcoming poverty through education and stereotypical Appalachian values. This is indicative of his self-reflective nature. Plus, David notes how major events have affected the trajectory of his path as well as having agency in his life. His life story connects the past, present, and future in a thoughtful and cohesive manner. For example, notice in the following interview text how he anchors his story to key life events:

It truly was one of the defining moments in my 34 years on this earth. Umm, because you know, I was the only one in the family who had traveled abroad, I mean my grandmother had gone to Canada, but actually being on a plane and flying. Umm, and it happened, I'm gonna say, right after my grandmother had passed away, if I remember correctly. Or she had become ill at that point, and knowing that that's where her mother had come from, her grandmother had come from, umm, and having a connection to somewhere else other than West Virginia. (David, January 17, 2017)

David actually rearticulated notions of "family" very, very broadly to thinking about particular blood relations perhaps very thin but present as bodies passed him on foreign streets:

'Cause who knows how many people going down the street were family that I didn't even know, while we were in Ireland. And just that concept of - hey, that could be a cousin somewhere in the lineage, who knows?.. I connected on that trip, I think even to myself in a way that I probably wouldn't have done otherwise...An Grianan, built in 
1754 - and you think of all of the history that's passed through those halls and that you're part of that history. Umm, it's a page in your story. (David, January 17, 2017)

At the beginning of David's life story, he seemed to fall into a closed narrative story as he did what was expected of him by others. However, his participation in the CEOS Trip to Ireland caused a shift and he has developed a more open use of his narrative that seems to fit with Goodson's (2013) conception of a "focused elaborator" which means that the person includes a good deal of interior thought and reflection or "re-selfing." "Re-selfing" includes commentary where the individual will "reinvent," "rediscover," or "resee" themselves as part of his or her growth steps (2013). One example of focused elaboration in the data above is when David "rediscovered" himself, stating that he is more capable of accomplishing things in his life than before. Another is how David talks about his increased self-confidence multiple times as he "resees" himself after the Ireland experience. Lastly, David continues to "reinvent" himself in a new town, at a new higher educational institution, with a similar career. However, David's shifting identities and uses of artifacts and individuals to help propel him forward (whether it be a photo or his father) show that even within the general patterns of narrative he tells, he is not "fixed" in a way that Goodson would seem to have it.

David's story, as the youngest participant, gave a similar perspective on intergenerational bonding during the experience as Martha. He also offered a different perspective related to identity than Martha. This could potentially be due to the ages of these two participants. The next story is Ruth's who was one of the older participants and should add more detail to the intergenerational discussion. 


\section{Ruth's Story}

Ruth was born in 1935 in Milton County, West Virginia, which is a primarily rural county and close to the Pennsylvania and Ohio borders. Ruth was 78 years old when she participated in the CEOS Trip to Ireland. Ruth was close in age to several of the other members of the trip. Only a few of these individuals had traveled as extensively as she had. Additionally, Ruth was a widow, unlike most of the members of the group. Both of her parents were college graduates who had the expectation their children would attend college as well. This is different from Martha's life story as her parents had not attended college and her mother had received her General Educational Development (GED) later in life. The parental expectations between the two women of a similar age speak to the varied trajectories of their life stories. Ruth graduated from a local university close to her home. In going to college, she left her home place and it continued her desire to learn. Ruth defines herself as a people person and it was her desire to learn about others that carried her from Milton County to her college days to her varied travels around the U.S. and the world, including Ireland. She has primarily lived on the same road where she grew up, but she did move to the West Coast for a short time; however, Ruth moved back to West Virginia to raise her family. This is unlike Martha and David, who had both stayed in West Virginia. As adults, Martha and Ruth lived in the same counties in which they were born, whereas David now resides in a county two and half hours from his home place. Each one articulates her rationale for staying or leaving, which connects to her life goal at that time (i.e. family, career).

Ruth is a CEOS member, has strong connections to $4-\mathrm{H}$, and she is also a world traveler who has been to many different places. Her mother was also a proponent of traveling and learning new things, who advocated the importance of travel to her children. "Well, my mother 
always said, go see what's on the other side of the mountain. So, we all did. I had a sister who lived in Africa and so, I traveled..." (Ruth, July 26, 2016). Ruth enjoys traveling most because, "I like people, I like to meet people and associate with them" (July 26, 2016). Ruth has been to every state except Louisiana. She has traveled to Switzerland, France, New Zealand and has even cruised the Rhine and Danube Rivers. As for why she chose to go to Ireland, Ruth said the following:

I've always wanted to go to Ireland... I'm sure that my heritage is Scotch Irish. I think maybe more Scotch than Irish really but I've always thought just the beauty of Ireland, you know, with the pictures that you see and the history that you hear about I've always wanted to go so that [trip] was made for me. (Ruth, January 6, 2016)

Ruth saw the trip to Ireland as a way in which she could connect with her heritage and in a way confirm herself. As she "always wanted to go to Ireland," essentially Ruth desired to see the country from which her family came and from which she came. According to Hadis (2005), improved self-awareness is one of the several characteristics that result from intercultural learning. Ruth mentioned the beauty and history of Ireland in the same vein as exploring her ancestral connection, which indicates that they are one in the same for her. Ruth was not the only participant who delved into personal improvements from intercultural education as it was also evident in David's story. David's “great grandmother came from Ireland, straight from Ireland" (David, January 17, 2017), therefore, he looked for a connection between himself and the country. At one point, he even refers to perhaps passing extended family members while walking the street in Ireland. With David, his intercultural learning improvements included greater independence and increased cultural appreciation as well as improved self-awareness. 
Moreover, Ruth mentions the importance her mother placed on traveling and "seeing what was on the other side of the mountain." Ruth's husband was also an advocate for travel; however, he passed away in 1990 and did not get to travel as extensively as Ruth has in the years since. "I have enjoyed traveling so much and my husband would have enjoyed it too. He always, you know, encouraged it so, umm, I’ve spent all my extra money on traveling (Ruth, July 26, 2016). Traveling is one way that Ruth can honor his memory, which she does quite admirably. Additionally, traveling allows Ruth to keep busy and move forward in life. She is a selfproclaimed people person and her choices reflect that. After her husband passed away, Ruth moved in with her mother. At some point after her mother's death, Ruth moved in with one of her daughters, in a "mother-in-law suite" as she calls it. She prefers to travel in a group and always requests a roommate. Ruth prefers being with people to being alone. I do not consider this an effort to avoid being lonely, but I believe she is rejuvenated by interactions with others.

Although she believed that she was well-traveled, Ruth continued to learn new lessons through Irish culture when she stated "They had the small children in [the pub]. That was just such revelation to us because you would never take a kid into a bar here [in West Virginia], if you have any self-respect that is." I responded with "Yeah, but that was part of...Yeah, part of their culture and quite normal. So, yeah." While Ruth added at the same time, "That's just part of their [Irish] culture" (Ruth, July 26, 2016). Children were seen at the pub in Drogheda one evening around 10:00 pm while our group listened to local musicians. This demonstrates her openness to understanding child-rearing customs in Ireland through an adult learning experience. This approach allows for the use of a lived experience as well as promotes reflection on experience. Brookfield (1991) articulates a three step process that utilizes critical reflection in learning from experience: 1) identify the assumptions of one's thoughts and/or actions; 2) 
explore the validity of the assumption based upon the experience; and 3) reconstruct the assumptions into inclusive and integrative perceptions. First, Ruth identified the basic assumption from the experience, which was good parents do not take children into a bar in West Virginia. She then moved to connecting her experience with the accuracy of her assumption, or when she affirmed that parents did have their children in a bar in Ireland and it did not seem odd or unacceptable to other Irish patrons at the pub. Lastly, Ruth revised the assumption in to something more inclusive with her statement, "That's just part of their [Irish] culture" (Ruth, July 26, 2016).

Additionally, the aforementioned statement made by Ruth is an example of intercultural learning, i.e., accepting and respecting the normality of diversity in all areas of life. Ruth begins her quote with her cultural ideals, yet finished with a statement that showed more of an awareness of cultural differences. In her quote, Ruth positions West Virginian families as having more 'self-respect' compared to Irish families because of children being in a pub/bar. This idea of families not visiting a pub/bar stems from the religious organizations that came to the 'unchurched Appalachia' in the mid 1800s (Shapiro, 1978). Furthermore, Ruth makes the statement, "That's just part of their [Irish] culture" (July 26, 2016) as a way to rationalize the unfamiliar Irish practice, which also separates families in West Virginia from families in Ireland. The pub/bar experience is an example of how ingrained cultural principles are when a situation arises that causes a clash between beliefs.

Ruth still likes to remain within her comfort zone, even with her vast amount of traveling. She also prefers English speaking countries and explains her rationale below:

I just like to visit other countries as well. I do like to go to English speaking countries because I don't speak other languages and - I mean I've picked up a few comments, you 
know - words here or there. But like in France when they say "oui” I always end up saying "si” because the Spanish just came - well Latin I think too, you know, but you hear so much Spanish now that - so I try not to show my ignorance and it works sometimes. I like people. (Ruth, July 26, 2016)

Ruth is a well-educated and well-traveled person; however, the above statement indicates her naivety concerning language differences. This statement is an example of how she would fall into the Defense stage of Bennett's (1993) DMIS model. Ruth is aware of the cultural differences; however, she is intimidated by the notion of using a foreign language so that she does not show her own inabilities. Additionally, individuals who are more interculturally sensitive "can observe subtle differences in nonverbal behavior or communication style, while a naïve traveler may notice only differences in the money, the food, or the toilets" (Bennett, 2004, p. 73). While she possesses the ability to become more interculturally sensitive, Ruth will most likely remain stagnant in this learning sphere, in part, due to her preference for English-only travel.

Ruth spoke often about meeting new people and how to get along with others, saying "you meet people wherever you go and you just have something in common with them and you learn that everybody is different and you just have different opinions about things. So, some things you keep your mouth shut about" (Ruth, July 26, 2016). Ruth believes in the old adage "if you don't have anything nice to say, don't say anything at all." Her quote about being silent derives from that saying. In lieu of starting an argument, Ruth prefers to not engage with others who hold different opinions. It appears that this is a mantra that Ruth follows and is not a result of her non-formal educational international experience in Ireland. However, this is contradictory 
to the notion that dialogue is true communication and there must be communication for there to be true education (Freire, 1970). For Ruth, it is more important to be on friendly terms than it is to gain understanding of others.

Ruth believes that her travel experiences have "Given me a broader view of life, you know? In other places - and yet it lets me know how close - how we're all alike - you know?" (July 26, 2016). Ruth sees the experience in Ireland through similarities to West Virginia. "I didn't know about the mounds [in Ireland] and I didn't want to tell them about our mound in Moundsville because I didn't figure that it would be half as much; I certainly didn't have as much history on it as we had on that [excursion]..." (Ruth, January 6, 2016). Additionally, Ruth was very impressed that Ireland had a similar grocery store to one found in West Virginia. 'I've told a lot of people that there's an Aldi's there. That just amazed me. 'Course it's not the same one. Every time anybody says they are thinking about going to Aldi's I say, 'Oh, there was one of those in Ireland"” (Ruth, January 6, 2016).

Ruth chose church, her family, and service as the three most important things in her life. Each of these aspects she has self-identified as her values: a strong faith, a love of family, and her desire to help others. Ruth appears to have an open narrative at times with only her bar/pub quote containing a disapproving tone. The open narrative demonstrates Ruth's desire to meet new people, learn about others, and see new places. However, she also likes to have common connections with others, which she uses to maintain a level of comfort as she travels with people she knows or have mutual acquaintances in common. Also, Ruth's examples of meeting new people and learning about others aligned with Dewey's (1944) broad view of education, the social continuity of life because learning is a social function that develops a socialized mind. Since Ruth was one of the older participants of the trip, these aspects may factor into upcoming 
discussions on the influences of age, education, location, etc. More so, she does reflect on her life and possesses a willingness to change her personal dialogue when she misspeaks.

Ruth's story includes the desire for ancestral knowledge and understanding, just like David. She sees herself as a person that brings people together and her comments about Ireland demonstrated her desire to be collaborative, not divisive. This is also evident when Ruth discusses the importance of traveling and learning about others in order to determine the similarities between people. Some of these threads will be seen again in the next story. Hannah is the second youngest participant of this study and one of the younger members of the group who traveled to Ireland. Hannah had a previous association with David and lives in the same county as Rebekah. Some of these connections will arise within Hannah's story.

\section{Hannah's Story}

Hannah was born at a local city hospital near Garrett County, West Virginia, where she was raised and continues to live. Garrett County is rural, farming community and is close to the border between West Virginia and Ohio. She was 40 years old during the CEOS trip to Ireland and she was one of the younger members of the group. Hannah commutes to a nearby university outside of the county for work. She is a first-generation college graduate, who earned her bachelor's and master's degrees from the same institution where she is employed.

Hannah is not a CEOS member; however, she learned of the trip to Ireland through a coworker. Here she discusses how she chose to go on the trip. 
I had never ever traveled abroad before but I love to travel. I've been all over the entire United States and I had such a draw to Ireland because my ancestors, I am huge - ah, I do a lot of genealogy research and I knew that I had a very strong Irish history. I thought, oh that would be so amazing. Just to have that connection to see where your ancestors started...it was trying to go back and maybe see why I am who I am based on probably some of the experiences of generations before. (Hannah, December 11, 2015)

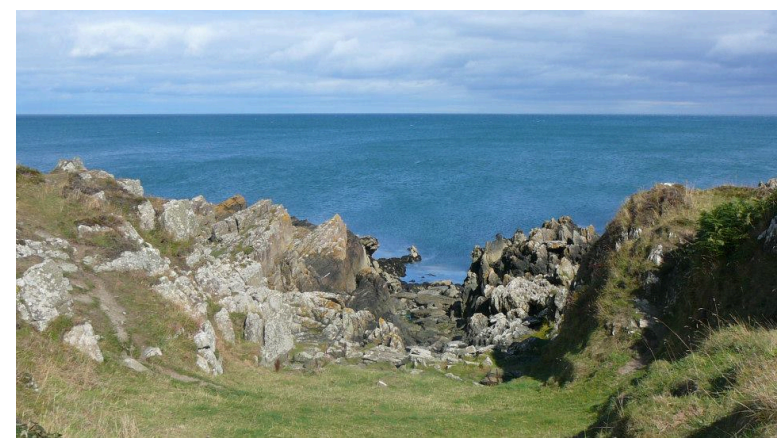

Figure 8: Cliffs at Port Oriel, Clogherhead

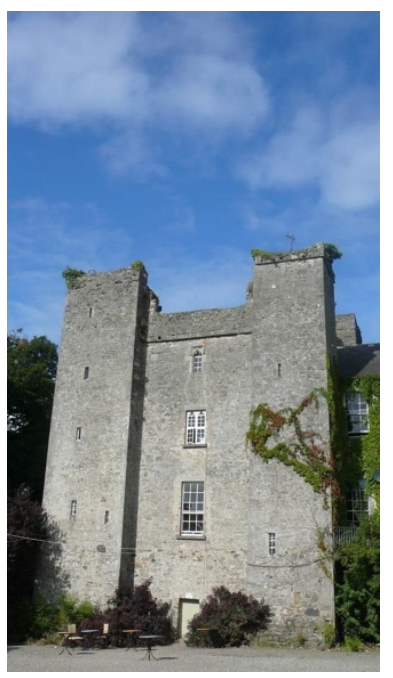

Figure 9: Dardistown Castle

Hannah had preconceived notions of who she is, which led to a great interest in traveling to Ireland. Subsequently, her time in Ireland and her desire to know her ancestry has led to further genealogical search through an online program as well as DNA testing. In the above 
quote, she connects part of her identity to the experiences of her ancestors, which may be associated with the Appalachia adage that a person should not "get above their raisin"" (Sohn, 2006). More so, Hannah's desire to visit and reflect on the experiences of her ancestors in order to better understand her present is demonstrative of Dewey's (1944) notion of experience in education. Experience in education is a fluid movement that travels backward and forward, weaving together experiences and reflection upon those experiences (1944).

One aspect that Hannah sees differently after this experience in Ireland is how she encourages others to travel out of their comfort zone, primarily internationally. "I try to encourage others to step across borders and do things maybe that they've never done...communicate the importance of getting out and exploring and seeing the world, that other people can have that change" (Hannah, December 11, 2015). Hannah's time abroad led her to advocate for others to travel internationally with the goal for them to have a similar experience to what she had in Ireland. In the above statement, she advocates for others to travel abroad as a method to try to understand and educate others on new ways of thinking or doing. Johnston (2012) defines this as dynamic learning. Hannah does not view behaviors as permanent traits that one is unable to control, i.e., fixed learning (2012). More so, her quote promotes possible change through a learning environment that will allow a person to construct new concepts of race, culture, and ethnicity through his or her experience (Banks, 2001). Hannah did not specifically comment on race or ethnicity, but she did refer to new perceptions on culture. "Different cultures have such a different way of communicating or have customs of what's appropriate to communicate and what's not. All of that has really been extended to me in a way that I would have probably been fearful of that before and now I'm just much more open and appreciative" 
(Hannah, December 11, 2015). She acknowledges her previous shortcomings related to fear and now self-identifies as being open and appreciative to different cultures.

One change that occurred from Hannah's time in Ireland was her way of thinking as it related to the pace of life. She describes a fast pace lifestyle at home, but felt the Irish culture moved at a slower pace. This change affected Hannah in a way that she now strives to replicate the slower pace at home. More so, Hannah also discusses some future goals that she would like to accomplish as a result of the trip.

My train of thought was that umm there's an opportunity to find joy, umm, in slowing down. Their culture does not move as quickly as our culture and so that is something that is still a struggle 'cause I think part of who we are just drives us all the time, we're always busy, busy, busy here but I want that back. So, I think that's part of my goal of going back to Ireland is to have a piece of that and to incorporate it maybe in small ways in everyday life. Umm, so I think that's probably one of the biggest things I noticed and the other is to you know, I would love - and I don't know what financial connection may make this happen someday - I would absolutely love to have a retirement home in Ireland where I spent so many months here stateside but I could go there and visit and stay when I wanted to. I honestly think that would just make me the happiest person in the world...I think it definitely changed me in regards to learning to slow down, wanting to go back, wanting other people to get to go. (Hannah, October 7, 2016)

Not only does Hannah want to incorporate the slower pace in life, she wishes to remove herself from the "rat race," a common aspect of U.S. culture. Additionally, she desires to return to 
Ireland, even as a part of retirement plans. For Hannah, this stems from the more relaxed pace she experienced while in Ireland.

Part of the rationale for Hannah to be a member of this trip was due to the ancestral links she has with Ireland. This is a common theme throughout these participants of this study. David and Ruth have also mentioned their heritage as reasons for going to Ireland. The notion of "connecting to one's roots" was prevalent no matter the age of the participant. David and Hannah, the younger participants, spoke with more detail and interest in their heritage than older participants, like Ruth.

Because that is something I could still be here and connect to the culture I grew up in but also go and see kind of roots where it all started. I think that's how I see Ireland - you know there's that craving when you do a family history to understand what it must have felt like for them to leave something they loved and how they changed and adapted when they got here to try to still find happiness and I think it ties back to it. I really like that concept. (Hannah, October 7, 2016)

Another reason was for Hannah to understand how her ancestors could leave what they loved and that resonates with her adult life. "We [Hannah and her husband] thought about leaving the state when we first got married and the pressure to take care of family again was to stay here and we did, I don't regret [it]...” (Hannah, October 7, 2016). She seeks to understand how her ancestors could leave their home and find happiness. For Hannah and her husband, leaving West Virginia was a thought, but it was an action taken by her predecessors. The association between the actions of her forefathers and the decisions made in her adult life is part of her desire for 
comprehension. After coming home from Ireland, Hannah began a second Masters in Humanities because it included Appalachian courses, which was a result of this trip. "You know, I didn't pursue the second Masters until I came back and had a craving to know more about the Appalachian and Irish connection umm, and then just to learn more about culture and stuff in general. So, I think it changed me in that way as well” (Hannah, October 7, 2016).

The intergenerational connections were also mentioned frequently by Hannah, whereas she enjoyed spending time with members of the group from a variety of ages. Hannah often said how much fun Martha was because she participated in all aspects of the trip, even though she was the oldest member of the group. She would say she hoped she had that much energy when she was Martha's age. She details her thoughts about the intergenerational aspect, both prior to and after the trip, below.

One of the things I found that was so interesting, I was younger than some of the folks on the trip and you know, there's this anticipation of will my views of the world because of my age be so much different than someone who's much older and umm, actually it was one of the more joyful things I think that I took back from the trip is that you know, it was fun to see [the older participants] interact...'cause I think we were all on the same view, we were all having the same experience of seeing this place that we'd never seen before and the age element kinda got taken away umm, in one aspect from that. (Hannah, October 7, 2016)

During both interviews, she felt inspired by some of the members on the trip. Hannah's perceptions of older people changed because of this trip. She learned that age does not limit 
one's capabilities and the experiences with the members of the group (from all ages) have become an integral part of her life story.

The three items that are most important to Hannah are the Bible (her faith); a picture of her son (center of her universe); and a globe (traveling). She has a high narrative intensity as she broke away from her predetermined scripts of no higher education, remaining in low socioeconomic status, and the impact of mental health issues on families. Hannah reflects often in her life story in order to bring meaning and understanding to her life and her decisions. However, she does not always follow through with new original scripts, like a focused elaborator. Hannah still follows some pre-destined scripts (i.e. family responsibilities, career expectations), but has branched out as well (i.e. college bound, traveling). She does not fall into just one of Goodson's (2013) predetermined narrative styles as all people will move between these narrative forms since none are completely whole. This is a significant factor that allows the participants' stories to remain "alive" and not be simply placed into a box. Since a goal of this study is to explore how the international experiences are viewed within the participants' life stories, the manner in which they share their life stories is a primary focus. Whether the individuals within this study align with a singular narrative character style or fall into multiple styles, either instance includes context, which tells about the participant and the culture in which they live.

In some parts of her story, Hannah's use of reflection is indicative of Dewey's (1944) perspective on learning being a fluid movement moving between one's past, present, and future. Yet, her comments were more about her identity as a resident of Appalachia and her Irish heritage than any reorganization of her experiences in order to better learn for future events (Dewey, 1944). Also, there was very little discussion from a critical perspective. Even though the CEOS to Ireland trip was a non-formal educational experience, there were aspects involved 
regarding an environment where educators and participants take responsibility of both the actions and the results in learning (Freire, 1970). However, this is not well reflected in Hannah's narrative story.

Similar to David and Ruth, Hannah's life story presents the search for ancestral knowledge and understanding. She also included intergenerational bonding and change in her preconceived ideas on age in her life story. Furthermore, Hannah desired to include aspects of the Irish culture with her life in Appalachia, i.e., a slower pace in life. Our last story is from Rebekah, who was in between the ages of the rest of the participants in this study and of the group who traveled to Ireland. Rebekah is from the same county as Hannah; however, they did not have a previous association prior to the trip. During the trip, Rebekah and David noted they had a similar acquaintance. This connection will arise within Rebekah's story.

\section{Rebekah's Story}

Rebekah was born and raised in Garrett County, West Virginia. She is in her mid-sixties and has lived not only in the same county, but on the same road for her entire life. She is a CEOS member with a very strong connection to 4-H, having grown up in the program and is currently serving as a volunteer leader. Rebekah was 63 years old when she went to Ireland with the CEOS in 2013. The county in which she lives is rural, farming community and it is close to the border between West Virginia and Ohio. Rebekah graduated high school and married soon after. She was a stay-at-home mom and continues to take care of her family by watching her grandchildren when needed. During their early adulthood years, Rebekah and Sam, her husband, traveled very little due to the demands of a working farm. Their first trip away was when their son was old enough to take care of the farm; "we just took off one weekend and we ended up at Niagara Falls and we did go over in Canada because then you didn't have to have a passport or anything 
(Rebekah, September 9, 2016). Since then, Rebekah has traveled quite a bit and almost exclusively with her family. She went to Hawaii with one of her youngest daughters during high school. She also talked her husband, Sam, into going on a cruise to the Bahamas with her other youngest daughter's senior school trip.

Sam wasn't interested [in going to Ireland] and I just thought that was a good opportunity because I would be with Julie had been over there before so I felt comfortable going with her. It was an area she knew and I would be with CEOS ladies and I just felt like ya know that I would feel comfortable going. (Rebekah, November 20, 2015)

As Rebekah points out, the members of the group going to Ireland were primarily female. We only had two male participants, one was a spouse of another member on the trip and then David. Rebekah never spoke of Sam having any concerns about men going on the trip and part of that could be that the difference in age mitigated that issue. Also, Rebekah and David found out quite early on that they had a mutual acquaintance, Rebekah's former daughter-in-law, which also assisted in alleviating any uncomfortable circumstances.

Rebekah enjoyed her first time abroad due to the many similarities between Ireland and West Virginia. Here she explains some of her thoughts on the two locales. "Well, um you know, you always hear bad things about a lot of other countries. But you know I really liked Ireland. Because I felt like I was right at home. Remember when we got there they were making hay, baling hay, and that just made me feel like I was at home in West Virginia" (Rebekah, November 20, 2015). Dewey (1963) argues that every experience should provide growth for the individual by preparing that person for deeper, more expansive experiences in their future. Part of 
Rebekah's observations included providing a sense of security while abroad by noticing cultural comparisons. By having a positive experience the first time abroad, she may be more willing to travel to other countries in the future, even though she has heard "bad things" about other countries. In the beginning, Rebekah seemed to seek out similarities in lieu of differences in order to maintain her cultural outlook, which goes against multicultural education where diversity is seen as an asset (Banks, 2001). Bennett (2004) states that a supposition exists that contact with cultural differences generates pressure for change in one's worldview. If one does not recognize or minimizes cultural differences, then there is no prompt to modify his or her perceptions of the world. Rebekah inadvertently shares her desire for personal safety throughout her life story, which can be seen in the above quote as well as future ones.

Rebekah did note some differences between Appalachia and Ireland, which includes being fearful of the "unfamiliar." The first difference she noticed was with driving. Martha also mentioned this difference as well, but from the perspective of overgrowth of the hedgerows that lined the narrow roadways. Rebekah states that "the only thing I didn't like over there was their driving. That first time my God I ended up in the front because I was late getting in and I told David, 'Uh uh, I'm getting clear in the back, that scared the life out of me'”' (Rebekah, November 20,2015). She was fearful of the driving because of the narrow roads and hedgerows along the side of the road would rub against the vehicle in certain areas. The hedgerows in Ireland are protected by law as they are a natural habitat for a variety of small animals; therefore, the overgrowth is actually due to environmental protection (National Parks and Wildlife Service, 2017), which was not discussed during the 2013 CEOS Trip to Ireland. Rebekah's viewpoint aligned with Bennett's (2004) ethnocentric viewpoint, where one avoids cultural difference (i.e., denies its existence, raises defenses against it, minimizes its importance). This viewpoint was 
also seen when Rebekah mentioned her fear of driving to big cities or long distances by herself (prior to the trip). It was not a fear due to lack of control in the situation, but more fear of the "unknown." Rebekah saw the country and bales of hay, like in Photo 5, as similarities of home. The driving was a regular reminder that she was not. The trip to Ireland affected Rebekah in the sense that she became more willing to travel to places she would not have gone prior to the trip to Ireland. She became more comfortable with being uncomfortable.

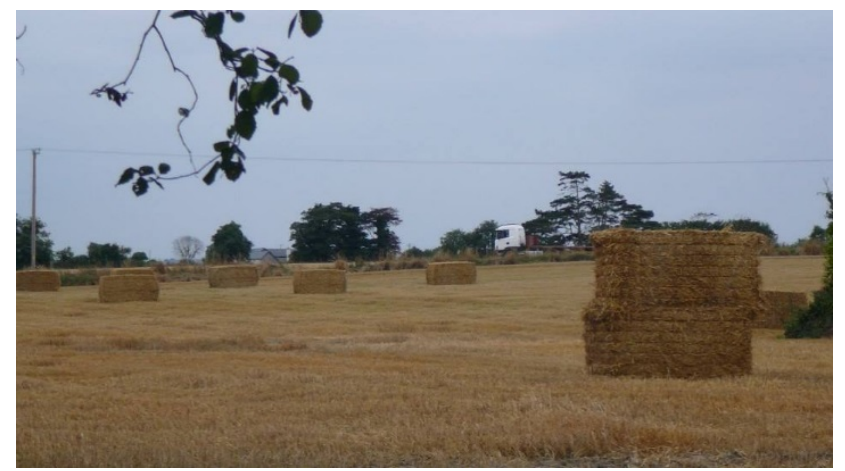

Figure 10: Hay bales beside An Grianan (lodging)

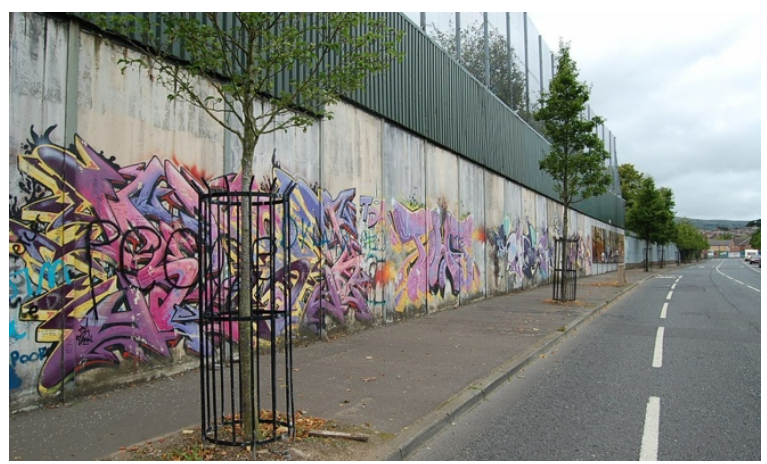

Figure 11: Peace Wall in Belfast

A development that occurred for Rebekah after the trip to Ireland was a chance to travel to Brazil. Four of her younger grandchildren were involved in a youth music group, which led to going to Brazil to represent the United States. Rebekah spoke of going to Brazil with her grandchildren and two daughters-in-law, saying, "I had the chance and I had my passport so I went there" (Rebekah, September 9, 2016). Rebekah begins her reflection on differences and similarities between the two experiences by searching for the location in Ireland in which to 
compare to Brazil. I prompted her by saying “like Dublin or Northern Ireland?" She responded with this comparison:

Northern Ireland, in Belfast, that's what I was trying to think of. I mean that it was kind of scary there and that's kind of how I'd always pictured ya know another country. I don't know why but I did. At the time, I didn't get off the bus when some of yins got off and took pictures I thought, I'm not getting off the bus...I took pictures from inside the bus. (Rebekah, November 20, 2015)

Rebekah was afraid while the group toured Belfast, especially during the visit to the Peace Walls, with an example of one in Photo 6. The Peace Walls are the dividers that separate the predominately Catholic communities from the predominately Protestant communities. These walls were often seen as way to protect the communities from "the other side." People may relate these walls to the Berlin Wall, which also carries with it a connotation of fear. With the excursion to Belfast, the bus driver discussed "The Troubles" that occurred between the Protestants and the Catholics, explained the current atmosphere, and warned the group about their safety while in Belfast. He spoke of the violence that had occurred during the tumultuous time in addition to the undiscriminating killings. In some ways, he manifested a sense of warning for various individuals of the group. This caution fed into Rebekah's preconceived notions of "foreign countries" and exacerbated her fears. "The Troubles" was a 40-year conflict between the Catholics (Ireland) against the Protestants (Great Britain) (Shapiro, 2014). The Catholics had been a marginalized group for centuries within the United Kingdom (United Nations, 2017). During the reign of Queen Elizabeth in England, the whole of the country became Protestant and to be Protestant was to be English and those who remained Catholic were labeled as traitors 
(British Broadcasting Corporation, 2017). According to Freire (1970), if one person takes away another person's ability to make decisions, one has made that person an object, no matter what the reasons. In essence, "The Troubles" were a clash between the oppressed and the oppressors, where the violence had been perpetuated from generation to generation (1970). As the bus driver was from the Republic of Ireland, there was a high probability that he was Catholic and part of the marginalized group, which explains his perspective on Belfast and Northern Ireland. Also, the conflict between these two religions was not seen to cause any dissension between the group members; however, more detail about what issues were caused will be explored in the collective group story.

Not only did Rebekah demonstrate a fear for her safety while in Northern Ireland, she also spoke of being fearful during a visit to Brazil that was after her experience in Ireland. According to Rebekah's comments below, trip organizers for Brazil were cautious about safety during their time in Brazil and the behavior of the store owners while shopping alluded to an unsafe environment.

And Brazil it was just, and don't get me wrong, there was nice people there...our kids would practice a lot outside the hotel and there would be people come by and they would stop and listen to them play and like I say, there was some nice people there...I didn't really feel safe there. They actually told us never to go out by ourselves always go in twos or threes...I couldn't understand their language. So, that was ya know kind of a drawback...the jewelry store that I got my earrings from they had their door locked and when we went in I went back out 'cause my one daughter was out there and the daughterin-law in and I decided I wanted these earrings and she had locked the door and had to unlock it for me to go back in. (Rebekah, November 20, 2015) 
Rebekah characterized the passersby and others that she met in Brazil as nice; however, it did not alleviate her unease about safety. Her perception of her safety could have been affected by the comments of the trip organizers more than any real threat that occurred during Rebekah's experiences in Brazil. It is also likely that her fear was due to being in the denial stage of Bennett's (2004) DMIS model. While Rebekah noticed the cultural differences, she did not make "the perceptual distinctions that allow cultural facts to be recognized" (p. 64). Due to her concern for her safety both domestic and abroad, this could have been a coping mechanism against the "unknown," i.e., change.

Rebekah was one of the members of the group that was in the middle section of ages and spoke on the intergenerational aspect. Martha, David, Hannah, and Rebekah included intergenerational memories of the experience in Ireland during their interviews. Martha walked along the cliffs with the youngest member of the trip; David recalled sharing stories and helping one another; and Hannah spoke specifically of Martha's energy. Rebekah's comments were primarily how she connected with other members of the trip. First, she mentioned Carol, who was a similar age to Rebekah. "I really met a lot of nice people and umm, got to be friends with them. Umm, Carol, she umm, she said she used to race cars" (Rebekah, September 9, 2016). Rebekah also mentioned Stacy, who was at least 15 years younger, when she talked about the emergency heart surgery Sam, her husband, went through during the trip. "The lady that's the nurse (Stacy)...Umm, she was such a great help to me you know? When Sam had that heart surgery...told me what all was happening and that was great! (Rebekah, September 9, 2016). She also mentioned David, the youngest member of the group and a previous connection she had with him that they found out during the trip. "David - got to be really good friends with him and 
he always looked out for me because he ended up knowing my ex-daughter-in-law and he said he had to take good care of me or she would get onto him" (Rebekah, September 9, 2016). Lastly, Rebekah mentioned our two oldest members of the group, Martha and Ruth. "I thought everyone was nice and friendly. Your grandma, I just loved her to death! I love to sit and talk to her. Umm, Ruth. It was just a real nice trip.” (Rebekah, September 9, 2016). Rebekah mentioned getting to be friends with several members of the group from a wide age range. By name, she included the youngest member and the oldest members of the group. It was very interesting that Rebekah mentioned individuals across the age spectrum of the trip.

Prior to the first interview, Rebekah asked for the questions in advance so that she could look up information in her Ireland book so that she could give accurate dates and places. She very much wanted to provide precise information and to have the answers to the questions I would ask. Like Martha, Rebekah wanted to do her best in the interview, thus her request for the questions. Also, it indicates a pattern that is counter to Dewey's approach, where education is growth and process, as Rebekah desired to focus on facts and dates (1944). Additionally, it suggests that for her knowledge is based on memorization and regurgitation, i.e., Freire's (1970) "banking system." Again, the data did not include any insights on learning from critical or progressive perspectives, but seemed to reiterate the forms of education that both Freire and Dewey sought to overcome.

Rebekah sees her role in life as a mother and now a grandmother, which is evident in the three items that she chose as the most important in her life: the Bible (her faith); her family, and 4-H/CEOS. Each of these aspects are interconnected. During her interview, Rebekah alluded to previous marital issues and stated without her "faith in God...I don't know where we'd be" (Rebekah, September 9, 2016). According to Rebekah, her family may not be quite as connected 
and together without faith. She also discusses how not only was she in 4-H as a child, but her children and grandchildren have all been in 4-H as well as assist with community service projects through the CEOS. Rebekah tends to follow a pre-established path with familial connections, which aligns with a closed narrative. However, she also steps out of her box, i.e. driving long distances by herself, more international travel, as she reflects on her international experience, gaining more self-confidence in her abilities.

There are 48 years' worth of difference between the oldest participant and the youngest participants; yet, the life stories of these five individuals have overarching aspects that connect each one. For example, the four women spoke of faith and its importance in their lives. Also, David, Hannah, and Rebekah commented on how taking care of family members have impacted their lives. More so, each participant included at least one other participant and/or this researcher in his or her life stories. These five life stories include perceptions on cultural comparisons, such as affirmative comments on host nationals, pub experiences, and similarities between Appalachia and Ireland. The comparisons and contrasts that were made by the participants of this study is a positive step towards the goal of WVUES with its international programming: assisting citizens in becoming cognizant of the changing world environment, thus seeking more global awareness for themselves as well as their communities in Appalachia. As these individuals continue to share their life stories and experiences in Ireland, the hope is that more Appalachia citizens will seek international and intercultural learning occurrences. While what the participants shared is a vital part of this study, how they told their stories is important as well. The following section will look at the participants' narrative character styles, how they fall into these types, and how they cannot be categorized into pre-set groupings. 


\section{Goodson's Narrative Styles}

As mentioned previously, Goodson's (2013) outlined four narrative styles: focused elaborators; armchair elaborators; multiple describers; and scripted describers. According to Goodson (2013), narrative character provides the key to understanding how the individuals approach and recount the transitions and critical events in life. Thus, how these individuals tell their story is an indicator as to how they will react to life events. Rebekah and Martha align with Goodson's scripted describers who follow their established path with a focus on family. As obstacles came along, they continued to concentrate on their families and the role they played within that family unit. David was primarily a focused elaborator who stated that the trip to Ireland was the catalyst for the agency in his life. He reflected on his choices and options based upon his experiences so that he could move beyond the expectations his family had for him to further his career and perhaps his education. Ruth could be a mix of the scripted describer and the multiple describer as she does have some reflexivity; however, she does not move as deeply into her introspection. Lastly, Hannah moved between a focused elaborator and armchair elaborator. She tries to follow her new path, yet finds difficulty in forging into those new original scripts. Overall, three of the five participants did follow Goodson's narrative styles for the most part; however, two of the participants did not fit into the pre-established molds.

Through these narrative character styles, we can also see how the trip influenced their viewpoint on the world. David and Hannah were the youngest participants and were also the most reflexive of the five; who both feel as though they got a small glimpse of the world and desire to see more. David spoke that [prior to the trip to Ireland] "international travel has - well not necessarily a goal in the beginning it became a goal throughout" (David, January 17, 2017). As for Hannah, she stated "since traveling to Ireland, I then traveled to El Salvador actually two 
times, this year and still I'm looking at possibly going to Italy at some point...I would say really my retirement goals really are all about travel" (Hannah, October 7, 2016). Most of their travel experience has been as adults, not as children, as they both grew up impoverished in rural areas of Appalachia.

Rebekah saw a part of the world a little differently upon her return. She said, "well, um you know, you always hear bad things about a lot of other countries. But you know I really liked Ireland. Because I felt like I was right at home" (Rebekah, November 20, 2015). While she felt at ease because of the similarities to her home in Appalachia, she learned that there are positive aspects to other countries, not just negative ones. Travel was more of an option for Rebekah, who came from a middle-class family in Appalachia that would visit relatives out of state. Even though she would reflect on her experiences at times, Ruth's world view did not change much. In part, it could have been because she was already a world traveler, having visited Switzerland, France, New Zealand, and cruised the Rhine and Danube Rivers prior to her Ireland experience. Lastly, Martha spoke of her time in Ireland by ticking off the places visited, but did not ruminate over her experience. Her view of the world did not change as well. Since Ruth and Martha were the oldest participants, one could surmise that their perspectives and identities were already wellestablished. The older a person is the more likely they will have a further developed selfperception due to contact with various contexts in the life-long process of identity development (Erickson, 1968).

The next section explores the collective group story that was derived from the analysis of the individual interviews. The subsequent aspects arose from the participants' experiences in Ireland in 2013, which are discussed in detail. 


\section{A Shared Story}

Each participant tells a part of the group story, which together shows a more complete picture of the collective experience of the non-formal educational experience in Ireland. Not only do the five participants add to this group story, I am a part of it as well in my role as a co-faculty lead of the trip. The fragments from the individual narratives can be threaded together to expand or correct what other participants have shared (Riessman, 2008). By using a textual analysis of the individual narratives, the themes of this group story were derived. This collective story provides insight into the culture of the group and experience through shared commonalities. It is the telling of this narrative that allows the moment to live beyond the moment (Agar \& Hobbs, 1982). Additionally, it possesses the ability to affect change due to the fluidity between reflections of past experiences (Dewey, 1944).

According to Goodson and Sikes (2001), life is a process not a product. The group story gives insights to the dialogic processes and co-construction of knowledge that took place within the group. As the 22 members of the 2013 CEOS Trip to Ireland group began their journey, few members knew each other. However, they quickly connected with one another during their time abroad. The themes explored below arose from the interviews with the five participants of this study. Their collective story drawn from overlapping patterns and themes indicates the impact of their experiences while in Ireland, and indicates their agency and possibilities for future changes. As these five individuals shared their experiences, they once again looked through the window at the outside to learn from others, while also looking through a mirror to reflect upon themselves (A. Slocum, personal communication, November 12, 2014). The purpose of the group narrative is to potentially serve as instruction for the participants as well as future groups. 
The first time the members of the group met each other was on July 29, 2013, almost one month prior to the day of departure. The group consisted of primarily women, but there were a couple of men. There were grandmothers, mothers, fathers, sons, and daughters in the group. A couple of the members were single, but most were married or widowed. They were from different parts of the state of West Virginia. The group could have sat down and picked one another apart based upon their differences; however, they did not. This group unity was one characteristic that the members showed during their time in Ireland with their interactions with the host nationals. Yet, it was not a picture-perfect experience. The participants made meaning of their visit abroad based upon their pre-existing assumptions. Their homogenizing viewpoints was the lens they used to view the experience. Therefore, the participants united around the similarities between the two cultures, while remaining circumspect over the differences. During the time abroad and upon their return, the participants exhibited these themes: fear of the unknown or "the Other"; judgment of the unfamiliar; and viewing the adopted culture as superior to their own. Secondly, the CEOS Trip to Ireland was noted in a positive fashion within the participants' life stories. Embedded in their life stories is the non-formal educational international experience that can be linked to these aspects: the agency in their life post-trip, and the connection between the participants' contexts, i.e., their age, class, gender, their life stories, and the experience.

\section{Fear of the Unknown}

Experience is an active-passive affair, which means a person cannot simply complete an activity to equal an experience (Dewey, 1944). When an individual learns from the positive or negative consequences of an action or an activity, that is an experience. Even though the participants of this study were apprehensive about what they did not know, the potential exists 
now to learn through the telling of their collective story. Riessman (2008) argues that stories function to alter the ways people view mundane everyday events and that indeed, stories can accomplish change. In the following paragraphs, I explore the story about the fears of the participants, primarily choosing to travel with familiar people, and the fear of the "Other" side. By exploring participants' experiences of challenges and fears, they disrupt the commonplace notions of tourism. More so, this reveals ruptures and fragmentation within themselves that open up hopeful possibilities for rethinking what they have always known.

Traveling with the familiar. One of the threads that was similar throughout the five narratives was the reason why they chose to travel specifically with the CEOS in 2013. Each participant was provided with a sense of comfort due to traveling with a group or by knowing another person going to Ireland. One participant showed very little fear; however, she had traveled extensively with the CEOS in the past as well as her granddaughter was one of the cofaculty leads on the trip. Another participant does not mention any fear or trepidation; yet she stated that she only travels with groups. This allows her to visit a number of countries and states, but within the confines of an organized, detailed excursion that provides an inherent amount of security. As for a third individual, she was comfortable with the knowledge and previous experience of one of the faculty leads. This person equated traveling to Ireland with the CEOS as similar to spending a week at WVU's conference center, Jackson's Mill. The point was that she would be with her "people." The notion of "sameness" is precarious because it does not include learning about cultural differences and how power is implicated in sameness and difference. By not actively addressing issues of culture and power, members can be left without a change in consciousness, reinforcing their beliefs that they are raceless and nonethnic (Banks, 2001). 
Still another participant received the information about the trip from a co-worker when it was distributed. She explained that a co-worker came in and said, "This sounds like such a great opportunity.... I think we kind of coached each other into saying you know we are going to do it" (Hannah, December 11, 2015). Traveling with a co-worker eased Hannah into the unknowns of her first international trip. The final participant of the five commented on knowing one of the co-faculty leads and how it was a natural fit and helped ease any concerns because this faculty member had been there before. This individual was forthcoming in stating that his fears of the unknown were alleviated due to knowing a person who had been to Ireland before. Any anxiety over traveling abroad was lessened due to being with a group, knowing one of the co-faculty leads of the experience, or relying on another person who was going to Ireland as well. The trust and mutual respect between the learners (the participants) and the educators (co-faculty leads), as mentioned by the participants, leads to knowledge through the shared experience (Freire, 1970; Goodson \& Gill, 2011).

Fear of the other side. Fear of the "Other" was very evident at the latter part of the trip during one of the daytime excursions to Northern Ireland, primarily Belfast. In Belfast, the group visited the "Peace Walls" (the walls that separate the Protestant and Catholic communities), drove by the mural of Bobby Sands (a martyr from the Irish Republican Army [IRA]) and other communities within Belfast, and toured the Titanic Museum. As previously stated, "The Troubles" were a conflict between Catholics (the minority) and The Protestants (the majority). One of the participants alluded to being apprehensive of visiting Belfast in Northern Ireland and even recounted the words of the tour bus driver during the visit to Northern Ireland: "[The bus driver said], 'We signed a law that if we didn't get out of there and we had Ireland tags we could have gotten shot, who knows?' I still remember that" (David, November 20, 2015). While 
explaining the history of "The Troubles," our driver stated that during the height of the 40 -year period of violence a person with an Irish car license could have been shot if they drove through a Protestant community.

It is difficult to ascertain the accuracy of that statement, yet it demonstrates the lasting effects of that period in time. Even though a peace treaty is in place, the feelings expressed by our bus driver demonstrate how the memories of violence and death still weigh heavy on the people. The participants only need to look into their own history as residents of Appalachia to see their own violent periods in time, such as the feud between the Hatfields and the McCoys, Civil War allegiance in West Virginia, and the battles over the unionization of coal mines. Unfortunately, their fear of Belfast was not contradicted since there was limited time to meet any host nationals with whom they could engage more deeply about these issues, and unpacking them was not part of our program. However, it is uncertain if the group would have engaged in that conversation, as they were apprehensive while in Belfast. I would surmise that some members of the group would have been cautious in speaking with citizens in Belfast due to their perceived safety concerns. Thus, learning both sides of this historical, cultural conflict was not possible as there must be dialogue to have communication, and there must be communication to have true education (Freire, 1970).

During the visit to the "Peace Walls," the group was given an opportunity to step off the bus, read the names and writings, and take pictures. One individual's recollection of the moment was that they were given 5 minutes and he compared it to the Berlin Wall. When speaking of future travel, the same participant indicated his desire to return to Ireland, but would not go back to Northern Ireland. This statement was made three and half years after the initial experience, but he is still wary of traveling to Northern Ireland. Another participant was so afraid at the "Peace 
Walls" that she did not get off the bus, but took pictures from inside. Unfortunately, the time in Northern Ireland reinforced the stereotypes this individual had of foreign countries. She said that it was how she always pictured another country. She even spoke of how there are "good people" and "bad people." This person relates her fear of being in Belfast to a fear of "bad people," i.e., anyone who is on the "Other" side. These residual fears appear to affect the participants' abilities to improve their cross-cultural competencies. Part of the benefits of international education includes the appreciation of different cultures, maturation, self-awareness and independence as well as gains in second language acquisition (Hadis, 2005). This does not seem to occur at the same rate within all the participants, nor does their age factor into less fear or larger understanding of others. Perhaps the participants will be able to decrease their fears through more experiences and interactions within an international setting. This also leads into the following subsection, which discusses judging the unfamiliar, in both positive and negative lights.

\section{Judgments of the Unfamiliar}

The most effective intercultural programs allow for participant reflection and reconsideration of assumptions, recognition of constant identity growth, and striving for genuine experiences (Rios, Montecinos, \& van Olphen, 2007). Reconsideration of assumptions was an area that was considered often. Some members of the group would often make references to how the Irish drive on the "wrong side" of the road, not the opposite side from U.S. practices. Even though Ireland is an English-speaking country, there are differences and areas of unfamiliarity. Experiences are a conduit of adult learning that should lead to new knowledge of how to cope with unfamiliar situations (Fenick \& Tennant, 2004). In the subsequent sections, I delve into how the participants judged the unfamiliar and what learning may have occurred. The themes I 
selected are those that were mentioned throughout the life narratives of the participants. First, I look at two Irish Pub experiences. Then, I explore the quality and content of exchanges with the host nationals. Lastly, I look at the desire of the participants to find similarities between the two cultures.

Irish pub experiences. There were two Irish pub experiences with this group that highlighted a cultural difference, which led to judgments of the Irish culture. The first visit to an Irish Pub consisted of the group going to the only pub in the small town of Termonfeckin. The second visit was to another pub in the larger city of Drogheda to listen to local musicians. During the first visit, most of the group decided to try a pint of Irish beer, and almost all chose Guinness. At the second visit, the beverages were basically soft drinks, coffee, etc. It was interesting the differences in opinions between the participants and even within the two visits themselves. There was acceptance of the experience to the fear of disapproval upon the return home. On one end of the spectrum, a participant chose not to even tell her family about going to the pub, most likely because of possible criticism by family members. In West Virginia, there is a negative connotation with going to a bar and it is likely that her family, like other residents of Appalachia, would use the same association with the Irish Pubs. Another participant made two dichotomous statements when reflecting on the two Irish Pub experiences. In the same description where she mentions liking the taste of Guinness, she admits her shock at seeing small children in a pub listening to music with their parents. According to this individual any self-respecting parent would never take his or her child into a bar in West Virginia. These two examples are indicative of judging the Irish Pub experiences based upon one's own cultural lens and expectations.

Another participant felt that the Irish pub experience in Termonfeckin was one of his favorite memories of the trip due to the bonding between the members of the group. This 
person's comments seemed to be more about being from Appalachia than being in Ireland. The individual felt that this excursion is what united the group; plus, it was one of the early activities of the trip with primarily our West Virginian group in the pub. One person offered a reflection on the cultural difference between a pub in Ireland and a bar in the United States in a different manner than the previously mentioned expectation of it being like a bar in West Virginia. This individual spoke of how pubs are not the "watering hole," but a place where people go in the evening in communities to talk and meet up, which is something not seen in Appalachia. This shows how the Irish stance on a pub or a bar is different than the West Virginian perception. These two participants demonstrate the acceptance side of the spectrum and their judgment of the unfamiliar is a positive association.

While none of the participants made any disapproving comments about going to Irish pubs, these two experiences brought out dual avenues of thought within the participants. One side was very open and accepting of the activities. They even discussed connections to their learning of Irish culture and identity as a resident of Appalachia within their interviews with respect to these experiences. The other side appeared to enjoy the activity, yet it brought about a slight culture shock with children being present. Not to mention, a level of uncertainty arose with how to explain their participation to others at home with the negative connotation in Appalachian culture. Although their judgments were contradictory, both sides connected the experience to a difference between Ireland and Appalachian cultures. How residents of Appalachia perceive their relationships with host nationals and the authenticity of those connections will be explored in the next section. 
Relationships with host nationals. The participants continually spoke of the friendliness of the host nationals and see most Irish natives through that same lens. The authenticity of those relationships comes into question as most of the Irish citizens in which they came into regular contact were kitchen and wait staff, reception staff, tour guides, and course instructors. In other words, the livelihoods of these host nationals are contingent upon the tourism industry. The Irish natives that the participants spoke most often about saw our group as customers more than friends. One participant spoke of the friendliness of those she met and specifically mentioned the reception desk staff and the wait staff. As these individuals were employed by the facility in which the group stayed, it brings into question the reality of the relationships. Whereas the members of the groups saw the people they encountered as friendly and used a broad stroke to paint all Irish nationals as friendly, the staff were just doing their job in a customer service field. Another participant remarked on how kind everyone was to the group, connecting it to positive political relations between Ireland and the U.S. Still another individual noted her observations in a blog entry during the trip, saying that she received a warmer welcome from the Irish natives than some of what she has experienced within her own community at home. Within her interviews, this same participant referred to the staff at An Grianan treating our group like family.

Nice, friendly, welcoming are all words utilized to describe the host nationals; however, the participants of this study focused less on themselves as customers in the tourism industry and more on the Irish natives as people. They viewed the Irish natives (primarily those with connections to tourism) more like friends, yet it is questionable if the Irish natives we encountered felt the same about our group. One exception to this would be with the Digital Photography instructor. This gentleman seemed to have a deeper connection with the members 
of the group in his class. He even became friends on social media with some individuals as a manner in which to stay in contact. Another aspect to consider is that the power within this relationship resides with the participants, with our group. The friendliness that some of the group members experienced was good customer service on behalf of the staff. This unbalanced connection did not seem to be exploited by our group, which is positive. However, it is disconcerting that the service component of the relationship was unnoticed by members of the group because what they perceived with their interactions may not have been real.

Being only 10 days in length was a short-coming of the CEOS experience in Ireland. Because of the brief duration of the trip, the participants had very little down time in which they could explore the local town on their own, or meet community residents. Thus, most of their interactions were limited to people connected to An Grianan. In this context, the level of learning and agency are constrained by the limitations of a short-term non-formal educational international experience. This is different from longer international programs where participants have greater opportunities for more interactions with host nationals, which could increase the genuineness of the exchanges (Armfield, 2004). More so, if another group had been staying at An Grianan during the 2013 trip, this could have added to the participants' learning about host nationals.

Finding the similar. Each of the participants brought up various aspects of the Irish culture of which they found similarities to West Virginia. It was almost as if some were searching for similarities to make it feel more like home so that they could construct a comfort zone while abroad. One participant repeatedly mentioned how she felt at home in Ireland or how it was just like home, for example when the locals were bailing hay. She commented that she did not feel homesick as it was almost like she was at home. Another participant noted the 
connections between the two cultures were very evident, which included the importance of family, use of storytelling, music, and strong value system are the similarities between Ireland and Appalachia. In other words, she articulated that what she viewed as aspects of Irish culture are components of Appalachian culture. One individual mentioned music and dance as being a major similarity. Still another participant stated comparisons like the push for local foods, the music, the culture of family, and personality traits, for example hard-working and stubborn. The participants were guided by the values and practices of their cultural communities, which allowed them to learn about Ireland as they participated in this experience (Rogoff, 2003). More so, the participants have a romanticized notion of culture that was designed to detract from the social, political and economic changes that occurred historically within the region (Whisnant, 1983).

Most of the participants indicated that Irish music and dancing resemble Appalachian music and dance. It was interesting that the participants brought out cultural characteristics of Appalachia more often than Ireland's. Goodson and Gill (2011) indicate that narrative learning enhances understanding about oneself, one's position in the world, and how histories, cultures and socio-political forces have helped shape who we are. Yet, some of the aspects discussed by the participants could be considered stereotypical of Appalachian culture, for example hardworking and stubborn as traits. The misperception of Appalachian culture outlined by the participants has been ingrained by the people of Appalachia since it was first introduced in the 1890s by religious organizations in the region who felt the isolated areas lacked a sense of community and culture, thus chose to help create one for them (Shapiro, 1978). It begs the question: Do cultural comparisons from study abroad programs, such as this, lead to stereotypes 
of the home culture? Specifically, in this case, is the identity of a resident of Appalachia reduced to a list rather than the many rich possibilities that exist within this culture?

When observing components of the daily life that was seen during the unplanned activities, most of the participants stated that Ireland felt like home. Whether it was visiting a local supermarket or watching the neighbors bale hay, the participants saw connections between Ireland and Appalachia. Most of the participants seemed to use West Virginia as the standard in which they judged other places. It was an "us and them" perspective with one's own culture being the dominant culture (Bennett, 2004). When these individuals were vocal about their fears, i.e., foreign travel, being in Belfast, and Irish driving, it was dichotomous to their above references regarding Ireland being like home. The participants utilized the concept of "home comfort" to alleviate their fears. In their minds, the rural locale of An Grianan in Ireland is similar to their homes in West Virginia, thus there is nothing to fear in Ireland. However, Belfast was urban and not like West Virginia, which added to the previously discussed fear about that visit. Since some participants positively connected rural Ireland to West Virginia, the "superior" culture, learning about Ireland was skewed in the same direction. Experience is seen as a conduit for effective learning, and as such it is a good but traditional educational practice (Tennant \& Pogson, 1995); however, the question of obtaining balance in these cases arise.

The reference to the "little things" is an example of "globalization from below" or seeking to better understand globalization through focusing on ordinary activities of cultures (Apple, Kenway, \& Singh, 2005). Being able to connect the everyday to the issues of the world is one way to take individuals from an egocentric cultural view to an exocentric perspective. International programs tend to confront the participant's identity, their understanding of their home culture, as well as their outlook on the world (Pagano \& Roselle, 2009). All the 
participants indicated some sort of confrontation to their identity, which is why they were fearful of the unknown. It is within these cultural spaces of difference that unequal power relations are evident as well as various cultures struggle against one other (Sharma, 2009). This led them to search for familiarities while abroad as a safety mechanism in addition to expanding their Appalachian cultural identity while abroad.

The next section will explore the intergenerational characteristic of the experience, which includes both the participants and all members of the 2013 group.

\section{An Intergenerational Experience}

The intergenerational bonding between the group was mentioned quite frequently with all the participants and it resonated with me as well. In their own way, each participant's life story was impacted by the intergenerational aspect. Some were small changes, while others were much larger. Some of the comments were simply generalities about the members of the group, while others explained with whom they made connections during the trip or were very specific in how age impacted their experiences. The overall influence of the intergenerational aspect was encouraging to the participants because the different age groups would share their knowledge with one another. The older participants would tell their stories, while the younger participants would help with the technology in the photography class. One person felt that the various personalities and abilities evened the group dynamic, more than the age spectrum. In other words, the discrepancies in knowledge helped form a collective where everyone had strengths and needs. This allowed for everyone to feel needed, which was beneficial for the group. Being able to share experiences aided in the learning process for the group. Adult learning via experience relates the present to the past, in a fluid manner, for the continuity of skill and knowledge acquisition (Tennant \& Pogson, 1995). 
When it came to determining the start of bonding between the generations, the first Irish Pub experience was the first time that mutual discourse occurred between the members of the group that occurred in Ireland. Since this activity brought about discussion and dialogue amongst the group, it allowed for learning to transpire. Authentic thinking is something that takes places in communication and deals in reality (Freire, 1970). The members of the group were a part of this communication that stimulated sharing knowledge and experiences. Also, it is with dialogue between people that provides communication, and it is communication like this that leads to true education (1970). Authentic thinking from the intergenerational discussions held at the first Irish Pub experience may be the impetus that changed the trajectory in one participant's life story. It is imperative to note the slightly incongruous aspect that while the members of the group were in Ireland, they were discovering the diversity, strengths, and needs of their neighbors in Appalachia. In the past and currently, residents of Appalachia have been and remain marginalized by the dominant U.S. culture. Research indicates that the Defense stage of Bennett's DMIS model tends to be experienced by people from non-dominant cultures as a method of discovering and strengthening a separate cultural identity to their dominant group (Banks, 1988; Parham, 1989). As their cultural identities were being questioned, their view of Appalachian culture was being further developed.

The younger participants noted that hearing the life experiences of other members of the group aided them in putting things into perspective. They felt inspired and desired to incorporate some of the lessons learned from other members of this group into their own lives. Additionally, the stories of how other members of the group were experiencing Ireland were woven into their own perspectives. Almost as if their stories were in part of summary of the group experience. Goodson and Gill (2011) argue that learning is far more than the perception of acquisition of 
knowledge and skills, but that the narrative is entwined with both the individual and the life lived through their narrative. As the participants connected to the other members of the group, they became a part of their narratives, thus their experiences impacted their life stories. The inclusion of various members of the group within these narratives demonstrates how the participants were influenced during and after the trip.

While a number of the participants spoke of how age did not matter during the experience, they did tend to bring up that physical abilities could be limiting. Both ends of the age spectrum made similar comments; however, it was the oldest participant that gave the strongest critique. In discussing the intergenerational component, this participant made references to the physical abilities of individuals making the trip. Not only was she the oldest member of the group, but she was also one of the most active. This participant believed that people on the trip as well as other trips with Extension did not take into consideration the physicality of the experience. In her opinion, if a person sits on the bus while the rest of the group walks around and sees things, they are not physically able to fully participate. She also noted that there were members of the 2013 group who really were not able to walk around. Most of the participants spoke often about the oldest participant's "get up and go" and how she desired to participate fully in the experience, which was motivating to them. This was especially noticeable when some members of the group needed to take multiple breaks and needed modified activities, when she did not. Our oldest participant believed that a person should not sign up to join in if he or she were not physically able to do so. From her perspective, if a person cannot participate in all the activities, he or she should reconsider signing up. In other words, mobility, not age, is an issue when traveling, according to this participant. One concern against this thought is that it could limit individuals with physical disabilities from participating in non- 
formal international educational programs. Yet, reasonable accommodation can be discussed to ensure the inclusion of all interested parties.

It was interesting how the concept of "old" was redefined by the participants during and after the trip. The younger participants commented that they now see age differently, especially as they have seen people of retirement age not "slowing down," but traveling the world. It allowed them to gravitate towards the notion that a person can travel at any age, despite societal assumptions about their abilities. Everyone in the group felt a sense of wonder and excitement, which crossed the generations and added to the bonding between them all, according to the participants. The younger participants desired to be like the older individuals from the group as they age. There seems to be no indication that this train of thought has currently changed their lives through future planning or spending more time with the older population at home. However, these narrative accounts shift between the past, present, and future through the connections they make; and they offer storytellers a way to re-imagine their lives (Riessman, 2003). The desire to make travel a long-term goal is how they are re-imagining their future lives. While the younger participants have yet to follow through with their plans that will exhibit actual behavior change, Goodson and Sikes (2001) argue that life is a process not a product. Therefore, it is not simply the final decisions that matter, but the small steps that are taken along the way, such as taking other international trips since their first one and a change in career that led to moving out of one's home county.

Most of the participants commented on knowing various people and forming relationships. One participant concentrated on knowing many people in common that seemed to be a way she could make connections with others from the group. This appears to be an approach in order to feel safe in a foreign place, where a "third space" was created for safety. This is 
concerning because it could potentially create barriers that would limit authentic interactions with host nationals. Especially since the participants were bonding as residents of Appalachia and stories of their lives were brought out, while in Ireland. No matter where a person currently is or resides, we are inescapably marked by the particularities of the circumstances in which we are born and raised (Slimbach, 2005). Even those who visit completely different cultures may be reminded of their own childhoods, their own past. One researcher indicated that she felt like she was in multiple "places" at the same time when her international educational experience brought about memories of her childhood and formative beliefs she developed from those days (Sharma, 2009). While Sharma (2009) found herself in similar circumstances unintentionally, a few of the participants of this study basically created the third "space" to feel a sense of comfort while abroad.

It was like having one foot in the present, for example being in an unfamiliar location while having one foot in the past, or your home place. This notion of place, particularly with international educational experiences, is interesting as it considers multiple locations, for example the host country, the home place, and other residences/lived areas. This pertains to residents of Appalachia as their identity is intertwined with their sense of place (Bennett, 1991). Moreover, the southern localism (of which I believe that West Virginia fits uneasily within) involves a tendency to think of communities as distinct from one another and to prefer one's own (Kincheloe \& Pinar, 1991). Considering both these ideas, residents of Appalachia are a target audience where one may see a change in their cross-cultural skills, but they could also be affected with respect to their identity and sense of place due to the connected nature between the two. As an individual from the 2013 CEOS Trip to Ireland, I can attest that various members correlated their sense of place in Appalachia with rural Ireland. It was something mentioned 
frequently by various members and the sense of place seemed to be a connecting link between the individuals on the trip. Being from Appalachia was a commonality to which they gravitated. While some members would say it was being from the country or from West Virginia, their identity as a resident of Appalachia was fostered by how the group collectively looked at themselves in the "mirror" as a culture.

People must be educated for life, which means innovative methods related to learning are necessary (Apple et al., 2005). Non-formal international educational programming is one approach to providing innovative learning. The learning aspects within individual stories and the group story were not of the planned excursions or classes they took, but facets related to fear, judgment, and culture. The participants discussed perceived similarities between the Irish and Appalachian cultures, which ultimately focused more on their own culture than the culture of "the other". An important component of the life narratives is the aspects of culture, such as common background, locale, dialect, class and spirituality, which vary considerably according to historical periods and cultural contexts (Goodson, 2013). During the experience, the participants recognized the common characteristics between themselves, no matter their age, which led to the greater discussion on intergenerational bonding. All of this culminated in our sense of purpose and meaning, selfhood, values and aspirations as they were based on our narratives (Grassie, 2008).

The next chapter begins with connecting the findings to the research questions. Next, I will discuss applications of the findings related to the improvement of these types of programs and the role of the WVU Extension Service. Lastly, I will provide recommendations for future research. 


\section{Chapter 5: Implications and Conclusion}

"Arriving at one goal is the starting point to another."

(Dewey, 1944)

This study helped to fill the knowledge gap in non-formal international educational programs by using a qualitative approach that looked at how participants from Appalachia were influenced by non-formal educational experiences both during and after the program. From a social constructivist perspective, the design was framed with a narrative theory to capture the life stories of the individuals. Specifically, this study examined the experiences of five participants from Appalachia to determine how these experiences are viewed within their life stories. The previous chapter explored and provided evidence for three themes that emerged from the data, which aided in answering the research questions. These themes provide an illustrative statement of Extension-sponsored non-formal international education: fear of the unknown, judgments of the unfamiliar, and an intergenerational experience. In this study, I wanted to understand how non-formal educational experiences in Ireland influenced participants from Appalachia both during the time abroad and upon their return (question 1); and how these experiences were viewed within their life stories (question 2). Many interesting outcomes were revealed in the analysis of this study and they connect to the broader literature related to non-formal international education and Appalachian culture and identity.

One of the ways that the Ireland trip influenced the participants was with individual and collective confrontations of their identities, which is why they were fearful of the unknown. This caused the individuals to pursue familiarities while abroad as a safety mechanism in addition to expanding their cultural identity as residents of Appalachia. More so, they experienced internal conflicts related to their fears, which led to reflection on what they have always known about the 
"Other." Sharma (2009) states that by refusing to acknowledge our own "whiteness," we permit the continuation of asymmetrical relations and privilege, especially "in social, material, political, and ideological contexts" (p.124). The participants from Appalachia perpetuated the dominant, white culture in Ireland while trying to reject the same privilege by embracing the marginalized Appalachian culture. As for judgment of the unfamiliar, it also related to the effects on the participants while abroad and upon their return. Often, participants would reconsider cultural assumptions they held between two English-speaking locales, Ireland and Appalachia. Whether the judgments were negative or positive, the differences between the two cultures was noticed. This was also a perspective within their life stories as this facet was a part of the unplanned excursions that were brought forth as experiences with lasting effects. With respect to their life narratives, the intergenerational component of this experience was highly evident in the data. It almost seemed like the participants formed an Appalachian subculture while in Ireland, a "third space" so to speak. The sense of place I noticed frequently as the participants often connected rural Ireland to rural Appalachia, which was a bonding link between these individuals. Age had no bearings on the common characteristics between the participants, which led to the relationships being built during a shared experience.

The present chapter broadens, deepens, and extends the answers to my research questions. In the next section, I explore the outcomes of the analysis that pertain to the implications on three levels: conceptual and theoretical implications, methodological implications, and practical and policy implications. Lastly, this chapter offers suggestions for future research on non-formal international education in Appalachian contexts and concludes with personal reflections on the research process. It is important to note that I have been developing a critical community of practice throughout this process. This critical community of 
practice has been formed within our Extension subgroup as we work together developing our international programs. Therefore, the implications involved in this chapter are not solely my responsibility, but are a part of our subgroup's work.

\section{Conceptual and Theoretical Implications}

The theoretical implications stem from the framework of this study, which was situated within the concepts of critical and progressive educational perspectives as well as multicultural and intercultural education. In Chapter 4, I explained how learning experiences abroad reveal important information about the shifting identities of participants from Appalachia and how culture is implicated in the non-formal international educational experience. Participants' understandings about cultures did not always fit neatly within particular approaches that I included in the framework for the study. That is the beauty and danger of narrative research; stories do not always emerge as planned, yet one of the strengths of this approach is that it reveals gaps and questions about dominant theories and theoretical approaches. This is a contribution to this research, which is situated in multiple contexts that have been largely unexplored. The participants' narratives brought into question how rural residents of Appalachia view themselves as learners, and how as adults in non-formal international education they learn best.

\section{A Strong Foundation: Learning in Community}

A sense of community was evident among the people who went on the 2013 CEOS Trip to Ireland. Social continuity is an important aspect of education that emerged in this group (Dewey, 1944). Dewey's social learning theory provided a strong framework that resonated with participants' experiences gleaned through their narrative tellings. Learning in community was apparent within the interviews as the participants mentioned the intergenerational relationships 
between the members of the group and connections to Appalachian culture that were made. The sense of community and continuity came about after the participants shared stories with one another and demonstrated a mutual trust. This type of dialogue was founded on love, humility, and faith in people, thus a relationship built on mutual trust was an obvious outcome (Freire, 1970). In that way, Freire's notions of dialogic education were sometimes apparent in group interactions and occasionally surfaced in individual participants' narratives. Even though the participants were mostly strangers at first, they connected within their common culture of Appalachia. They shared common traditions and history that was taught through stories, both via intentional and incidental narratives (Rogoff, 2003). More so, these individuals from Appalachia have been viewed as "the other" throughout history (Shapiro, 1978). Even though residents of Appalachia are portrayed as ignorant and are often mocked, they want to be seen and treated as equals, regardless of social or economic status (Fiene, 1988). These various aspects seemed to culminate in participants' stories based on their experiences to construct a feeling of "home" while they were together in a foreign country.

Additionally, community increased social capital by facilitating networking and relationships among participants. Social capital is the networks among people that imbibe power and respect in cultural worlds (Szreter, 2002). The group relied on one another throughout the trip. A community is not one body, but many that are loosely connected through the formation of networks (Dewey, 1944). During the experience, the younger members of the community shared their knowledge of using technology with the older members of the community. Likewise, traveled and experienced community members aided the inexperienced community members as needed throughout the trip. The helpful nature of the group members and the relationships they built were discussed by all the participants. These particular residents of Appalachia were a 
community of people "trying to accomplish some things together, with some stability of involvement and attention to the ways they relate to each other" (Rogoff, 2003, p. 80). Working together and looking out for one another throughout the trip was a result of the sense of community and relationships that developed.

\section{How Participants Troubled Identity and Learning Theories}

The participants' learning resonated with Dewey's (1944) theory of education as experience because they lived educational moments in Ireland that helped them to see, clarify, and articulate how their pasts, presents, and futures as residents of Appalachia stood out in relief to Irish culture. This was a socially constructed task, in line with Dewey's (1944) discussion of transactional pedagogies. Examples of this occurred when the participants gathered at pubs, and talk often turned to who they were as residents of Appalachia in relief to what they were notIrish. Additional examples of participants from Appalachia constructing certain notions of their identities through learning occurred when they interacted with Irish tour guides and workshop leaders who taught them about history and culture, yet were situated within the broader tourist economy.

When people converse together, the action is a trans-action where both individuals show their interest in the topic and the results pass from one to the other (Dewey, 1927). Based upon the interview data, it does not appear that much dialogue occurred between most of the Irish tour guides and workshop presenters because of the brief nature of the workshops and the touristic nature of the project. The potential of Dewey's progressive pedagogies, therefore, went largely unrealized and the potential for leveraging deep reflection and Appalachian experience was diminished. Although the participants did create spaces to use their experiences on their own throughout the trip, this was not facilitated in a way that pushed for deeper understandings. My 
own potential positioning as a cultural broker is an important part of this. A cultural broker, a term coined by Delgado-Gaitan (2001) in her work on bilingual and bicultural education, points to the necessity of the teacher or facilitator as one who can help individuals "bridge" between worlds, helping them to legitimately see and understand the cultural transactions. The cultural broker has some deeper knowledge of both the contexts of the newcomers and the culture they are trying to understand and learn from; it is a liminal position.

Compared to Dewey's notions of progressive pedagogies, there were differences in the roles that myself and other Extension professionals participated and constructed to provide broader meanings from the discussions. Part of this adaptation was because Dewey (1944) focused on the improving public education with youth, not adults in non-formal settings. The role of the teacher in Dewey's schema was to either guide or direct the learner. With guidance, the teacher assists "through cooperation the natural capacities of the individuals guided.

Direction is a more neutral term and suggests the fact that the active tendencies of those directed are led in a certain continuous course, instead of dispersing aimlessly" (p. 23). It is through guidance or direction that the teacher also participates in the shared activity, thus leading to reciprocal learning, where the roles of educator and learner are reversed. Dewey sees education as growth and it is this concept where he pushes me to think more broadly and deeply about the role of experience in education within the context of the participants' experiences. I expected the narratives would include large gains in growth and cultural connections to be made by the participants. However, this was not the case and I had to remain cognizant of the starting points of each participant. The participants did not start out as blank slates from which an international perspective could then be constructed, but as human beings with many life stories that would impact their time abroad as much as the experience itself would. Through this shared experience, 
reciprocal learning has occurred due to what I have learned from the participants and their narratives, thus having experienced growth in my education as a researcher.

Finding the "Right" Theoretical Fit in Context. I realized very early on that I had to reevaluate my own assumptions on Appalachian culture prior to delving further into this study. The works of Shapiro (1978) and Whisnant (1983) were especially beneficial as both gave a nuanced and historicized perspective to the Appalachian context and the stereotypes that surround it. Having this theory available was important as I considered the participants' identities which seemed to stand out strongly in somewhat stereotypical ways as I observed them in Ireland and even more so as I analyzed the narratives they told about themselves during their time on the trip — it was, according to them, a time and space for being more Appalachian.

Rogoff (2003) would argue that Appalachian identity is something culturally constructed and not inherently biologically and internally developed. However, the intercultural perspective introduced by Bennett (2004) concentrates on psychological and the individual levels of cultural competence. Bennett's theory does not leave much space for understanding how multiple, fluid, and fragmented contexts matter to residents of Appalachia who are not objects or stereotypes, but complex people with multiple, shifting, and fluid identities which were captured in their narratives. This creates a dissonance between looking at the context of the experience and utilizing intercultural theory, particularly Bennett's. While one would have thought intercultural competencies would have been a natural fit for this study, there were times when it was seamless and other occasions when it was not. This begs the question of if another theory may have been more suitable for analyzing the narrative data. However, I did creatively utilize Bennett's DMIS model in a different manner than what he intended. 
The same can be said about Goodson's (2013) theory of life story analysis. By applying the theory to analyze identity development, I saw beyond the linear descriptions to the fluidity within their personalities. I did not place the participants into a "box" or individual boxes based upon how they told their stories according to his spectrum. Indeed, his structure for seeing the possibilities and constraints of globalization were helpful in understanding the participants' narratives. But given the complex interactions among the participants and the importance of the co-construction of knowledge during the trip, considering individual positioning became a secondary task of my analysis. Instead, understanding how to be a better cultural broker, facilitator, and teacher for a group engaged in co-constructing identities and experiences came forward.

One of the first aspects that I noticed during analysis was that there were fewer and less robust learning experiences stemming from pedagogy influenced by critical and progressive theories than I had expected. After all, reflection focuses on the forward and backward connection between our actions and their consequences, which is needed for learning to occur (Dewey, 1944). Equally important to note is that reflection and action are a source of knowledge and creation (Freire, 1970). These two theories use reflection as a part of learning in manner that works well in the Appalachian context as it parallels the use of storytelling within our culture. While I still consider the framework provided by those educational perspectives to be appropriate for this study, it does lend to some recommendations that were made in the above section about being more intentional in connecting theory within the program. I elaborate more on how the analysis of theory leads to practical implications included in the practical and policy implications section of this report. 
As for Goodson's (2013) theory on narrative life stories and Bennett's (2014) intercultural theory, both were very prescriptive in nature. These theories, which are prominent and important to my study, had some drawbacks because, at first, I took them quite "literally." I was "box" oriented, seeking to fit the participants into the descriptions that best fit their data profiles. However, people do not always fall into predetermined categories. Dewey (1944) maintains that there is a fluid movement across the spectrum of time. It allows for reflection on previous experiences as well as generating opportunities to apply this newly gained knowledge to future endeavors. Dewey's approach to learning was not only beneficial for the participants, but for me as well. Dialogue helped me to be more reflexive in my process, which allowed me to become more fluid with my analysis and the narrative format. From this work, I learned to be more organic with my approach to research, particularly in the ways I grew to think about theory. In the next section, I discuss the methodological implications associated with this study.

\section{Methodological Implications}

The methodological approach that a researcher utilizes in his or her study brings about implications regarding the research questions, the format of the study, and the outcomes of the study. The analysis, findings and conclusions are all a part of this. In this research, the methodological implications that are most important to discuss were about deciding between a quantitative and qualitative study in this type of research, further narrowing down the "right" fit for the study, and how my personal connections with participants influenced the research. The first implication is finding the right approach for the study. The direction I conceptualized at the beginning and the direction this research ended up taking were not in alignment, which I explore below. The second methodological implication is the connection between the researcher and the 
participants, due to the existing relationship these individuals had prior to the study. This was an interesting and complex insight.

\section{Quantitative vs. Qualitative}

Currently there is pressure within Extension Service to produce quantitative data to justify the impact of programs in ways that resonate with funding institutions and others in power. For these reasons, we are regularly tasked to provide data on the results of our programming in order to demonstrate the effectiveness and worthwhile investment. Most often, this is done through quantitative approaches. However, each program has methods that are more beneficial depending on the program's design. Having pretest and posttest results of A1C testing on individuals with diabetes works well for determining the value of a "Dining with Diabetes" class, an educational series on healthy nutrition for individuals with diabetes, family members, and caretakers. Another example is a simultaneous study with controlled plots and treatment plots to investigate weed control to determine the percent reduction with weed control treatments. With our summer reading program, Energy Express, we can show the gains in broad reading skills statewide from the assessments given at the beginning and end of the program.

However, there are times when qualitative research is the best tool for assessment, as in the case of this study, in which it was the relationships among participants and quality of the teaching and learning and its transfer that was being considered. Qualitative work does not seem to have the same level of support as quantitative. For example, each county office can have one computer with SPSS installed on it for research use, yet there is no option to obtain a product like NVivo for qualitative studies. There is not a "one size fits all" research paradigm; yet clearly one methodological approach is supported more than the other in my sub-field. I argue that both qualitative and quantitative research should be supported. There should be resources available to 
assist Extension faculty members in their research endeavors, whether they are quantitative or qualitative. Perhaps part of this disparity is because of antiquated thinking that qualitative studies are not as robust or rigorous as quantitative research. A benefit of qualitative research is that it provides a mechanism to leverage the power of the narrative. Thus, we can educate our stakeholders on not only the benefits of our programs, but it offers another avenue through which we can share the importance of our work.

\section{Finding the Right Fit}

The method went through a few iterations before I could determine the best approach for this study. Initially, I had desired to do a program evaluation of the Ireland program that would include quantitative and qualitative components. As a part of the WVU Extension Service, I saw the practical need for our organization to perform research that would better improve the programs that we offer, especially those related to global awareness and education. However, I was swayed in the direction of narrative research. By using a narrative study, I could investigate other contexts that would impact the experience of the participants as well as the programmatic aspects. I could take into consideration the individuals' backgrounds, their morals, their values, and their beliefs. Narrative research was the right fit for me because it connects well with social constructivism, which is my epistemological viewpoint. I believe that a person interprets and constructs his/her reality through experiences and interactions. I do not think the context can be taken out of knowledge; it is an essential part of one's reality, and narrative research does just that.

While researching narrative methods, I became interested in the work of Ivor Goodson and his life history approach, as it includes both the historical and social contexts influencing individuals' life stories. With my academic background, I wanted to include life histories in this 
study. Additionally, the wide range of ages and experiences among the participants suggested many complex influences I wanted to explore. One aspect I had not considered fully in my original plan was the time needed to adequately develop life history research. Due to my work responsibilities, it was not feasible to incorporate life histories into this study. I can, however, build upon this study with the life history approach in future research. Throughout this entire process, I learned quite a bit, including what my life can sustain as a qualitative researcher. Additionally, I learned that even with the best of intentions, the researcher does not know what they do not know until they are in the thick of it all. Both narrative research and the life story approach include the researcher's voice in the study. I learned as much about the five participants and their stories as I did about myself since this study began.

\section{Personal Connections}

With the methodological approach of narrative life stories, I was both a researcher in this study and a member of the group who went to Ireland in 2013. This had a positive effect on my ability to find participants for this study. I had already gained entrée since I was a part of the 2013 CEOS Trip to Ireland group from the beginning. I had built up trust with the members of the group, thus the participants were agreeable to being a part of this research. I felt compelled to honor the trust they placed in me with their stories as they welcomed me into their homes and places of work. I was introduced to family members and co-workers prior to the interviews, which also lent itself to the openness and amiability I felt with these five participants.

A potentially negative effect of having a personal connection to the participants is how it affected my analysis. Goodson and Gill (2011) indicate that a main critique of this method is the relationship between the researcher and the participants. I was a researcher in this study and I am a friend, a very good acquaintance, and a granddaughter of certain participants. It was difficult to 
analyze and write up some of the narratives because of the pre-existing relationships I had with these individuals. I did not want to hurt their feelings by revealing my observations. Yet, main themes from the data needed to be articulated in order for others to learn from this experience as well.

Additionally, I was related to one of the participants, Martha, and that allowed for another layer of complexity. This participant was an "open book" with a lot of the questions I asked, and a good portion of her responses I had known before she shared them. In discussing some of her childhood, I learned new information about my extended family. Also, at one moment during the first interview, I had to pause the interview because of the emotional state at which the participant arrived when discussing her childhood. While I was prepared for the answers to the questions I asked, I was not prepared for was the discussion among my extended family members after my first interview with my grandmother. My grandmother's sister was very upset that I interviewed my grandmother about their childhood and subsequently called my aunt to ascertain the premise of my actions, prior to my grandmother's death. I believe that my great aunt did not want me to continue to interview my grandmother or have any discussions with my grandmother about that topic. However, she did not have any conversation with me to discuss her concerns. I thought it was inappropriate that I was not contacted directly or even a phone call made to my mother. Even if my great aunt relayed her concerns to my grandmother, Martha was the type of person who would have done what she thought was best or needed in the situation. Even before my grandmother passed away, a few of my relatives had asked to read my dissertation upon its completion. This now leads me to wonder what discussions will arise about Martha and her portrayal in this study.

In the following section, I explore the implications related to practice and policy. 


\section{Improving Practice and Policy}

Qualitative research takes time and currently, time is not something that many Extension faculty have, with all their other responsibilities. If more resources were available, there would be vastly greater potential to do more deep, collaborative qualitative research with organizations such as CEOS, 4-H, and Master Gardeners. For example, each of these programs has a built-in service component that would be advantageous to explore. Not only why are these individuals joining these organizations, but why are they staying and helping others. Also, is there a foundational aspect that could be replicated in other programs to strive for similar outcomes? Unfortunately, there are no discussions on any study like this, plus the decrease in funding makes it more difficult. With less resources, more work is being completed by less people, which means we need to work together and less in silos. When Extension faculty members are involved with meaningful research that can inform other areas of their work, then we return to the founding principle of the Cooperative Extension Service: research informs practice, which directly impacts the people in the communities, and whom we serve. In this section, I outline specific practical and policy applications of the narrative research findings for WVU Extension Service. The practical implications include: building authentic relationships and intentionally developing a praxis orientation. Then, I discuss policy implications, which center on shifting towards innovations which resist the commonplace neoliberal movement influencing WVUES, but provide grounded, authentic, and critical possibilities for change.

\section{Practice Considerations}

Building authentic relationships. The initial premise of the Cooperative Extension Service was to use the research advances of land grant institutions to help people, particularly with respect to agriculture. Local Extension Agents were tasked to build authentic relationships 
that would facilitate trust within the community, so that there could be dialogue between the educators and the learners. It is through the dialogue that critical education for social change becomes possible (Freire, 1970). Therefore, it is the genuine relationships and trust between the Extension Agents and the community members that provide the foundation for learning to occur. Unfortunately, there is now increasingly a rift between WVU Extension Service and the foundation upon which it was originally built. With the recent budgetary reductions, WVU Extension is becoming more like a business. The goals are now quantitatively focused. When the funding available for various organizations dwindles, these groups are pressed to present their finest arguments for why it is best to provide the funds to the respective agencies. Impact is now often measured by the number of people included as a part of our programming. There is increasingly less emphasis placed on building the relationships and assessing the quality of these relationships and experiences, except when we are placed in the role of advocacy.

Our largest programs involve people that remain with these programs for long periods of time, sometimes for life. A West Virginia 4-H member can remain with the program for 12 years. Upon aging out of the program, they can apply to serve as a volunteer. Individuals have received recognition for being members or volunteers of Extension programs for over fifty years. These people are more than just numbers indicating how many people participated in our programs or how many hours they spent volunteering. They have stories to tell. More than numbers, their stories would better serve to demonstrate the rich, robust, and sometimes powerfully emotional real-life impact of the programs. For example, a few years ago a young 4-H member in one of my groups opened up to his peers and some adults that they had considered committing suicide. We were all shocked to hear about this because of his funny, outgoing nature. This person stated they would have probably followed through with his intent if 
it was not for 4-H and 4-H camp and the community and opportunity for giving back these spaces provided. He shared his story with others to advocate for being active in the 4-H program and to give back through service. Personal stories such as this one can potentially be filmed and shared publicly if the individuals telling them desire this; they can be effective in illustrating the powerful outcomes of Extension's programs. In the 4-H world, we often say that our goal is to develop "blue ribbon kids, not blue ribbon projects." If that is still truly the case, then we need to refocus and (re)build authentic relationships with the people in our programs. This is reminiscent of Freire’s (1970) literacy organizing strategy of “each one reach one.”

Cultivating a praxis orientation. In addition to being strategic about capturing and dispersing narratives that reflect the influences of programs, critical reflection related to improving and transforming programs is vital. The co-faculty leads need to be more intentional in facilitating participants' learning by using knowledge derived from multiple learning theories, as explained previously. There is an expectation that the participants will learn individually and together from "absorbing" the experience and spontaneously talking together. One way to intentionally support praxis is for the co-leaders and participants to connect the everyday to the issues of the world, thus moving from an egocentric cultural view to an exocentric perspective. This could be done both in structured discussions led by the co-leaders, as well as by the coleaders serving as cultural brokers throughout the trip. This "globalization from below" approach relates an understanding of globalization "through mundane and vernacular activities" (Apple, Kenway, \& Singh, 2005, p. 7). This viewpoint is essential for residents of Appalachia as it connects the citizens to others outside of their "norm" and hopefully strengthens their sense of 
community on a social level. It also maintains a comfortable level of dissonance, so that participants are challenged, yet have a space to learn.

One suggestion is to formally encourage the participants to pay attention to diverse people and places during the experience. As their lives and identities intersect with other people and their experiences with those of others, they can see facets of globalization (Luke \& Tuathail, 1998; Urry, 1995). We did not intentionally set up, promote, or reflect on this concept, which could be part of the reason it is not an outcome of the study. Participants' narratives reveal that although there was growth in most cases, there remains a lack of global awareness in some respects related to understanding and acceptance of the differences of others, for example their cross-cultural competencies. This provides us the opportunity to be more intentional in our usage of Freire's (1970) “problem-posing” approach. In applying Freire's problem-posing approach to our work as co-leaders in Ireland, we might include Freire's view of dialogue throughout the process, which includes reflection and action. This notion of dialogue contains mutual discourse and reflection about the experience as a process; thus, the educator and the participant would take action that was informed by their reflection, which leads to open dialogue and reflection, i.e., a continuous repetition of the cycle. Additionally, this would have to be planned throughout each day, not for a short-time in the evenings.

Faculty members would need to be cognizant of the approach and how to include it within the experience. When all parties are involved in the process, the educator and the students learn from each other, creating an environment with "acts of cognition, not transferals of information" lead to true knowledge (Freire, 1970, p.79). We can be more strategic in looking for opportunities to weave problem posing into the program in critical, authentic, and innovative ways so that the actions taken and results observed are the responsibility of the entire group. For 
example, we should delve deeper during formal reflection times and discuss generative themes that arise from cross-cultural contexts, such as the fears and judgements that arose from this study. Allowing the participants to analyze these perceived problems should bring about acknowledgement of their own cultural perceptions. Another idea would be to incorporate a service learning activity that would move the participants from the tourism-based experience into the local community. The goal for such an activity would be to co-identify a need with community partners, engage with action alongside host nationals, and then reflect on all aspects of the process.

This all may be counter to the expectations of CEOS members, yet, it connects better to creating a community, supporting dialogue, etc. The ownership that would arise from a “problem-posing” approach could provide more opportunities for communal reflection to take place, not primarily individual ones. Additionally, the "problem-posing" approach would provide us the opportunity to be more intentional when working with the group, to understand their common learning goals and how to achieve them, in a global setting. The Extension Service uses this technique at times, but we have never approached global education and awareness from this perspective. However, for individuals to be educated for life, innovative ways of renovating the policies, pedagogies, and politics are necessary (Apple et al., 2005).

Furthermore, the role of participants' voices in planning is important. We often take the participants' suggestions into consideration while we are on the trip by adding to the itinerary, i.e., a visit to a mall in Northern Ireland and going to the second Irish Pub to hear local musicians. The question becomes, why do we not include that perspective during the planning stage? We have done this with some of our youth programming and have individuals from around the state come together over a weekend to provide ideas and plan activities for the week- 
long residential state camps. Additionally, I do this on the county level using open-ended evaluations as well as youth on the planning committee for our county week-long residential 4-H camp. In this instance, I would recommend either conference calls or a group planning meeting to highlight ideas and suggestions for the international trip. Understandably, not every suggestion or idea is feasible, but allowing for participant input promotes ownership of the program. Additionally, the evaluation tool could be modified in order to gather more specific data on the knowledge and questions from the participants and then use that information to contribute to learning experiences during the trip. As residents of Appalachia, we have been told throughout history that we are not smart enough to be take care of our own natural resources, we cannot solve our own problems, and that we are not good enough (Shapiro, 1978; Whisnant, 1983; Sohn, 2006). It begs the question of whether or not the Extension Service has been doing the same thing to its own people as we do not always include them in planning the programs in which they participate.

Policy considerations. On the national level, the effects of neoliberalism have resulted in reducing of government spending; loosening or eliminating domestic and international government regulation; privatization of government enterprises; and large cutbacks to social programs (Kotz, 2003). The Extension Service receives federal, state, and local funding, so the economy and decision models for dispersing available funds have a large impact on the resources available to support the organization. There is the potential for the WVU Extension Service to receive a decrease of financial backing in triplicate because it receives money from the United States Department of Agriculture, the state of West Virginia, and county governments, i.e., boards of education and county commissions. When the various levels of government choose to reduce their spending, social programs are often cut first, and the Extension Service is frequently 
viewed as a social program. More so, the neoliberal perspective strives to reduce society to simple economics, where individuals become profits and losses.

Within the Appalachian context, the neoliberal impact is reflected by the "Great Recession" of 2008, where the region lost all jobs gained since 2000 and saw a 25 percent decline in the per capita market as compared to the rest of the U.S. (Anglin, 2016). Less demand and more competition has taken a toll on the Appalachian economy, which has been exportbased for years (Shapiro, 1978; Sohn, 2006). Most recently, the crisis within the American coal industry has caused a downturn in this region's economy (Anglin, 2016). With the latest recession, more cuts have been made on the state level, which has negatively impacted the Extension Service. Given all this, there is now a push for federal deregulation to try to boost the local economy. However, the price to turn a profit will come at the cost of the lives of the workers from Appalachia.

When I started in Extension, the Global Education Specialist for WVUES just received a $\$ 25,000$ annual budget for global programming. This was to support the efforts of global awareness for residents of Appalachia and to support international work. As previously mentioned, traveling internationally can be quite expensive as roundtrip airline tickets can range from $\$ 400$ to $\$ 2,000$ per person, depending on the destination (Priceline, 2015). As was explained earlier in this study, the average worker in Appalachia earns $\$ 21.60$ dollars less per day than their outside counterpart; and the largest economic disparities are with individuals that live in rural areas. This additional funding was a great benefit to WVU Extension. However, when the economic downturn occurred in Appalachia and the Extension Service budget was reduced, financial support for global education was one of the first cuts made. Another decrease was seen in the number of faculty grants available through WVU. Prior to the recession, 
employees could apply for a University-wide faculty development grant and a faculty travel grant in the same year for no more than $\$ 1,200.00$ (cumulative). Currently, there is only the faculty development grant with a request cap of $\$ 800.00$. The University's colleges and departments may have additional support available for programs conducted by their own faculty members. If an international program is run through WVU's Global Affairs office, they can build the budget to support two faculty members traveling with the group. This covers the lead organizers of an outbound program, but does not include those who may want to gain more international experiences, but are not comfortable leading a group themselves. All in all, the employees and volunteers who work with global awareness programs must discover creative ways to find aid to support these efforts.

On the micro-level, neoliberalism has affected the Extension Service through cuts to resources in the counties. If counties do not have viable funds to support the Extension Service through taxes or levy money, then there is little financial backing for the Extension Service. In other words, the county governments still want the Extension Service and its programs in their area, but cannot financially afford to support them. If the Extension Service is listed with a levy, the success of gaining funding lies with the employees demonstrating the importance of its work and advocating for the levy in that county. Understandably, the primary need for county governments is having employees to handle the essential functions of a county rather than supporting the Extension Service. This could be something as small as decreased travel or office supply budget amounts to defunding county Extension support staff or even defunding Extension Agent positions. There is an old saying that "you can't get blood out of a turnip," which means you cannot get money out of someone who has none to give. When counties do not have a sufficient local economy to support their citizens, it is unrealistic to expect that these counties 
could cost-share with Extension. While most people appreciate the programs the Extension Service provides, when it comes to financial support Extension is often viewed as a social program, not an essential service like other county departments. Because of the economic woes in Appalachia, we have counties that currently have no full-time employees in the Extension offices and some offices with only one full-time Extension Agent. The citizens of the county still desire the various programs offered by Extension; however, the decrease in resources negatively impacts achieving the basic Extension work, let alone expanding the international component. Extension in my mind is not a business; it is an essential service that has the potential to generatively support individuals and groups and work together in ways that promote health, wellbeing, community, critical consciousness, problem solving, and development. Businesses are interested in generating numbers to show impact, but not necessarily true quality. An essential service considers the importance of history, daily life, authentic relationships, future growth, reciprocity, economic change, and the power and potential of educators, local people, and the stories that they tell.

The following section expands on future research endeavors.

\section{Future Research}

\section{Promoting Collaborative Research}

Expanding research is critical for the development of Extension as an essential service for and with the people of West Virginia. To create spaces to produce more public narratives of impact and engage in critical pedagogies, it is important to create stronger networks by working collaboratively with others. Through collaborative research, we may be able to expand the power of narratives, which is essential to our work. Demonstrating the impactful nature of narratives offers a different way to show the importance of our programs, especially those that become a 
part of the lives of the participants. Within the literature, a few models do exist. One is a DVD video that was a collective effort between the American Heart Association, state library system, and the Extension Service to share the stories of women in West Virginia who survived heart disease and strokes (American Heart Association, Prevention Research Center, West Virginia University Extension Service, \& West Virginia Library Commission, 2006). While this focuses more on the narrative aspect than the research, it shows the various groups who worked together to tell these stories. Another example is a focus group study on female high school employed students and was a mutual effort between the Louisiana State University Extension Service and their Schools of Human Ecology and Forestry (Garrison et al., 1999). This project appears to be a true collaboration where faculty members from both colleges worked together on the study. A few research studies exist that demonstrate the cooperative nature between Extension Service and university (or other) partners; however, most use quantitative approaches. Additionally, I could find very little cross-college research within the WVU Extension Service and few studies involving qualitative methodology.

I have proposed an action plan that outlines how the WVUES can move in a positive direction that marries research and practice, particularly in the areas of international education and narrative studies. Not only must we begin to think and act bilaterally within WVU Extension, but we can partner with other WVU colleges to accomplish these goals. WVU Extension has the existing connections and relationships that provide entrée to the target audience of the projects, knowledge of the contexts involved, and to serve as members of the research team. The faculty from other WVU colleges can benefit from a system that is already in place from which these research projects can start. These details are included in Table 5, which is found below. 
Table 5

WVUES Research Action Plan

\begin{tabular}{|c|c|}
\hline Objective & Action/Activity \\
\hline $\begin{array}{l}\text { Think and act bilaterally } \\
\text { on research projects }\end{array}$ & $\begin{array}{l}\text { Have a meeting with interested individuals from across the units } \\
\text { within WVUES and include program directors. } \\
\text { Brainstorm potential projects that could be done within WVUES as } \\
\text { well as with collaboration from other colleges. } \\
\text { Locate faculty members with research emphases that connect to } \\
\text { potential projects. }\end{array}$ \\
\hline $\begin{array}{l}\text { Make connections } \\
\text { across colleges }\end{array}$ & $\begin{array}{l}\text { Provide the Dean of Extension with a list of potential projects and } \\
\text { contact information to take to the Dean's meeting. } \\
\text { Any interested Deans and colleges can provide the information to } \\
\text { their respective faculty members. } \\
\text { If no response has been received by a predetermined date, contact } \\
\text { the faculty members directly. }\end{array}$ \\
\hline $\begin{array}{l}\text { Work collaboratively } \\
\text { within the university } \\
\text { system }\end{array}$ & $\begin{array}{l}\text { Each research group shall collaboratively determine their research } \\
\text { project, either from the list or through other discussions. } \\
\text { Identify capstone classes where these types of projects may provide } \\
\text { a mutual benefit to the student and the research team. } \\
\text { Work through the processes involved in a research study, i.e. } \\
\text { literature review, IRB, data collection, analysis. }\end{array}$ \\
\hline
\end{tabular}

This approach is designed to bring various individuals to the table to ensure the best possible partnerships are made, which could also lengthen the time frame to start. Having a system of communication in place should allow the collaborations to continue in the event of attrition. Overall, the action plan is flexible in nature as it contains a dialogic process that will permit changes based on the dynamic ideas of the group. In case this approach does not glean the desired results, there is the possibility to directly contact faculty members who have research interests in relatable areas from other colleges. 
Once a network is in place, we can begin the collaborations between all kinds of people (colleges, faculty, media and library specialists, web designers, archivists, historians, local media, and most importantly local people) in order to share the stories of residents of Appalachia in thoughtful ways. I would advocate for using narratives and life story research as the methods in which this can be accomplished. So that we can create a strong research network, we must look towards the common goal of promoting our people and our state from a critical perspective. Too often, outsiders have spoken for us; instead, we can use narrative research to speak for ourselves. This would provide the opportunity to transform the image of West Virginia as well as the Extension Service.

The global education and awareness work in WVUES is divided into two categories: outbound (i.e., going abroad) vs. inbound (i.e., focusing on global awareness efforts within the state). As for our various inbound programs that involve bringing international students to West Virginia, we have done little to no research with these activities. Part of this is due to the complexities associated with those who partake in these programs: all are youth participants, the international children are non- U.S. citizens and have English as a second language, which combines to add a layer of difficulty that increases the time constraints for a narrative study. However, this could be a potential collaborative study between Extension and the Department of World Languages, Literature, and Linguistics, who would have the language expertise needed. By involving other colleges and departments, we can promote collaborative research connections as outlined above in Table 5. In addition to cooperative efforts, Extension faculty members must deepen their own understandings of critical pedagogy and narratives in order to drive the outcomes of their programs below the surface to greater comprehension. 


\section{Concluding Remarks}

I have always thought the work of the Extension Service was important and that our efforts were effective. After this study, I have come to realize that we need to change our mentality. While I continue to believe in the power and potential of Extension Service, one of the themes from this dissertation is the need for critical pedagogy in our communities in Appalachia. While we are diligent, we are missing the mark when it comes to truly transforming our areas. We are guilty of utilizing the "banking system" within our programs, which only deposits our ideas into the minds of others (Freire, 1970). If we are to ever have lasting effects, we must strive to incorporate critical education in all programming areas. At times, we have pieces of this within our projects, but I am not sure if we, the Extension Service, have a firm grasp on what critical pedagogy is.

This process has also led me to see how the Extension Service must change our mindset when it comes to our premise. We began as a service, not a business, but a shift has occurred in recent years. We look at how many people we are reaching, not the magnitude and the ways in which we reach them and that they contribute in dynamic and generative ways. While I understand that we must "pay the bills," I also believe we must be relevant in the future so we can maintain our existence and truly make an impact. In order to do so, we need to defy the current push to follow business models and once again work toward initiating relationshipbuilding, to become an essential service. I define our success as when we connect with our participants and treat them as a people, not numbers. Through narratives, we can not only cultivate the relationships, but we can demonstrate how impactful Extension work is. I recently received a letter from a 4-H volunteer that stated how, throughout his childhood, that 4-H camp was the one week a year he felt safe. He also said that his time as a camp counselor this past year 
was one of the best weeks he had in a long time and thanked us for that. Stories like this that better illustrate the impact of our work through the meaningful nature of our connections rather than stating how many people participated in an activity.

This notion of relationships also revealed the Appalachian need for connections in this study. The desire to relate to one another was prevalent, which could be between knowing the same people or having a similar history. One of my main connections from this 2013 group was my maternal grandmother. Both this trip and this study provided me the opportunity to see her in a different light and through the eyes of others. This was beneficial as I could apply the same notion in order to see each of the participants from various perspectives as I moved through this process. While her narrative is entwined with mine, the sense of community within the group wove her presence into the life stories of other participants. While it was humbling as her granddaughter to witness this, it exemplifies the potential that exists with narrative research for me, the researcher.

This research experience was enlightening because it caused me to see myself in multiple viewpoints. This process forced me to look at people I had personal relationships with and myself in a whole new light. I felt like it broke my personal and professional identities into fragments of my former self. The benefit to this is that I can further develop my own theoretical understandings, and now better engage the participants of my programs. Particularly, I must reflect and renovate aspects of our international programming so it will achieve more critical outcomes. Change is as inevitable as it is necessary. This was something I learned during my first time abroad and something I am reminded of each time I am involved in international work. These are the reasons I want to help others have international experiences where they can have the opportunity to not only find out who they are, but who they want to be. 
Appendix A: 2013 CEOS Trip to Ireland Final Schedule

Day 1 (Mon): Arrival at Dublin Airport 10:30 a.m.

Left for Drogheda at Noon

Checked in at An Grianan, had lunch at 1:00 p.m.

Tour of Drogheda at 2:00 p.m.

Dinner at 6:00 p.m.

No evening entertainment

Day 2 (Tues): Breakfast at 8:45 a.m.

Tour of Beaulieu House at 10:00 a.m., returned at 12 Noon

Lunch at 1:00 p.m.

Talk on the ICA/ An Grianan by John McCullen at 2:30 p.m.

Tour of grounds and course locations at 4:00 p.m.

Dinner at 6:00 p.m.

Walk to beach \& the Irish Sea at 7:00 p.m.

Evening entertainment: Irish singing and dancing by Mary Harahill and her neighbors at 9:00 p.m. until 11:30 p.m.

Day 3 (Wed): Breakfast at 8:45 a.m.

Courses were held from 10:00 a.m. - 1:00 p.m. and 2:00 p.m. - 4:00 p.m.

A tea break was offered at 11:00 a.m. each morning.

- Digital Photography Course with Terry Collins

- Medley Course (Cookery Demonstration) with Edward Hayden

Lunch at 1:00 p.m.

Dinner at 6:00 p.m.

Visit to the local pub in Termonfeckin at 7:00 p.m.

Evening Entertainment: Local singer with accordion at 9:00 p.m. until 11:30 p.m.

Day 4 (Thurs):Breakfast at 8:45 a.m.

Courses were held from 10:00 a.m. - 1:00 p.m. and 2:00 p.m. - 4:00 p.m.

A tea break was offered at 11:00 a.m. each morning.

- Digital Photography Course with Terry Collins

- Medley Course (Gardening Demonstration)

Lunch at 1:00 p.m.

Dinner at 6:00 p.m.

Evening entertainment: Visit to Cairns Gastropub in Drogheda

Day 5 (Fri): Breakfast at 8:45 a.m.

Courses were held from 10:00 a.m. - 1:00 p.m. and 2:00 p.m. - 4:00 p.m.

A tea break was offered at 11:00 a.m. each morning.

- Digital Photography Course with Terry Collins

- Medley Course (Rambling to a local Abbey and Monasterboice) 
Lunch at 1:00 p.m.

Dinner at 6:00 p.m.

Photography Exhibition at 7:00 p.m.

Style \& Image Program at 7:30 p.m.

Day 6 (Sat) Breakfast at 8:45 a.m.

Depart for Dardistown Castle at 10:00 a.m.; had tea $\&$ scones, $10 €$ per person

admission.

Picnic lunch around Noon at Newgrange Interpretative Center

Did tour of Newgrange Interpretative Center

Visited Knowth at 2:15 p.m.

Spent around 30-45 minutes in the gift shop

Departed for An Grianan

Dinner at 6:00 p.m.

After dinner - participants played cards, went for walks, journaled, watched tv.

Day 7 (Sun) Breakfast at 8:45 a.m.

Depart for Belfast at 10:00 a.m.

Visited the Peace Wall and specifically Falls Road (Catholic/Republican area)

and Shankill Road (Protestant/ Unionists).

Arrived at the Titanic Museum

Had lunch at restaurant in the museum (15£ per person)

Tried to stop by Hillsborough Castle (place where Tony Blair \& GW Bush had talks over Iraq in 2003), but it was closed off due to a local festival.

Stopped at local outlet mall in Northern Ireland for shopping.

Had dinner in Cross Station, Northern Ireland

Returned to An Grianan around 8:00 p.m.

No evening entertainment. Participants played cards, went for walks, journaled, watched tv.

Day 8 (Mon) Breakfast at 8:00 a.m.

Genealogy participants met with Sean Collins over breakfast

Depart for Martyr Mill - one of three operating grain mills in Ireland. For $5 €$

admission, everyone received a $5 \mathrm{lb}$ bag of wholemeal flour.

Drove by Slane Castle, but had no time to stop.

Stopped by the home of Francis Ledwidge, a famous Irish poet

Visited the Hill of Slane, but again had limited time to get off the bus and sight see.

Had lunch around Noon at the Oldbridge Café, home of the Battle of Boyne

Interpretative Center

Met the Mayor of Drogheda

Free time in Drogheda from 2:30 p.m. $-5: 45$ p.m.

Dinner at An Grianan at 6:00 p.m.

Presentation on Honeybees at 7:00 p.m. 


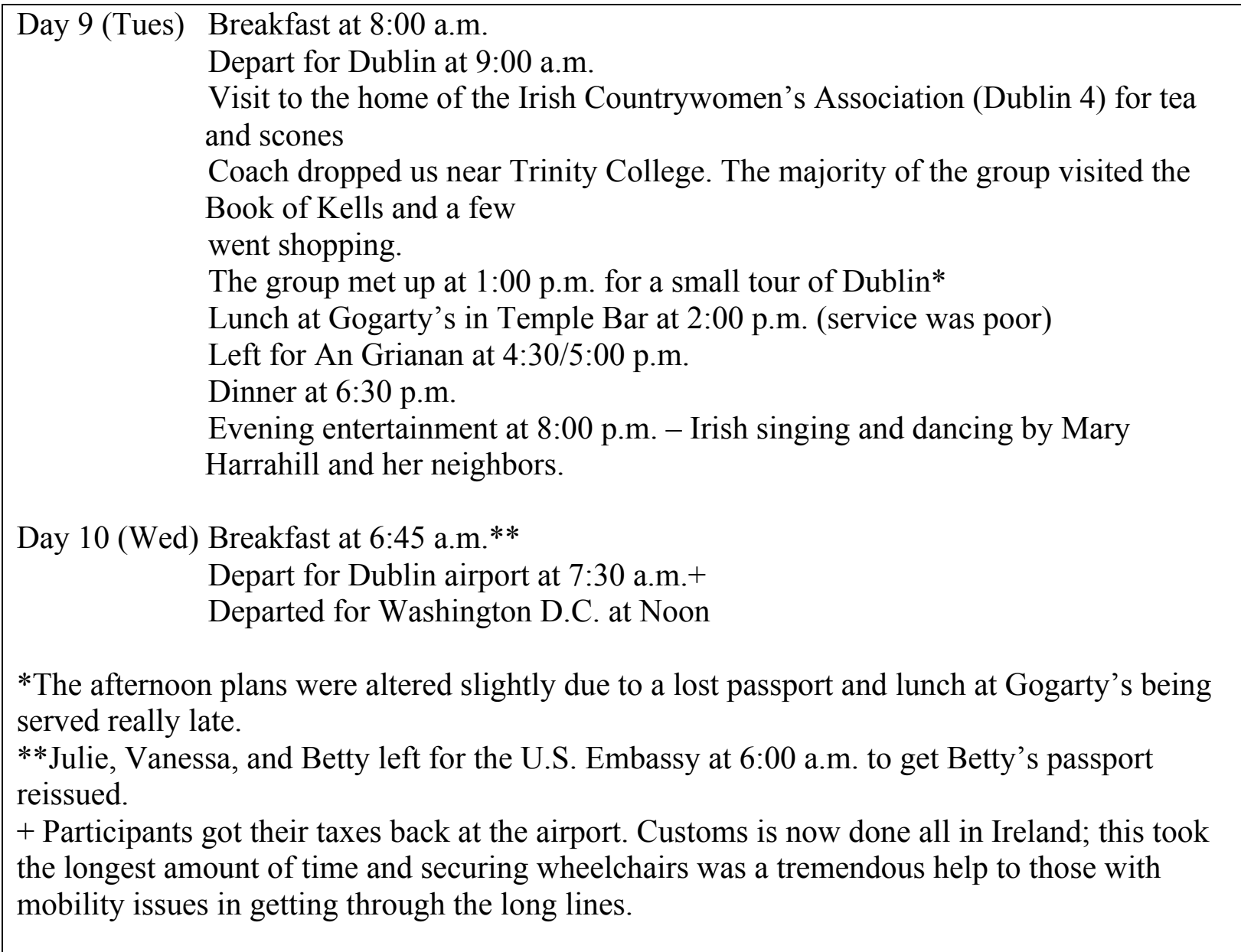




\title{
Appendix B: Interview Protocols
}

\author{
Participant Life Story Interview
}

Introductory Protocol

I have planned this interview to last no longer than two hours. During this time, I have several questions that I would like to cover. It may last less than two hours, but should not last more than that amount of time. Thank you for your agreeing to participate.

\section{Introduction}

You have been selected to speak with me today because you have been identified as someone who went on the 2013 CEOS Trip to Ireland, was born in Appalachia, and are a resident of West Virginia. My research project as a whole focuses on how the West Virginia University Extension Service sponsored non-formal educational experience to Ireland has influenced the lives of its participants from Appalachia. I am simply trying to learn more about how international experiences affect residents of Appalachia both while abroad and upon their return home. First, let's start with the items you chose.

1. Please share with me the three items you chose to bring with you today that represent what is most important to you in life. Why did you selected these items?

2. Briefly describe your childhood.

Probe: When and where were you born? Where did you grow up? What was the land and community like, was it rural? What was the house like in which you grew up? What was it like traveling when you were growing up?

3. Tell me about your parents.

Probe: Where were they born? When were they born? What memories do you have of them?

4. How many brothers and sisters do you have? When were they born? What memories do you have of each of them from when you were growing up?

5. Tell me why you chose to go on the CEOS Trip to Ireland. How did you decide to go?

6. What is one thing you learned from taking this trip? Do you see your connections with other people differently now? How so?

Probe: Do you see your connections with people in countries other than Ireland and the USA differently after taking the trip? How so?

7. What is one thing you learned about yourself from taking this trip? 
8. How did you share this experience with others upon your return home?

Probe: Did you give any presentations? Did you talk to family members or friends? What were the reactions of those with whom you spoke?

\section{Conclusion}

Thank you again for your time and agreeing to participate in this study. I will be in further contact to set up the second interview and allow you time to review the information from this interview as well. Have a nice day! 


\section{Participant Ireland Story Interview}

Introductory Protocol

I have planned this interview to last no longer than two hours. During this time, I have several questions that I would like to cover. It may last less than two hours, but should not last more than that amount of time. Thank you for your agreeing to participate.

\section{Introduction}

You have been selected to speak with me today because you have been identified as someone who went on the 2013 CEOS Trip to Ireland, was born in Appalachia, and are a resident of West Virginia. My research project as a whole focuses on the exploration of the impact of the West Virginia University Extension Service sponsored non-formal educational experience to Ireland had on its participants from Appalachia. I am simply trying to learn more about how international experiences impact residents of Appalachia both while abroad and upon their return home. Now that I have learned more about you and your life, I would like to ask you questions specifically related to the CEOS Trip to Ireland and traveling. First, let's start with the items you chose.

1. What dreams and goals did you have for your life after high school? How did you decide what you wanted to do with your life? Did any of these dreams have travel connections? International connections? How do you feel about your choices?

2. How have your dreams and goals changed through your life?

3. What have been the most influential experiences in your life?

Probes: What did you learn from those experiences?

What learning experiences have shaped you the most?

Have any of these involved travel? International connections?

4. What does being a resident of Appalachia mean to you? How has being a resident of Appalachia shaped your life experiences?

Probe: How has being a resident of Appalachia shaped your educational experiences? Your learning experiences? Your travel experiences?

5. What are your thoughts about the Irish culture?

6. Describe any changes in your goals, way of thinking, etc. that came as a result of the 10 days in Ireland.

Probes: Did you have any experiences with culture shock during the trip? Did you have any experiences with reverse culture shock? 
7. How did your interactions with others in the group shape your experience?

Probe: Can you give a couple of examples?

Conclusion

Thank you again for your time and agreeing to participate in this study. I will be in further contact to allow you time to review the information from this interview. Have a nice day! 


\section{Appendix C: West Virginia University 2020 Plan Goal 5}

\section{GOAL 5}

Enhance the well-being and the quality of life of the people of West Virginia.

\section{OBJECTIVE 1}

Create an academic health system and health professions programs that enhance the well-being of West Virginians.

\section{OBJECTIVE 2}

Increase opportunities for the citizens of the state through workforce education, lifelong learning, and outreach to every county.

\section{OBJECTIVE 3}

Promote sustainable economic development and a cultural environment that improve the quality of life throughout the state.

\section{ACTIONS}

1. Promote sustainable economic development and a cultural environment that improve the quality of life throughout the state.

2. Expand outreach efforts to connect the campuses to citizens and communities throughout the state. Provide resources and information to equip West Virginia University Extension agents, and other personnel engaged in outreach and care, for a broader role as ambassadors for the institution.

3. Meet regularly with state and industry leaders to articulate University successes and initiatives, to learn of the needs of the state, and to promote the commercialization of research, economic development, and global commerce.

4. Create a nimble academic health system that is responsive to patient access needs, ensures high quality, cost-effective, and safe care, and delivers patient satisfaction and value.

5. Strengthen relationships with alumni, stakeholders, and the communities that neighbor West Virginia University campuses. 


\section{Appendix D: 2013 CEOS Trip To Ireland Photographs}

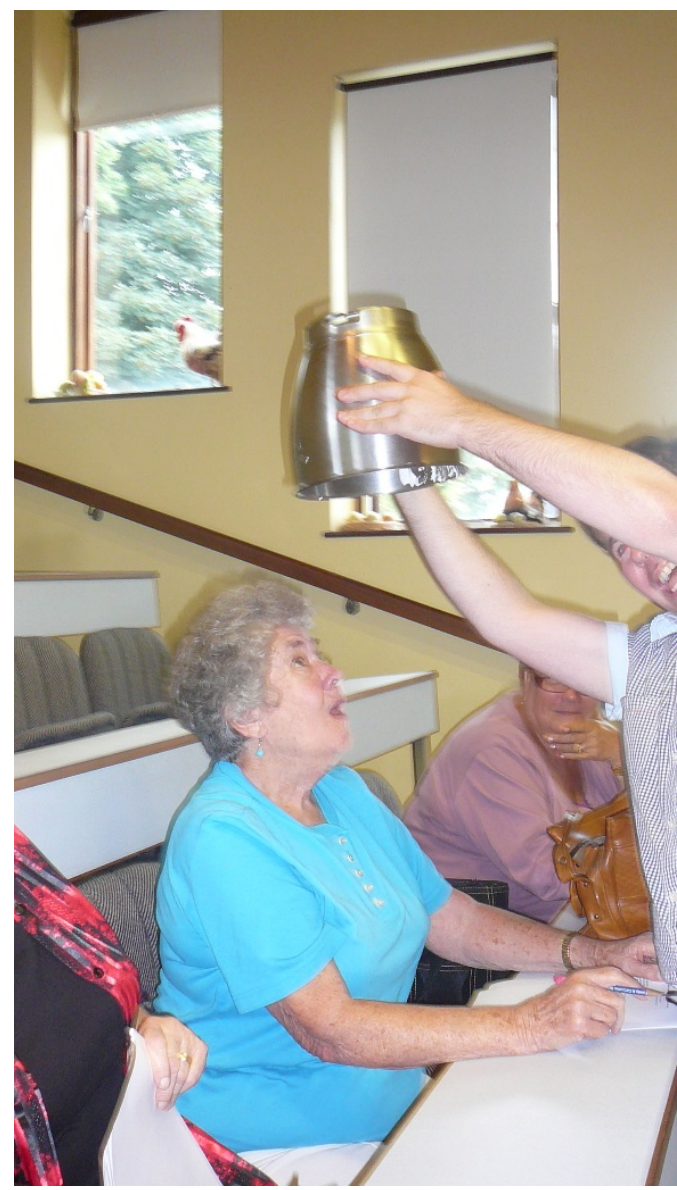

Photo 1:

Cookery instructor, Edward

Hayden, demonstrating the thickness of the batter to a participant.

Photo 2: A participant taking in the sites at Mellifont Abbey during the Rambling Class.

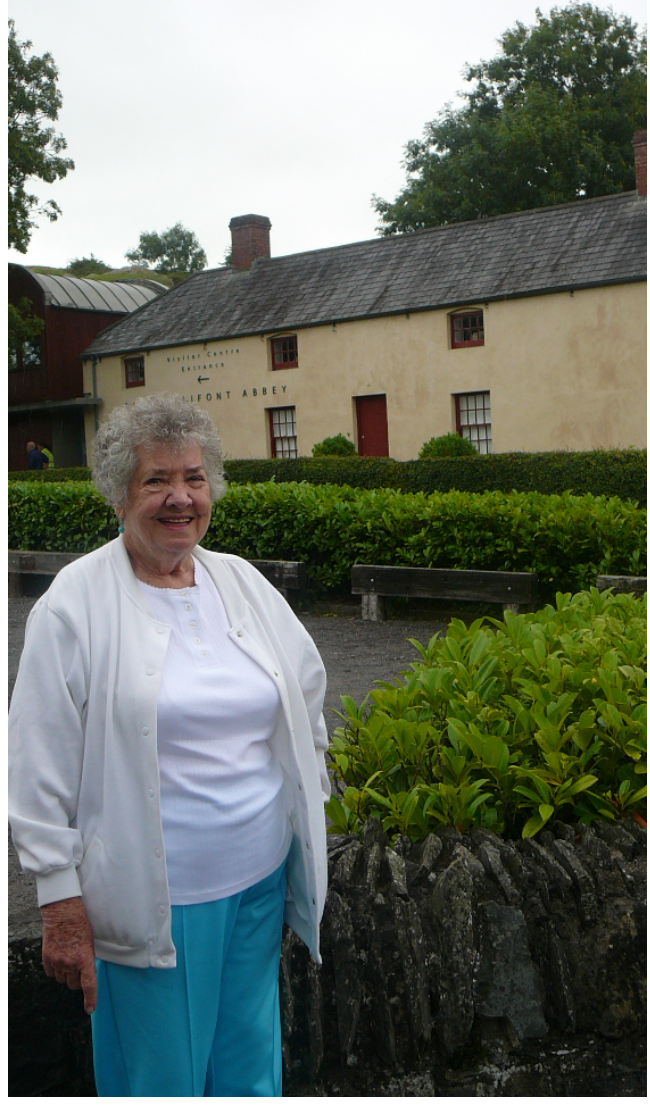

Photo 3: The backyard of the Gardening Class instructor, who lived nearby.

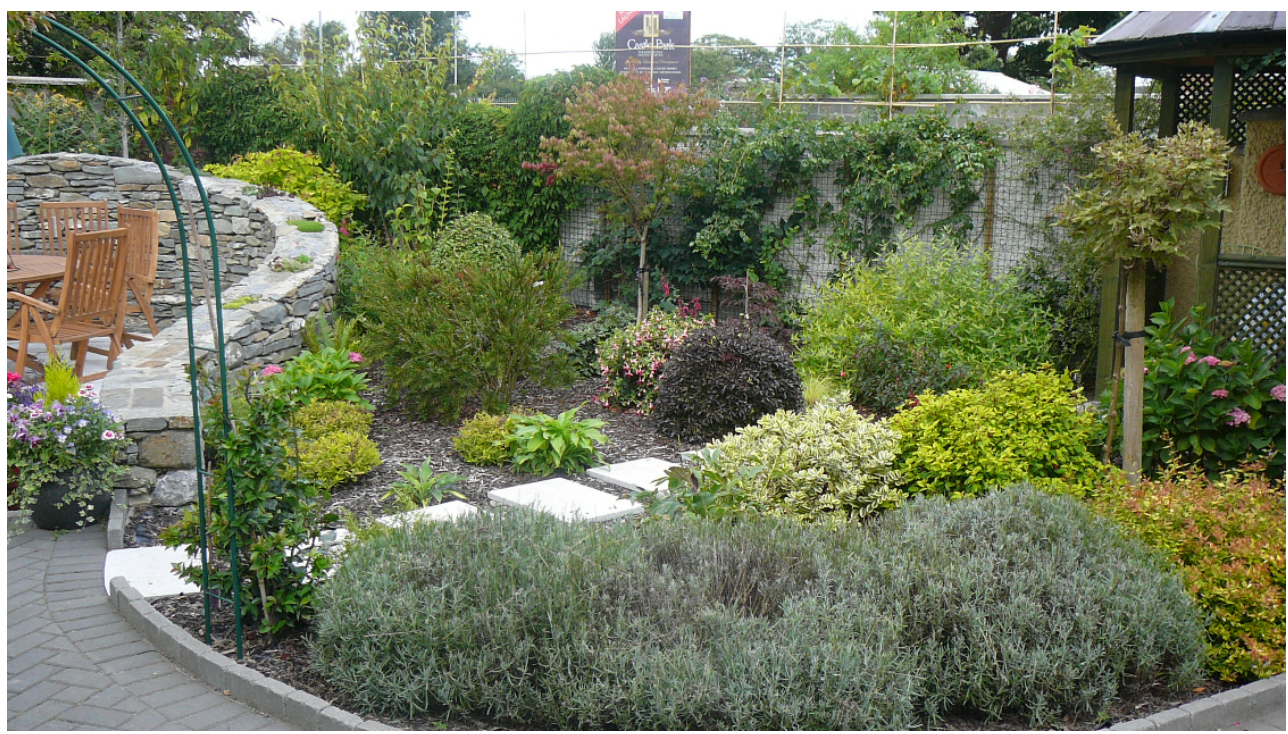


Photo 4: Members of the Digital Photography class getting ready for a small snack at Clogherhead.

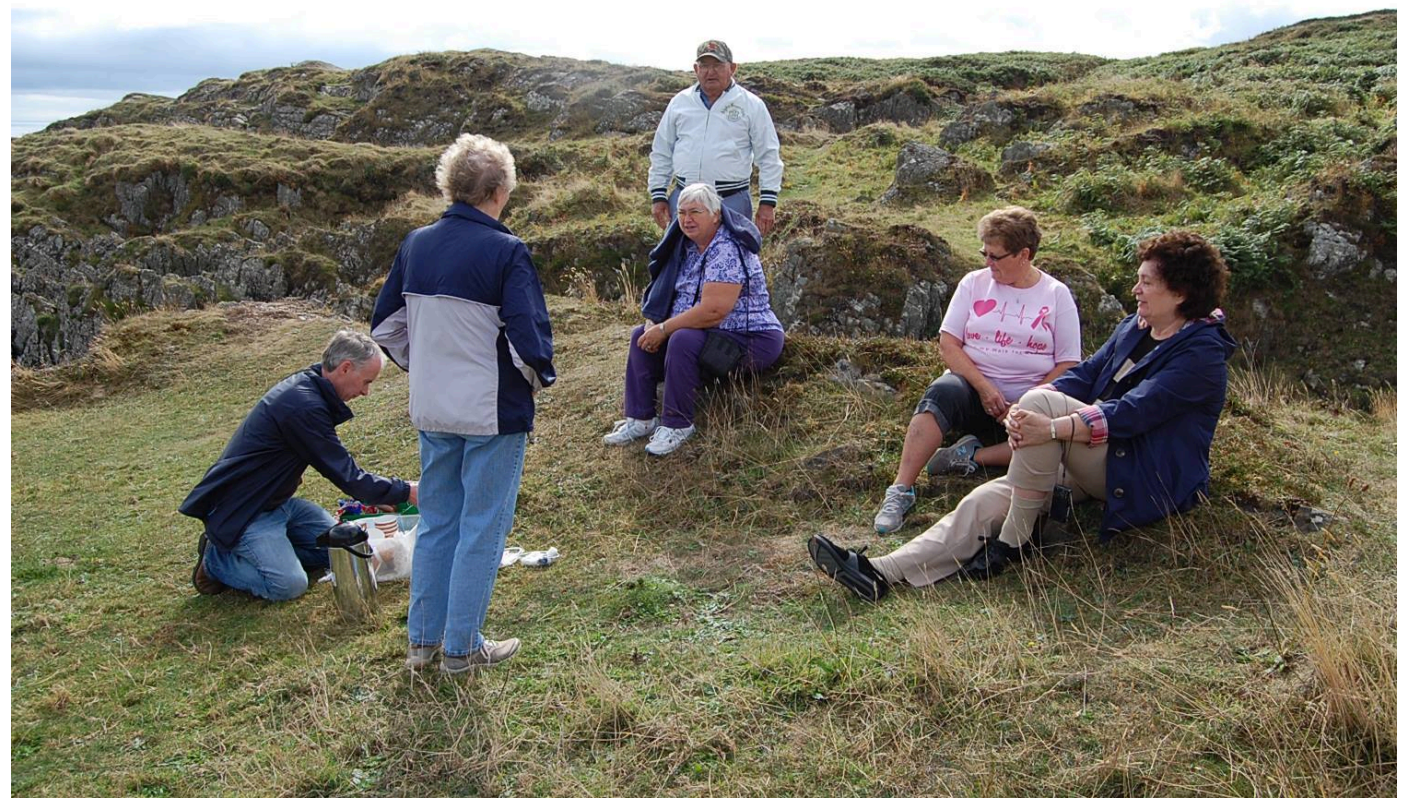

Photo 5: The 2013 CEOS Trip to Ireland members on the staircase in An Gríanan.

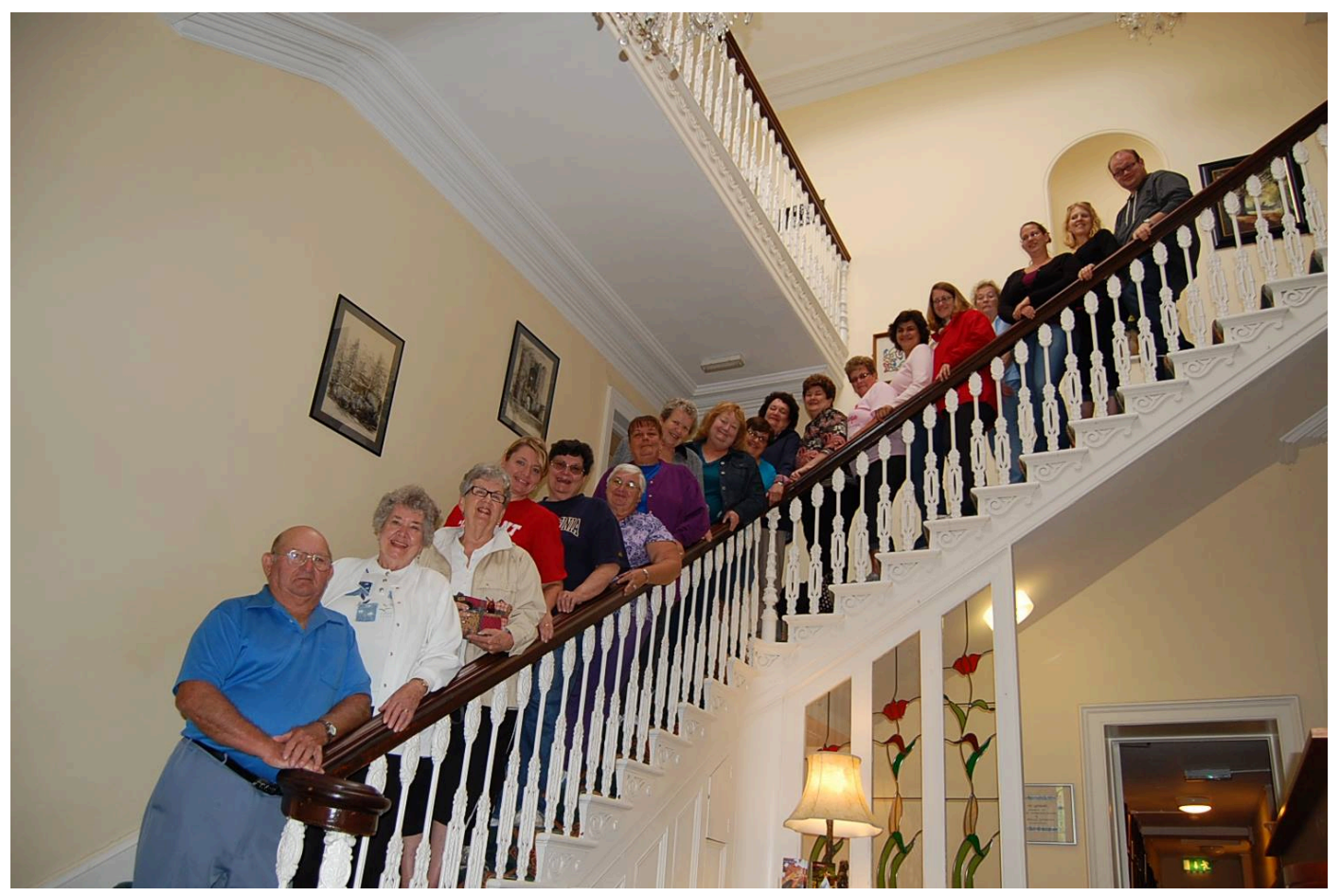




\section{Appendix E: Martha's Timeline Findings}

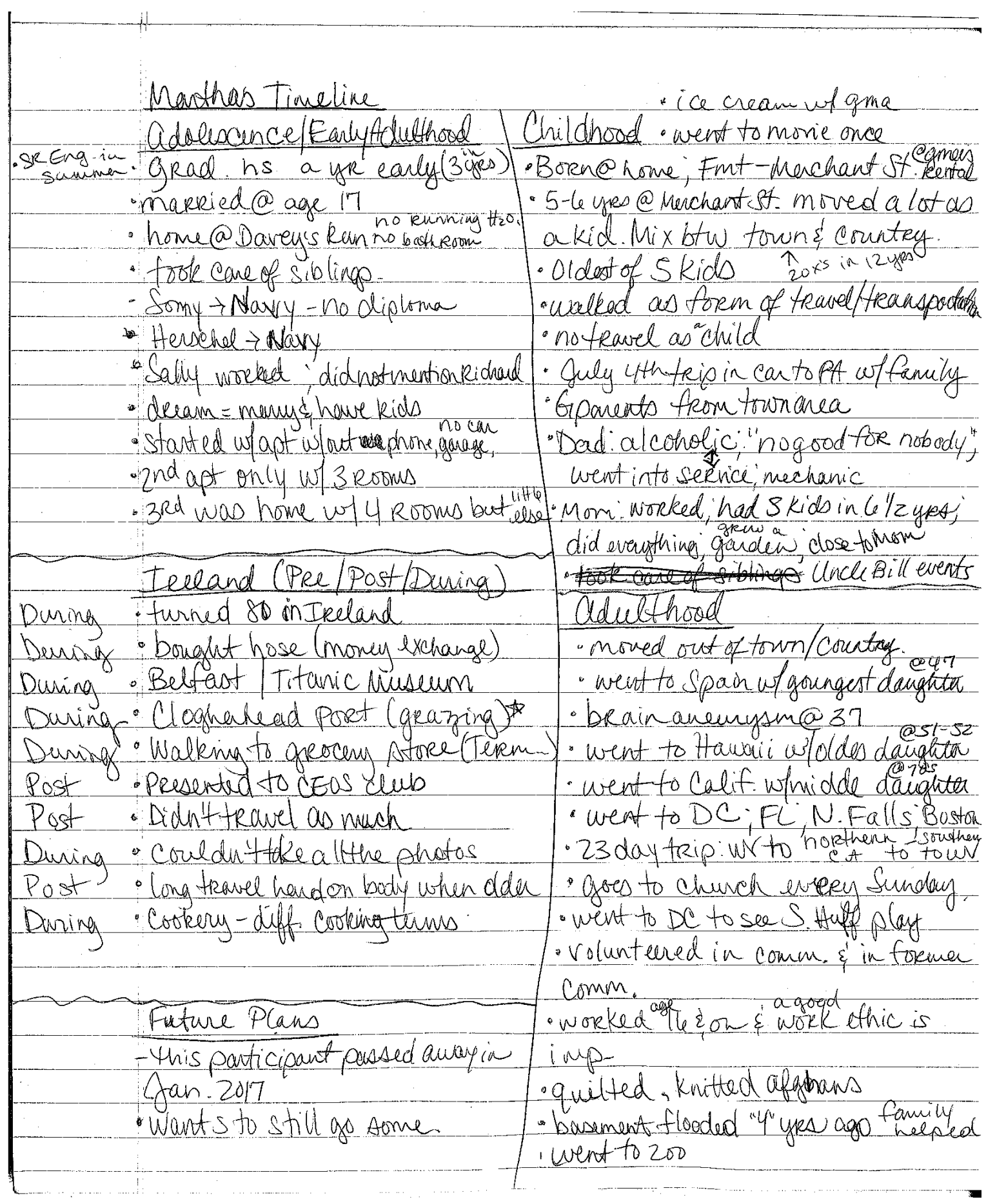




\section{Appendix F: David's Timeline Findings}

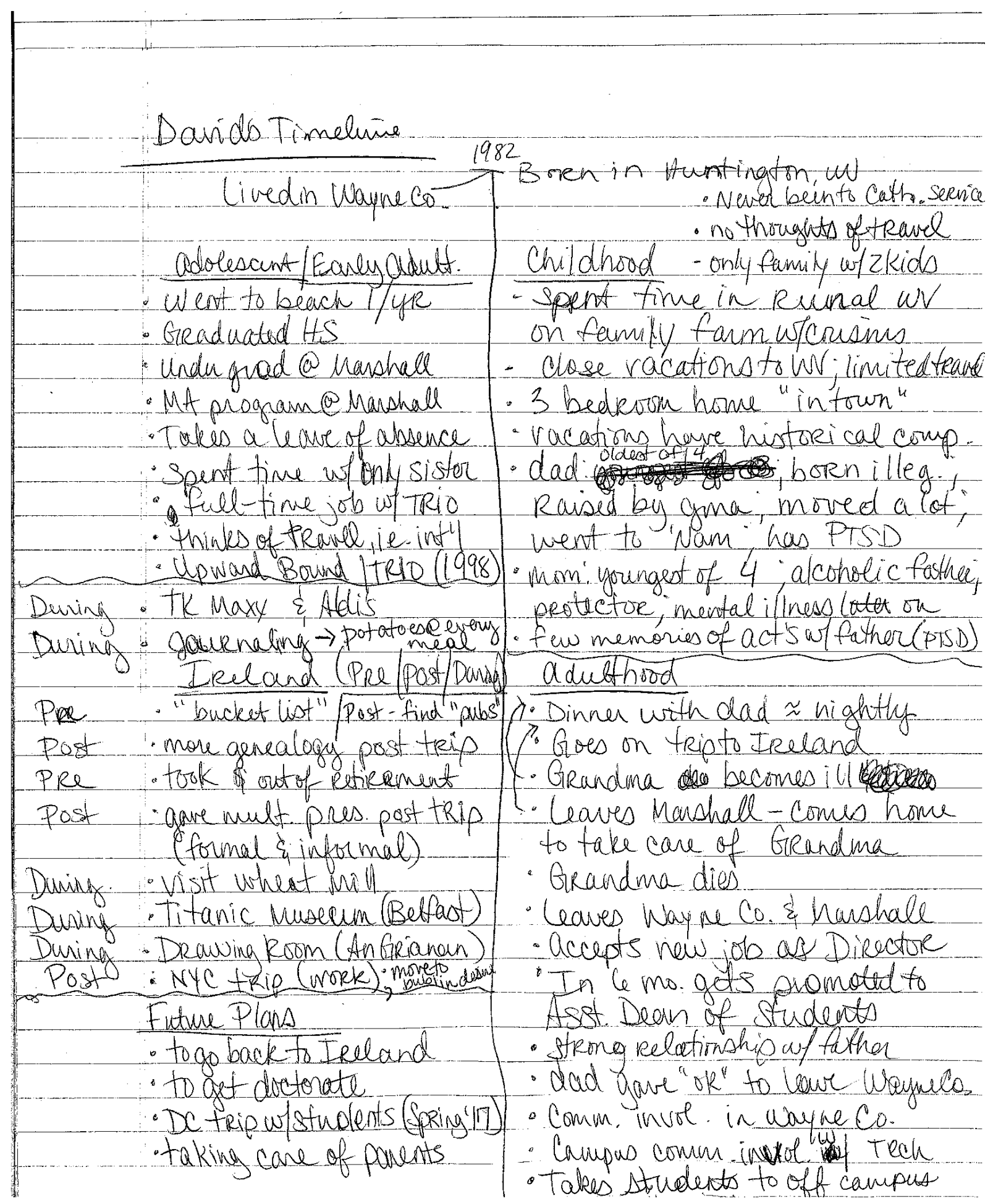




\section{Appendix G: Ruth's Timeline Findings}

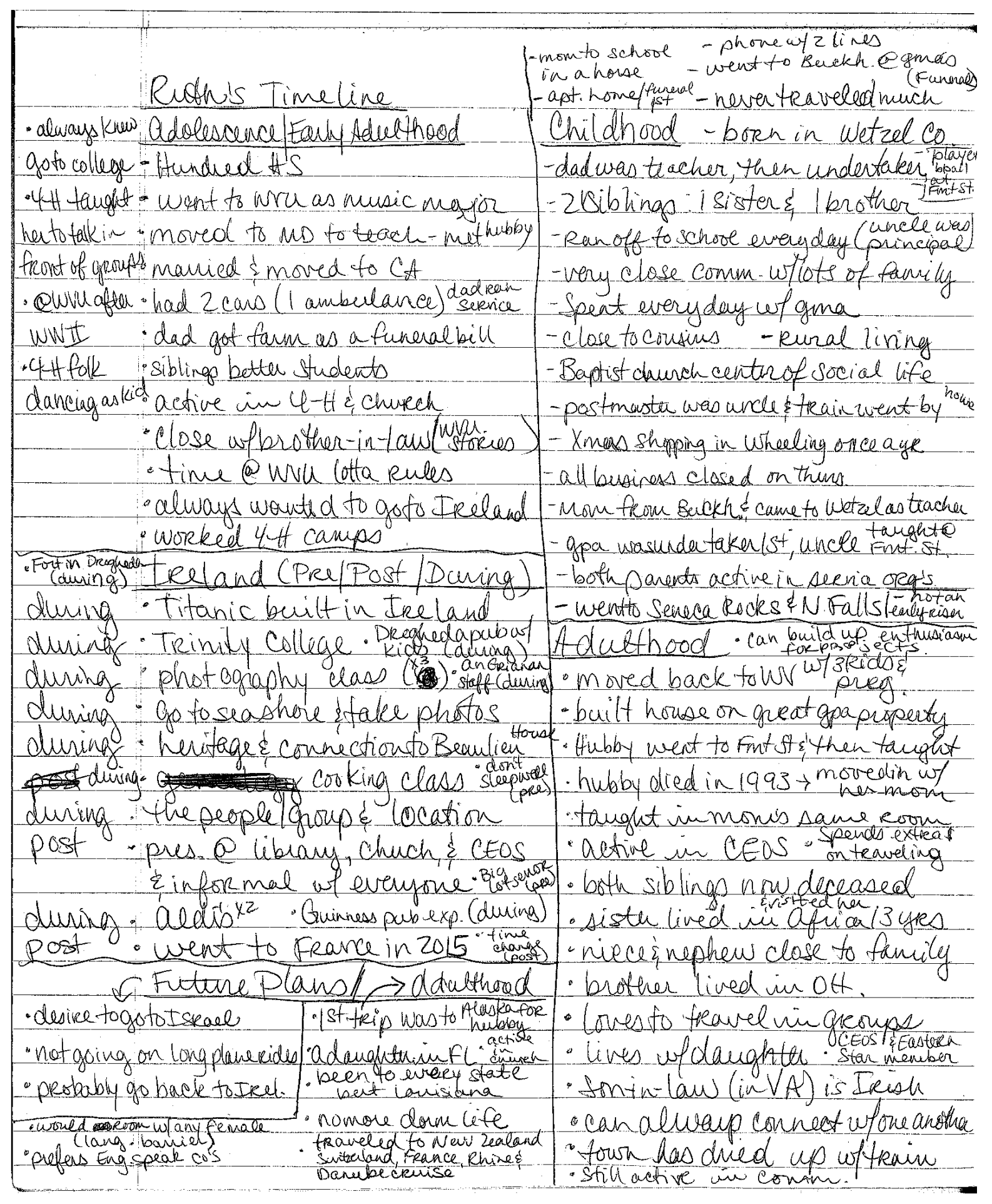




\section{Appendix H: Hannah's Timeline Findings}

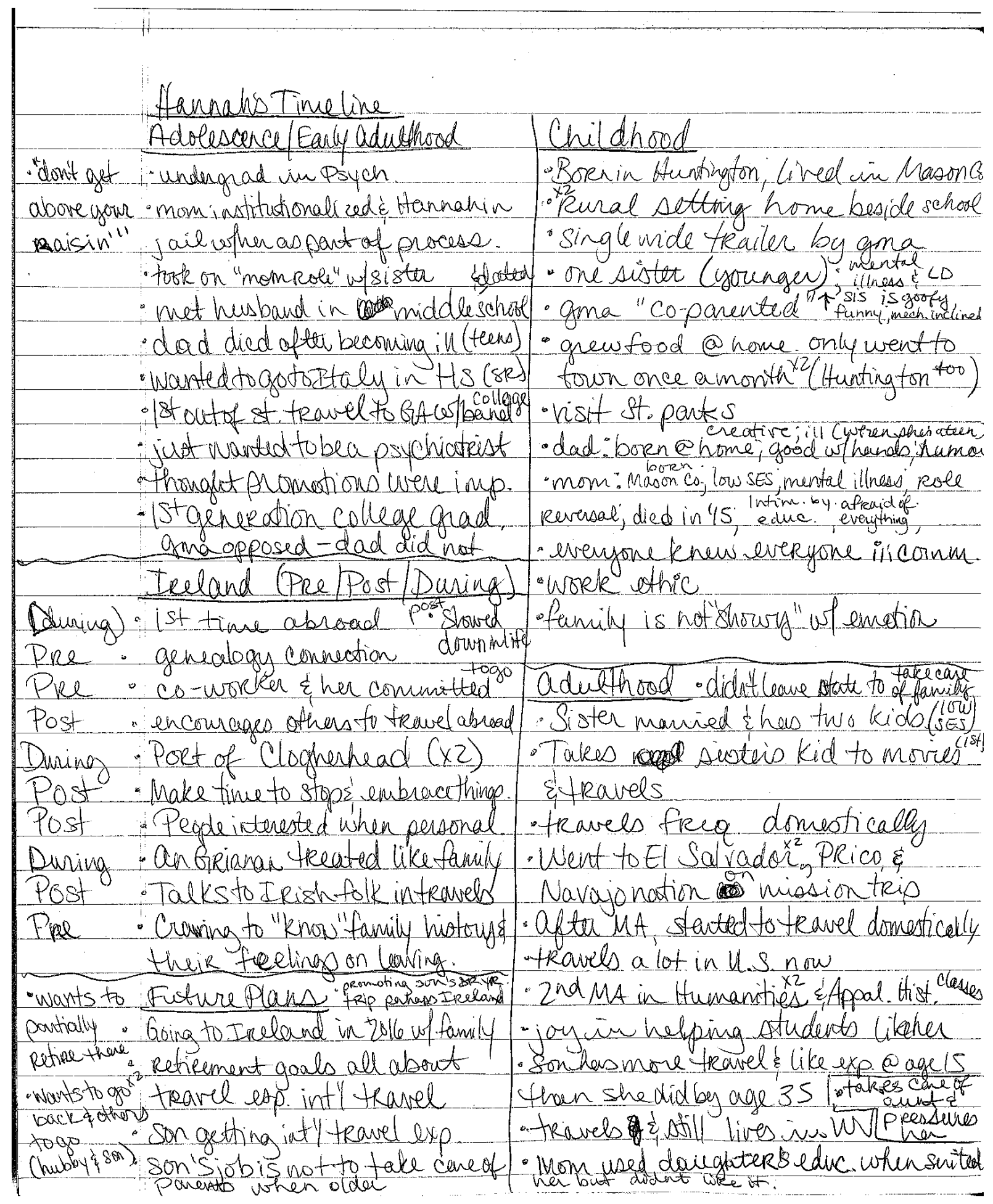




\section{Appendix I: Rebekah's Timeline Findings}

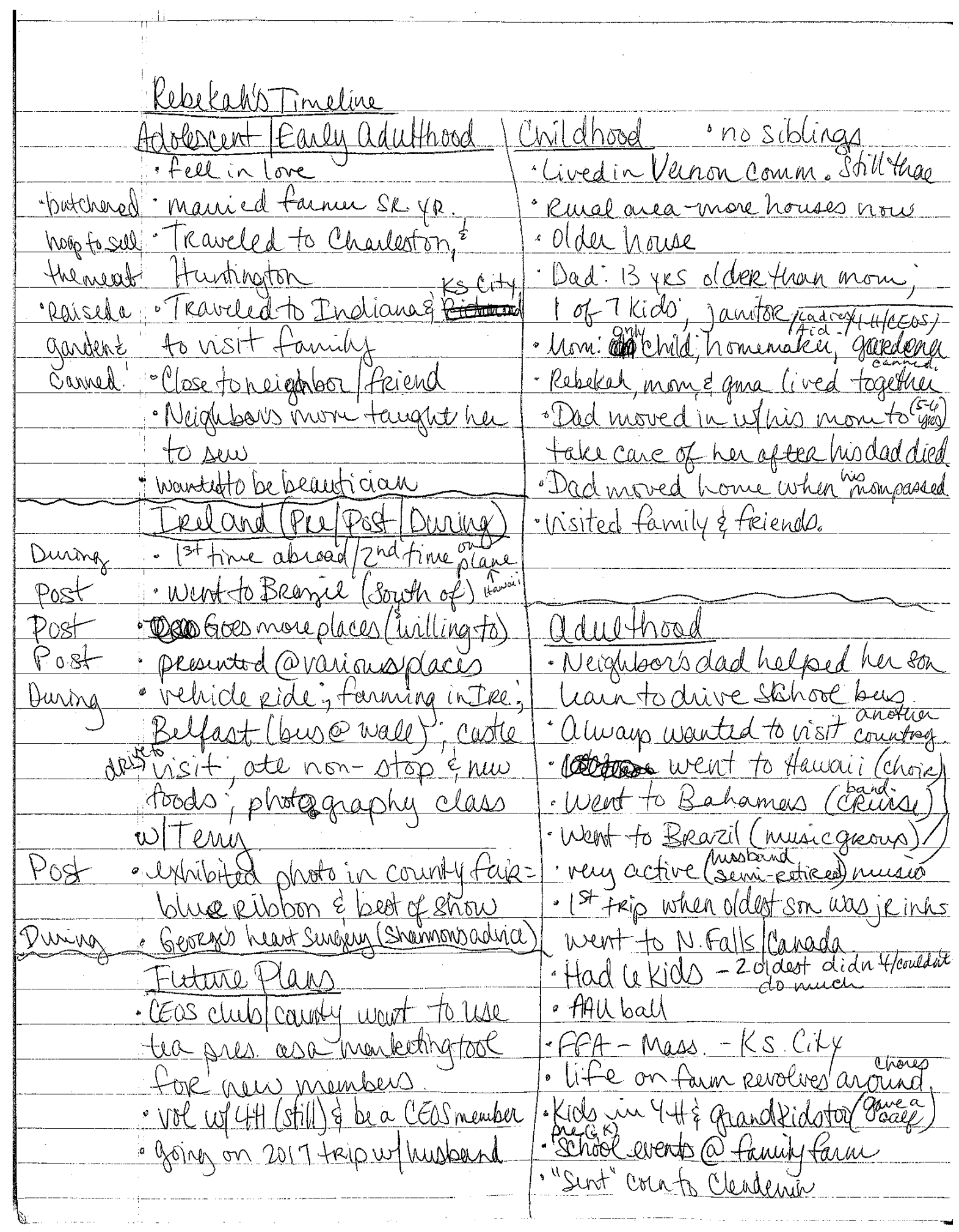


Appendix J: Content Analysis Example from Martha

\begin{tabular}{|c|c|c|c|c|c|}
\hline $\begin{array}{c}\text { Type of } \\
\text { Experience }\end{array}$ & $\begin{array}{l}\text { Type of } \\
\text { Event }\end{array}$ & $\begin{array}{c}\text { Category of } \\
\text { Event }\end{array}$ & $\begin{array}{l}\text { Effect of } \\
\text { Event }\end{array}$ & $\begin{array}{l}\text { Influences } \\
\text { on life } \\
\text { stories }\end{array}$ & $\begin{array}{l}\text { Memoing/ } \\
\text { Notes to } \\
\text { Consider }\end{array}$ \\
\hline $\begin{array}{l}\text { Intercultural } \\
\text { Education - } \\
\text { Martha }\end{array}$ & Planning & $\begin{array}{l}\text { Port of } \\
\text { Clogherhead }\end{array}$ & $\begin{array}{l}\text { Reminiscing } \\
\text { of the } \\
\text { activity }\end{array}$ & $\begin{array}{l}\text { Water and } \\
\text { cows } \\
\text { grazing on a } \\
\text { big hill }\end{array}$ & $\begin{array}{l}\text { Did not } \\
\text { remember } \\
\text { "hopping the } \\
\text { fence" to get } \\
\text { into the } \\
\text { pasture field }\end{array}$ \\
\hline $\begin{array}{l}\text { Intercultural } \\
\text { Education - } \\
\text { Martha }\end{array}$ & Other & $\begin{array}{l}\text { Vehicle } \\
\text { transportation } \\
\text { in Ireland }\end{array}$ & $\begin{array}{l}\text { Differences } \\
\text { between } \\
\text { cultures }\end{array}$ & $\begin{array}{l}\text { Roads were } \\
\text { smaller and } \\
\text { not clear } \\
\text { along sides } \\
\text { (safety } \\
\text { concern) }\end{array}$ & $\begin{array}{l}\text { Other } \\
\text { participants } \\
\text { have } \\
\text { mentioned this } \\
\text { concern }\end{array}$ \\
\hline $\begin{array}{l}\text { Intercultural } \\
\text { Education - } \\
\text { Martha }\end{array}$ & Other & $\begin{array}{l}\text { Walking as } \\
\text { transportation }\end{array}$ & $\begin{array}{l}\text { Differences } \\
\text { between } \\
\text { cultures }\end{array}$ & $\begin{array}{l}\text { People in } \\
\text { Ireland and } \\
\text { large cities } \\
\text { in US walk } \\
\text { faster and } \\
\text { more than } \\
\text { people in } \\
\text { WV }\end{array}$ & $\begin{array}{l}\text { Is this rural vs } \\
\text { urban? }\end{array}$ \\
\hline $\begin{array}{l}\text { Intercultural } \\
\text { Education - } \\
\text { Martha }\end{array}$ & Teaching & $\begin{array}{l}\text { Differences in } \\
\text { language }\end{array}$ & $\begin{array}{l}\text { Recognition } \\
\text { of language }\end{array}$ & $\begin{array}{l}\text { They use } \\
\text { different } \\
\text { terms with } \\
\text { cooking }\end{array}$ & $\begin{array}{l}\text { Has difficulty } \\
\text { expressing } \\
\text { herself with } \\
\text { American } \\
\text { terminology }\end{array}$ \\
\hline $\begin{array}{l}\text { Intercultural } \\
\text { Education - } \\
\text { Martha }\end{array}$ & Reflection & $\begin{array}{l}\text { Lack of } \\
\text { gardens }\end{array}$ & $\begin{array}{l}\text { Differences } \\
\text { between } \\
\text { cultures }\end{array}$ & $\begin{array}{l}\text { DMIS } \\
\text { Defense } \\
\text { (Superiority) } \\
\text { - you see } \\
\text { gardens in } \\
\text { WV and US }\end{array}$ & $\begin{array}{l}\text { gardens }= \\
\text { food and } \\
\text { taking care of } \\
\text { your own }\end{array}$ \\
\hline
\end{tabular}


Appendix K: Content Analysis Example from Hannah

\begin{tabular}{|c|c|c|c|c|c|}
\hline $\begin{array}{c}\text { Type of } \\
\text { Experience }\end{array}$ & $\begin{array}{l}\text { Type of } \\
\text { Event }\end{array}$ & $\begin{array}{c}\text { Category of } \\
\text { Event }\end{array}$ & $\begin{array}{l}\text { Effect of } \\
\text { Event }\end{array}$ & $\begin{array}{l}\text { Influences } \\
\text { on life } \\
\text { stories }\end{array}$ & $\begin{array}{l}\text { Memoing/ } \\
\text { Notes to } \\
\text { Consider }\end{array}$ \\
\hline $\begin{array}{l}\text { Mulitcultural } \\
\text { Education - } \\
\text { Hannah }\end{array}$ & $\begin{array}{l}\text { Peer } \\
\text { Teaching/ } \\
\text { Facilitating }\end{array}$ & $\begin{array}{l}\text { Multiple } \\
\text { presentations } \\
\text { at home }\end{array}$ & $\begin{array}{l}\text { Sharing of } \\
\text { experience }\end{array}$ & $\begin{array}{l}\text { Talked to } \\
\text { anyone who } \\
\text { would listen }\end{array}$ & $\begin{array}{l}\text { General } \\
\text { knowledge } \\
\text { gained }\end{array}$ \\
\hline $\begin{array}{l}\text { Mulitcultural } \\
\text { Education - } \\
\text { Hannah }\end{array}$ & $\begin{array}{l}\text { Peer } \\
\text { Teaching/ } \\
\text { Facilitating }\end{array}$ & $\begin{array}{l}\text { Make a } \\
\text { personal } \\
\text { connection }\end{array}$ & $\begin{array}{l}\text { Sharing of } \\
\text { experience }\end{array}$ & $\begin{array}{l}\text { Those } \\
\text { interested } \\
\text { want to } \\
\text { know more } \\
\end{array}$ & $\begin{array}{l}\text { General } \\
\text { knowledge } \\
\text { gained }\end{array}$ \\
\hline $\begin{array}{l}\text { Progressive } \\
\text { Education - } \\
\text { Hannah }\end{array}$ & Teaching & $\begin{array}{l}\text { Photography } \\
\text { class }\end{array}$ & $\begin{array}{l}\text { Desire to } \\
\text { learn digital } \\
\text { photography }\end{array}$ & $\begin{array}{l}\text { Has a } 35 \mathrm{~mm} \\
\text { camera and } \\
\text { chose not to } \\
\text { take the } \\
\text { digital } \\
\text { photography } \\
\text { class }\end{array}$ & $\begin{array}{l}\text { Didn't know if } \\
\text { she could } \\
\text { have learned } \\
\text { that quickly, } \\
\text { so she did not } \\
\text { take very } \\
\text { many pictures }\end{array}$ \\
\hline $\begin{array}{l}\text { Progressive } \\
\text { Education - } \\
\text { Hannah }\end{array}$ & Teaching & $\begin{array}{l}\text { Photography } \\
\text { class }\end{array}$ & $\begin{array}{l}\text { Desire to } \\
\text { learn digital } \\
\text { photography }\end{array}$ & $\begin{array}{l}\text { Could not } \\
\text { take pictures } \\
\text { like the kids } \\
\text { could }\end{array}$ & $\begin{array}{l}\text { Did enjoy } \\
\text { taking the few } \\
\text { that she did }\end{array}$ \\
\hline $\begin{array}{l}\text { Life Story - } \\
\text { Hannah }\end{array}$ & Reflection & Rural Living & $\begin{array}{l}\text { Knew all in } \\
\text { neighborhood }\end{array}$ & $\begin{array}{l}\text { Surrounded } \\
\text { by pasture } \\
\text { fields, cattle, } \\
\text { and tobacco } \\
\text { with school } \\
\text { next door }\end{array}$ & Comfort zone \\
\hline $\begin{array}{l}\text { Life Story - } \\
\text { Hannah }\end{array}$ & Reflection & $\begin{array}{l}\text { Low Socio- } \\
\text { economic } \\
\text { Status }\end{array}$ & $\begin{array}{l}\text { Space with } \\
\text { family of } 4 \\
\text { was limited }\end{array}$ & $\begin{array}{l}\text { All the } \\
\text { family could } \\
\text { afford }\end{array}$ & $\begin{array}{l}\text { Lived on } \\
\text { grandmother's } \\
\text { property }\end{array}$ \\
\hline $\begin{array}{l}\text { Life Story - } \\
\text { Hannah }\end{array}$ & Reflection & Co-Parenting & $\begin{array}{l}\text { Grandmother } \\
\text { lived next } \\
\text { door }\end{array}$ & $\begin{array}{l}\text { Grandmother } \\
\text { helped raise } \\
\text { her }\end{array}$ & $\begin{array}{l}\text { Connect to } \\
\text { other } \\
\text { participants' } \\
\text { co-parenting }\end{array}$ \\
\hline $\begin{array}{l}\text { Life Story - } \\
\text { Hannah }\end{array}$ & Reflection & $\begin{array}{l}\text { Family } \\
\text { garden }\end{array}$ & $\begin{array}{l}\text { Raised a } \\
\text { vegetable } \\
\text { garden for } \\
\text { food for } \\
\text { family }\end{array}$ & $\begin{array}{l}\text { We grew a } \\
\text { lot of our } \\
\text { foods we } \\
\text { didn't have } \\
\text { to go to the } \\
\text { grocery store } \\
\text { often }\end{array}$ & $\begin{array}{l}\text { Gardening for } \\
\text { survival }\end{array}$ \\
\hline
\end{tabular}


Appendix L: Critical Event Analysis Findings

\begin{tabular}{|c|c|c|c|c|}
\hline Critical & Progressive & Multicultural & Intercultural & Life Story \\
\hline Class -5 & Teaching -9 & Dialogue -1 & Dialogue -6 & Future Planning -1 \\
\hline Gender -0 & Planning -2 & Facilitating -4 & Other -16 & Planning -6 \\
\hline \multirow[t]{6}{*}{ Race -0} & Provocation - 1 & $\begin{array}{l}\text { Peer Teaching/ } \\
\text { Facilitating }-9\end{array}$ & $\begin{array}{l}\text { Peer Teaching/ } \\
\text { Facilitating }-4\end{array}$ & Reflection - 126 \\
\hline & & Provocation -8 & Planning -17 & \\
\hline & & Reflection - 5 & Provocation - 1 & \\
\hline & & $\begin{array}{l}\text { Relationship- } \\
\text { building - } 1\end{array}$ & Reflection - 14 & \\
\hline & & & $\begin{array}{l}\text { Relationship- } \\
\text { building - } 7\end{array}$ & \\
\hline & & & Teaching -2 & \\
\hline
\end{tabular}




\section{References}

Agar, M. \& Hobbs, J.R. (1982). Interpreting discourse: Coherence and the analysis of enthnographic interviews. Discourse Processes, 5, 1-32.

Alred, G., Byram, M., \& Fleming, M. (2003). Intercultural experience and education. Clevedon, England: Multilingual Matters.

American Heart Association, Prevention Research Center, West Virginia University Extension Service, \& West Virginia Library Commission. Library Television Network (Directors). (2006). Heart of the mountains: Real stories of hope and survival from real West Virginia women. [Motion picture on DVD]. Library Television Network.

Amizade Global Service-Learning (2013). History. Retrieved from https://amizade.org/about/history/.

Andrews, M., Squire, C., Tamboukou, M. (2013). Doing narrative research. Thousand Oaks, CA: SAGE Publications, Inc.

Anglin, M. (2016). Toward a new politics of outrage and transformation: Placing Appalachia within the global political economy. Journal of Appalachian Studies. 22 (1), 51-56.

Appalachian Regional Commission. (2004). Households and families in Appalachia. Washington, DC: U.S.

Appalachian Regional Commission. (2014). The Appalachian region. Retrieved from http://www.arc.gov/appalachian_region/TheAppalachianRegion.asp.

Apple, M., Kenway, J., \& Singh, M. (2005). Globalizing education: Policies, pedagogies, \& politics. New York, NY: Peter Lang Publishing Inc.

Armfield, P. (2004). An examination of the relationship between students' interaction with host nationals while on study abroad and their development of intercultural sensitivity. 
(Thesis for M.-A. Degree) University of Florida.

Arnow, P. (1987). Appalachian Veterans. Now and then: The Appalachian magazine, 4, 1-53.

Association of Public and Land-Grant Universities. (2012) The Land-Grant Tradition.

Washington, DC: Association of Public and Land-grant Universities.

Aydlett, L., Randolph, M. \& Wells, G. (2010). Project Panama: An International Service

Project. International Journal of Teaching and Learning in Higher Education, 22, 152157.

Banks, J. A. (1988). The stages of ethnicity: Implications for curriculum reform. In J. A. Banks, Multiethnic education: Theory and practice (2), 193-202. Boston: Allyn \& Bacon.

Banks, J. (2001). Citizenship education and diversity: Implications for teacher education. Journal of Teacher Education, 52(5), 5-16.

Bennett, C. (1986). Comprehensive multicultural education theory and practice. Boston, MA: Pearson Education, Inc.

Bennett, K. (1991). Wrenched from the earth: Appalachian women in conflict. In Kincheloe, J.L. \& Pinar, W.F (Eds.), Curriculum as social psychoanalysis: The significance of place. Albany, NY: SUNY.

Bennett, M.B. (2012). Spices around the world. Morgantown, WV. West Virginia University Extension Service 4-H Youth Development Department.

Bennett, M.J. (2004). Becoming interculturally competent. In Wurzel, J. (Ed.). Toward multiculturalism: A reader in multicultural education (2nd ed., pp. 62-77). Newton, MA: Intercultural Resource Corporation.

Bennett, M. J. (2013). Basic concepts of intercultural communication: Paradigms, principles, \& practice: Selected Readings. Boston, MA: Intercultural Press. 
Billings, D. \& Blee, K. (2000). The road to poverty: The making of wealth and hardship in Appalachia. New York, NY: Cambridge University Press.

Bolgiano, C. (2011). On becoming Appalachian. Appalachian Journal, 38(2), 164-168.

Borders, J. (2011, February 27). Fairmont Field Club begins new chapter. The Times West Virginian. Retrieved from http://www.timeswv.com

Bourke, R. \& Burns, J. (1998, June). The chameleonic learner: The effect of multiple contexts on students' conceptions and experiences of learning. Paper presented at the meetings of the International Society for Cultural Research and Activity Theory, Aarhus, Denmark.

Boyd, B., Giebler, C., Hince, M., Liu, Y., Mehta, N., Rash, R., . . Yanta, Y. (2001). Does study abroad make a difference? An impact assessment of the International 4-H Youth Exchange program. Journal of Extension, 39.

Brislin, R. W. (1981). The benefits of close intercultural relationships. In S. H. Irvine, \& J. W. Berry (Eds.), Human assessment and cultural factors. New York, NY: Plenum Press.

British Broadcasting Corporation (2017, September 12). Christianity in England. Retrieved from http://www.bbc.co.uk/religion/religions/christianity/history/uk_1.shtml\#h3

Brookfield, S. (1991). Using critical incidents to explore assumptions. In J. Mezirow and Associates (Eds.), Fostering Critical Reflection in Adulthood. San Francisco, CA: JosseyBass.

Brown v. Board of Education, 347 U.S. 483 (1954).

Bunting, M. (2009, June 28). Market dogma is exposed as myth. Where is the new vision to unite us? The Guardian.

Childs, A. W., \& Melton G. B. (Eds.) (1983). Rural psychology. New York: Plenum. 
Clandinin, D. (2006). Narrative inquiry: A methodology for studying lived experience. Research Studies in Music Education, 27 (1), 44-54.

Clandinin, D. \& Connelly, F. (1989). Narrative and story in practice and research. In D. Schon (Ed.), The Reflective turn: Case studies of reflective practice. New York, NY: Teachers College Press.

Clandinin, D. J., \& Connelly, F. M. (1994). Personal experience methods. In N. K. Denzin, \& Y. S. Lincoln (Eds.), Handbook of qualitative research (pp. 413-427). Thousand Oaks, CA: Sage.

Clandinin, D. \& Connelly, F. (2000). Narrative inquiry: Experience and story in qualitative research. San Francisco, CA: Jossey-Bass.

Coburn, A., MacKinney, C., McBride, T., Mueller, K., Slifkin, R., \& Wakefield, M. (2007). Understanding the impacts of the medicare modernization act: Concerns of congressional staff. Journal of Rural Health, 21(3), 194-197.

Coers, N., Rodriguez, M.T., Roberts, T.G., Emerson, H.C., \& Barrick, R.K. (2012). Examining the student impacts of three international capstone experiences. NACTA Journal, 56(2), $55-62$.

Conle, C., Blanchard, D., \& Burton, K. (2000). The asset of cultural pluralism: An account of cross-cultural learning in pre-service teacher education. Teaching and Teacher Education, 16(3), 365-387.

Connelly, F. M., \& Clandinin, D. J. (1990). Stories of experience and narrative inquiry. Educational Researcher, 19(5), 2-14.

Crabtree, R. (2008). Theoretical foundations for international service-learning. Michigan Journal of Community Service Learning, 15, 18-36. 
Crabtree, R. (2013). The intended and unintended consequences of international service-learning. Michigan Journal of Higher Education Outreach and Engagement, 17, 43-65.

Craig, C. (2004). The dragon in school backyards: The influence of mandated testing on school contexts and educators' narrative knowing. The Teachers College Record, 106(6), 12291257.

Craig, C. (2007). Story constellations: A narrative approach to contextualizing teachers' knowledge of school reform. Teaching and Teacher Education, 23(2), 173-188.

Crissman, J. (1989). Family type and familism in contemporary Appalachia. Southern Rural Sociology, 6, 29-44.

Cross, W. E., Jr. (1995). The psychoIogy of nigrescence: Revising the Cross model. In J. G. Ponterotto, J: M. Casas, L. A. Suzuki, \& C. M. Alexander (Eds.), Handbook of multicultural counseling, (93-121). Newbury Park, CA: Sage.

Crotty, M. (1998). The foundations of social research: Meaning and perspective in the research process. Thousand Oaks, CA: Sage Publications.

Cruz, B. C. \& Patterson, J. (2005). Cross-cultural simulations in teacher education: Developing empathy and understanding. Multicultural Perspectives, 7(2), 40-47.

Dantas, M. L. (2007). Building teacher competency to work with diverse learners in the context of international education. Teacher Education Quarterly, 34(1), 75-94.

Delgado-Gaitan, C. (2001). The power of community: Mobilizing for family and schooling. Lanham, MD: Rowman \& Littlefield Publishers, Inc.

Denzin, N. \& Lincoln Y. (1998). Strategies of Qualitative Inquiry. Thousand Oaks, CA: Sage Publications.

Dewey, J. (1927). The public and its problems. In J.A. Boydston (Ed.), The collective works of 
John Dewey: The later works, 1925-1953. Carbondale, IL: Southern Illinois University Press.

Dewey, J. (1938). Education and experience. New York: Collier Books.

Dewey, J. (1944). Democracy and education. New York, NY: The Free Press.

Diao, W., Freed, B. \& Smith, L. (2011). Confirmed beliefs or false assumptions? A study of home stay experiences in the French study abroad context. Frontiers: The Interdisciplinary Journal of Study Abroad, 21, 109-142.

Dollard, J. (1949). Criteria for the life history. Magnolia, MA: Peter Smith.

Donesky, F. (1999). America needs hillbillies. In D. B. Billings, G. Norman, and K. Ledford (Eds.), Confronting Appalachian stereotypes: Back talk from an American region (pp. 284-299). Lexington, KY: University of Kentucky Press.

Dorfman, L., Murty, S., Evans, R., Ingram, J. \& Power, J. (2004). History and identity in the narratives of rural elders. Journal of Aging Studies, 18. 187-203.

Echols, I., Gabel, C., Landerman, D., \& Reyes, M., (1988). "An Approach for Addressing Racism, Ethnocentrism, and Sexism in the Curriculum," in C. Jacobs \& D. Bowles (Eds.), Ethnicity and Race. Silver Spring, MD: National Association of Social Workers. Economic Research Service of the United States Department of Agriculture. (2013, December 30). What is Rural? Retrieved from http://www.ers.usda.gov/topics/rural-economypopulation/rural-classifications/what-is-rural.aspx

Elliott, D. (2006, May 27). Tall tales from West Virginia’s top 'liars'. National Public Radio. Podcast retrieved from http://www.npr.org/templates/story/story.php?storyId=5435852.

Ellsworth, E. (2005). Places of learning. New York, NY: Routledge Falmer.

Encyclopedia of Appalachia (2012). Celtic Influences. Retrieved from 
encyclopediaofappalachia.com/entry.php?rec $=50$

Erickson, E.H. (1968). Identity: Youth and crisis. New York: Norton.

Etling, A. \& Barbuto, J. (2002). Proceedings from Association for International Agricultural and Extension Education $18^{\text {th }}$ Annual Conference: Globalizing Colleges of Agriculture. Durban, South Africa: AIAEE.

Farrell, P. \& Suvedi, M. (2002). Proceedings from Association for International Agricultural and Extension Education $18^{\text {th }}$ Annual Conference. Studying Abroad in Nepal: Understanding Impact on Student's Lives, Durban, South Africa: AIAEE.

Fenwick, T. \& Tennant, M. (2004). Understanding Adult Learners. In Foley, G., (Ed.), Dimensions of Adult Learning. Columbus, OH: Open University Press.

Fessler, P. (2014, January 18). In Appalachia, poverty is in the eye of the beholder. National Public Radio. Podcast retrieved from http://www.npr.org/2014/01/18/263629452/inappalachia-poverty-is-in-the-eye-of-the-beholder.

Fiene, J. (1988). The social reality of a group of rural, low-status Appalachian women: A grounded theory study. (Doctoral Dissertation). Knoxville, TN: University of Tennessee.

Fraser, J. (2010). The school in the United States: A documentary history. New York, NY: Routledge.

Freire, P. (1970). Pedagogy of the oppressed. New York: Continuum International Publishing Group.

Frost, N. (2011). Qualitative research methods in psychology. Berkshire, GBR: McGraw-Hill Education.

Gareis, E. (1995). Intercultural friendship: A qualitative study. Lanham, MD: University Press of America. 
Garrison, M., Pierce, S., Monroe, P., Sasser, D., Shaffer, A. \& Blalock, L. (1999). Focus group discussions: Three examples from family and consumer science research. Family and Consumer Sciences Research Journal, 27, 428-450.

Gay, G. (2000). Culturally responsive teaching: Theory, research, \& practice. New York, NY: Teachers College Press.

Geiger, R. \& Sorber, N. (2013). The land-grant colleges and reshaping of American higher education. New Brunswick, NJ: Transaction Publishers.

Gemma Ferranto, M.L. (2013). An interpretive qualitative study of baccalaureate nursing students following and eight-day international cultural experience in Tanzania. (Unpublished doctoral dissertation). Kent State University, Ohio.

Giroux, H.A. (1981). Schooling and the myth of objectivity: Stalking the hidden curriculum," McGill Journal of Education, 17, 282-304.

Goodson, I.F. (2013). Developing narrative theory: life histories and personal presentations. New York, NY: Routledge.

Goodson, I.F. \& Gill, S. (2011). Narrative pedagogy. New York, NY: Peter Lang.

Goodson, I.F. \& Sikes, P. (2001). Life history research in educational settings: Learning from lives. Philadelphia, PA: Open University Press.

Grassie, W. (2008). Entangled narratives: Competing visions of the good life. Paper presented at a symposium of the US-Sri Lankan Fulbright Commission in Colombo, January 4, 2008.

Green, S. S., Comer, L., Elliott, L., \& Neubrander, J. (2011). Exploring the value of an international service-learning experience in Honduras. Nursing Education Perspectives, $32(5), 302-307$.

Grossman, P. (1992). Why models matter: An alternative view on professional growth in 
teaching. Review of Educational Research, 62, 171-179.

Hadis, B. F. (2005). Why are they better students when they come back? Determinants of academic focusing gains in the study abroad experience. Frontiers: The Interdisciplinary Journal of Study Abroad, 11, 57-70.

Harriman, L. \& Daughtery, R. (1992). Staffing extension for the $21^{\text {st }}$ century. Journal of Extension, 30(4).

Hazen, K. (2014) 'A new role for an ancient variable in Appalachia: Paradigm leveling and standardization in West Virginia', Language Variation and Change, 26(1), 77-102.

Headlee, K., Hovatter, D., Mulkeen, P., Pruett, B., \& Waugh, T. (1998). A journey begun...4-H Charting. (WVUES Publication No. 4-H-M-3111-98). Morgantown, WV. West Virginia University Extension Service 4-H Youth Development Department.

Howley, C.B., \& Howley, A. (2010). Poverty and school achievement in rural communities: A social-class interpretation. In K.A. Schafft and A.Y. Jackson (Eds.), Rural education for the twenty-first century: Identity, place, and community in a globalizing world (pp. 3450). University Park, PA: The Pennsylvania State University Press.

IFYE Association of the USA, Inc. (2013, Nov 3). A short history of the IFYE association of the USA, inc. Retrieved from http://ifyeusa.org/

Jackiewicz, E. (2006). Community-centered globalization: Modernization under control in rural Costa Rica. Latin American Perspectives, 33(6). 136-146.

Jehangir, R., Williams, R., \& Jeske, J. (2012). The influence of multicultural learning communities on the intrapersonal development of first-Generation college students. Journal of College Student Development, 53(2), 267-284.

Johnson, N. (Winter 1999). An African American landmark in Fayette County camp 
washington-carver. Goldenseal, 25(4), 56-63.

Johnston, P. (2012). Opening minds: Using language to change lives. Portland, ME: Stenhouse Publishers.

Josselson, R. (1995). Imaging the real: Empathy, narrative and the dialogic self, in R. Josselson and A. Lieblich (eds) Interpreting Experience, p.27-44. Thousand Oaks, CA: Sage Publications.

Kane, L. \& Kiersz, A. (2015 April 2). How much you have to earn to be considered middle class in every US State. Retrieved from http://www.businessinsider.com/middle-class-in-everyus-state-2015-4.

Kincheloe, J.L. \& Pinar, W.F. (1991). Curriculum as social psychoanalysis: The significance of place. Albany, NY: SUNY.

Kleis, J., Lang, L., Mietus, J.R. \& Tiapula, F.T.S. (1973). Toward a contextual definition of non-formal education. Non-formal education discussion papers, East Lansing, MI: Michigan State University.

Kolb, D. (2015) Experiential learning: Experience as the source of learning and development. Upper Saddle River, NJ: Pearson Education, Inc.

Koro-Ljungberg, M. (2008). A social constructionist framing of the research interview. In Holstein, J. \& Gubrium, J. (Eds.). Handbook of constructionist research. (1st ed., pp. 429-444). New York, NY: The Guilford Press.

Kotz, D. (2003). Neoliberalism and the US economic expansion of the 1990s. Monthly Review. $54(11), 15-33$.

Kvale, S. \& Brinkmann, S. (2009). Interviews. Learning the Craft of Qualitative Research Interviewing. Thousand Oaks, CA: SAGE Publications, Inc. 
Latimer, M., \& Oberhauser, A. M. (2004). Exploring gender and economic development in Appalachia. Journal of Appalachian Studies, 10(3), 269-291.

Lash, M. (2016). Proceedings from RECE'16. White girls going global: Weaving color into the tapestry of teaching. Taupo, NZ.

Ledford, K. (1999). A landscape and a people set apart: Narratives of exploration and travel in early Appalachia. In D. B. Billings, G. Norman, and K. Ledford (Eds.), Confronting Appalachian stereotypes: Back talk from an American region (pp. 47-66). Lexington, KY: University of Kentucky Press.

Lee, L. (2012). Engaging Study Abroad Students in Intercultural Learning through Blogging and Ethnographic Interviews. Foreign Language Annals, 45(1), 7-21.

Lewis, R.L. (1998). Transforming the Appalachian countryside: Railroads, deforestation, and social change in West Virginia, 1880-1920. Chapel Hill, NC: University of North Carolina.

Lewis, R. L. (1999). Beyond isolation and homogeneity: Diversity and the history of Appalachia. In D. B. Billings, G. Norman, and K. Ledford (Eds.), Confronting Appalachian stereotypes: Back talk from an American region (pp. 21-43). Lexington, KY: University of Kentucky Press.

Lloyd, G. 2004). The man of reason: "Male" and "female” in Western Philosophy. London, UK: Routledge.

Locklear, E. A. (2011). Negotiating a perilous empowerment: Appalachian women's literacies. Athens, OH: Ohio University Press.

Lorber, J. (1994). "Night to his day": The social construction of gender. Paradoxes of Gender, 13-36. 
Luke, T., and Tuathail, G. (1998). “Global Flowmations, Local fundamentalisms, and fast geopolitics." In A. Herod, G. Tuathail, and S. Roberts (Eds.), Unruly World. Globalization, governance and geography. London, UK: Routledge.

Louisy, P. (2001). Globalisation and comparative education: A Caribbean perspective. Comparative Education, (37)4, 425-438.

Luttrell, W. (1997). School smart and mother-wise: Working class women's identity and schooling. New York, NY: Routledge.

Maharaja, G. (2009). An "island" study abroad program and its impact on the intercultural sensitivity and cross-cultural adaptability of its participants: Perspectives from a research intensive university. (Doctoral Dissertation) ProQuest LLC, 3365462.

Maloney, C. J. (2011). Back to the land: Arthurdale, FDR's New Deal, and the costs of economic planning. Hoboken, NJ: John Wiley \& Sons.

Marcum, C. (2008). Appalachian Cultural Awareness and Community Development. (WVUES Publication No. WLG 318). Morgantown, WV. West Virginia University Extension Service Families and Health Department.

Marnoogian, M., Jurich, J., Sano, Y., \& Ko (2015, February). My kids are more important than money: Parenting expectations and commitment among appalachian low-income mothers. Journal of Family Issues. (36), 326-350.

Maurer, B. (1980) Mountain Heritage. Parsons, WV: McClain Printing Company.

McAdams, D. (1996). Personality, modernity, and the storied self: A contemporary framework for studying persons. Psychological Inquiry, (7)4, 295-321.

McHenry-Sorber, E. \& Schafft, K. (2015). 'Make my day, shoot a teacher': Tactics of 
inclusion and exclusion, and the contestation of community in a rural school-community conflict. International Journal of Inclusive Education, 19(7), 733-747.

McHenry-Sorber, E., Schafft, K., Burfoot-Rochford, I., \& Hall, D. (2016). The masculinized work of energy development: Unequal opportunities and risks for women in Pennsylvania shale gas boomtown communities. Journal of Rural Social Sciences, 31(1), $1-23$.

Merriam, S.B. (1998). Qualitative Research and Case Study Applications in Education: Revised and Expanded from Case Study Research in Education. San Francisco, CA: Jossey-Bass.

Miller, K. \& Gonzalez, A. (2010). Domestic and international service learning experiences: A comparative study of pre-service teacher outcomes. Educational Research, 20(1), 29-38.

Montgomery, S. (2009). Why men left: Reconsidering the feminization of teaching in the nineteenth century. American Educational History Journal, 36(1), 219-236.

National 4-H Council (2013). 4-H history. Retrieved from http://www.4-h.org/about/4-h-history.

National 4-H Council (2015). 4-H Youth Development and Mentoring Programs. Retrieved from http://www.4-h.org/about/

National 4-H Council (2014). Growing a better future by investing in the youth of today. Chevy Chase, MD: National 4-H Council.

National 4-H Council (2013). The positive development of youth: Comprehensive findings from the 4-H study of positive youth development. Chevy Chase, MD: Lerner, R.M., Lerner, J.V. \& Colleagues.

National 4-H History Preservation Program (2013, July 23). Preserve 4-H history...the 
foundation of our future. Retrieved from http://4-hhistorypreservation.com/History/M-C$\mathrm{P}$

National Agricultural Library Rural Information Center of the United States Department of Agriculture. (2014, December 16). What is Rural? Retrieved from http://ric.nal.usda.gov/what-is-rural.

National Institute of Food and Agriculture (2009). National Initiative to Internationalize Extension. Retrieved from http://www.nifa.usda.gov/nea/international/in_focus/intl_if_internationalize.html

National Institute of Food and Agriculture (2015, August 22). International: Global Engagement and Global Food Security. Retrieved from http://nifa.usda.gov/topic/global-engagement National Parks and Wildlife Service (2017, September 12). Restrictions on Cutting Hedgerows. Retrieved from https://www.npws.ie/legislation/irish-law/restrictions-cutting-hedgerows.

Nieto, S. (1992). Affirming diversity: The sociopolitical context of multicultural education. New York, NY: Longman.

Olsen, S. (2005). County agents and university tenure and promotion systems. Journal of Extension, 43(3).

Pagano, M. \& Roselle, L. (2009). Beyond reflection through an academic lens: refraction and international experiential education. Frontiers: The Interdisciplinary Journal of Study Abroad, 18, 217-229.

Parham, T. A. (1989). Cycles of psychological nigrescence. The Counseling Psychologist, 17(2), 187-226.

Patterson, S. (2006). A new pattern of life: The public past and present of two New Deal communities. (Doctoral Dissertation) ProQuest LLC, 3243204. 
Pennington, B., \&Wildermuth, S. (2005). Three weeks there and back again: A qualitative investigation of the impact of short-term travel/study on the development of intercultural communication competency. Journal of Intercultural Communication Research, 34(3), 166-183.

Priceline. (2015, July 25). Flights. Retrieved from www.priceline.com

Quezada, R. L. (2005). “Beyond educational tourism:” Lessons learned while students teaching abroad. International Educational Journal, 5, 458-465.

Reed, J.S. (1982). One south: An ethnic approach to regional culture. Baton Rouge, LA: Louisiana State University Press.

Reighart, .\& Loadman, . 1984.

Reissman, C.K. (2003). Narrative Analysis. In M.S. Lewis-Beck, A. Bryman and T. Futing Liao (Eds.), The Sage Encyclopedia of Social Science Research Methods (pp. 1-6). Thousand Oaks, CA : Sage Publications.

Reissman, C.K. (2008). Narrative methods for the human sciences. Thousand Oaks, CA: Sage Publications.

Rexeisen, R., Anderson, P., Lawton, L., \& Hubbard, A. (2008, Fall). Study abroad and intercultural development: A longitudinal study. Frontiers: The Interdisciplinary Journal of Study Abroad, 17, 1-20.

Rios, F., Montecinos, C., \& van Olphen, M. (2007). Lessons learned from a collaborative selfstudy in international teacher education: Visiones, preguntas, y desafios. Teacher Education Quarterly, 34(1), 57-74.

Rogoff, B. (2003). The cultural nature of human development. New York, NY: Oxford University Press. 
Sachs, C. (2014). Gender, race, ethnicity, class, and sexuality in rural America. In C. Bailey, L. Jensen, and E. Ransom (Eds.), Rural America in a globalizing world: Problems and prospects for the 2010s. (pp. 421-434). Morgantown, WV: West Virginia University Press.

Sage, R., et. al. (2013). Safety in numbers: Are major cities the safest places in the United States? Annals of Emergency Medicine, 62, 408-418.

Saldaña, J. (2013). The coding manual for qualitative researchers. Thousand Oaks, CA: Sage Publications.

Savick, V., Adams, I., Wilde, A., \& Binder, F. (Winter 2008). Intercultural development: Topics and sequences. Frontiers: The Interdisciplinary Journal of Study Abroad, 15, 111-126.

Scholte, J. (2000). Globalization: A critical introduction. Houndmills, UK: Macmillan.

Shapiro, A. (2014, November 28). For northern Ireland, wounds From 'The Troubles' are still raw. National Public Radio. Retrieved from http://www.npr.org/sections/parallels/2014/ 11/28/367183005/for-northern-ireland-wounds-from-the-troubles-are-still-raw

Shapiro, H. (1978). Appalachia on our mind: The southern mountains and mountaineers in the American consciousness, 1870-1920. Chapel Hill, NC: University of North Carolina.

Sharma, S. (2009). From a red-dot-Indian woman to jet-set-mangoes and all the hyphens-inbetween: Studying abroad and discovering myself. Journal of Curriculum Theorizing, 25(3), 119-136.

Sharma, S. (2014). Internationalizing teacher education through study abroad: Crossing borders, building bridges, and raising consciousness toward social justice. In. S. Sharma, J. Phillion, J. Rahatzad, \& H. Sasser (Eds.), Internationalizing teacher education for social 
justice: Theory, research, and practice (pp. 171-192). Charlotte, NC: Information Age Publishing, Inc.

Sharma, S. \& Phillion, J. (2014). Introduction. In. S. Sharma, J. Phillion, J. Rahatzad, \& H. Sasser (Eds.), Internationalizing teacher education for social justice: Theory, research, and practice (pp. 171-192). Charlotte, NC: Information Age Publishing, Inc.

Shaw, K. (2012). People First Language. Florida Inclusion Network. Retrieved from http://www.floridainclusionnetwork.com/Uploads/1/docs/centers/CRSRL/FIN/Articles/ People\%20First\%20Language.pdf

Shenk, D. (1991). Older rural women as recipients and providers of social support. Journal of Aging Studies, 5, 347-358.

Shenk, D. (2002). Narratives and self-identity in later life: Two rural American older women. Journal of Aging Studies, 16. 401-413.

Sherman, J. 2009. Those Who Work, Those Who Don't: Poverty, Morality, and Family in Rural America. Minneapolis: University of Minnesota Press.

Shore, S. (2005). New policies, new possibilities? In M. Apple, J. Kenway, \& M. Singh (Eds.), Globalizing education: Policies, pedagogies, \& politics. New York, NY: Peter Lang Publishing Inc.

Shubert, A. (2008). "The pursuit of exotica:” a comment. Frontiers: The Interdisciplinary Journal of Study Abroad, 15, 197-201.

Slimbach, R. (2005). The transcultural journey. Frontiers: The Interdisciplinary Journal of Study Abroad, 11, 205-230.

Sohn, K. K. (2006). Whistlin' and crowin' women of Appalachia. Carbondale, IL: Southern Illinois University. 
Stachowski, L. L., \& Mahon, J. (1998). Cross-cultural field placements: Student teachers learning from schools and communities. Theory into Practice, 37, 155-162.

States 4-H International Exchange Programs. (2015, July 26). About us. Retrieved from http://www.states4hexchange.org/

Stevens, G., Smith, B., \& Downing, A. (2014). International study abroad experiences with agents and students: A case study in Belize. Journal of Extension, (52)1, 11 pgs.

Stewart, G. (1969). A touch of charisma. Morgantown, WV: West Virginia 4-H All Stars.

Struthers, C. (2014). The past is the present: Gender and the status of rural women. In C. Bailey, L. Jensen, and E. Ransom (Eds.), Rural America in a globalizing world: Problems and prospects for the 2010s. (pp. 489-505). Morgantown, WV: West Virginia University. Press.

Szreter, S. (2002) The state of social capital: Bringing back in power, politics, and history. Theory and Society, 31, 573-621.

Tamdgidi, M. (2011). The simultaneity of self- and global transformations: Bridging with Anzaldúa’s liberating vision. In A. Keating \& G. González-López (Eds.), Bridging: How Gloria Anzaldúa's life and work transformed our own (pp. 218-225). Austin, TX: University of Texas Press.

Taylor, C. (1989). Sources of the self: The making of the modern identity. Cambridge, MA: Harvard University Press.

Tesch, R. (1990). Qualitative Research: Analysis Types and Software Tools. London, GBR: Falmer Press.

Tennant, M. \& Pogson, P. (1995). Learning and change in adult years: A developmental perspective. San Francisco, CA: Jossey-Bass. 
Tickamyer, A.R. \& Tickamyer, C. (1991). Gender, family structure, and poverty in Central Appalachia. In B. Ergood \& B. E. Kuhre (Eds.), Appalachia: Social context past and present. Dubuque, IA: Kendall/Hunt.

Tritz, J., Dransfield, D., \& Scott, D. (2012). Irish and Scottish influences on Appalachia. (WVUES Publication No. WLG 524). Morgantown, WV. West Virginia University Extension Service Families and Health Department.

Troy, G. (1999, September 24). Prosperity doesn't age well. The New York Times.

United States Census Bureau. (2016, November 24). 2010 Census Urban and Rural Classification and Urban Area Criteria. Retrieved from http://www.census.gov/geo/reference/ua/urban-rural-2010.html

United Nations. (2017, September 22). Peace agreements as a means for promoting gender equality and ensuring participation of women - A framework of model provisions. Retrieved from http://www.un.org/womenwatch/daw/egm/peace2003/reports/ EP4NiAolain.PDF

Urban, W.J., \& Wagoner, Jr., J.L. (2009). American Education: a history. New York, NY: Routledge.

Urry, J. (1995). Consuming places. London, UK: Routledge.

Waks, L. (2010). John Dewey on listening in school and society. Paper presented at the Annual Conference of Society of Educational Philosophy, March 2010, Oxford.

Ward, N., and D. L. Brown. 2009. "Placing the Rural in Regional Development.” Regional Studies 43 (10): 1237-1244.

Webster, L. \& Mertova, P. 2007. Using narrative inquiry as a research method. New York, NY: Routledge. 
Wertz, F., Charmaz, K., McMullen, L., Josselson, R., Anderson, R., \& McSpadden, E. (2011) Five ways of doing qualitative analysis. New York, NY: The Guilford Press.

West Virginia University Department of Diversity, Equity and Inclusion (2012, April 26). Nondiscrimination statement. Retrieved from http://diversity.wvu.edu/policies/non_discrimination_statement

West Virginia University (2011, May 13). The history of West Virginia University. Retrieved from http://about.wvu.edu/history/presidents.

West Virginia University (2014, December 22). WVU 2020 strategic plan for the future.

Retrieved from http://strategicplan.wvu.edu.

West Virginia University Extension Service Community, Economic, \& Workforce Development Program Unit (2014, December 28). Community resources and economic development. Retrieved from http://cred.ext.wvu.edu.

West Virginia University Extension Service Community Educational Outreach Service (2014, December 28). CEOS-at-glance. Retrieved from http://ceos.ext.wvu.edu.

Wheeler, R. (2014). Mining memories in a rural community: Landscape, temporality, and place identity. Journal of Rural Studies, 36, 22-32.

Whisnet, D. E. (1983). All that is native and fine: The politics of culture in an American region. Chapel Hill, NC: University of North Carolina Press.

Williams, M.E., Lawrence, L.D., Gartin, S.A., Smith, D., \& Odell, K.S. (2002). Evaluation of the International 4-H Youth Exchange (IFYE) program. Journal of International Agricultural and Extension Education, 9, 57-64.

Williamson, J.W. (1977). On the naming of Appalachia. An Appalachian symposium: 
Essays written in honor of Cratis D. Williams. Boone, NC: Appalachian State University Press.

Woods, M. (2011). Rural. London, UK: Routledge.

World Population Statistics (2015, July 25). World population 2014. Retrieved from: http://www.worldpopulationstatistics.com/world-population-2014/

Wren, T. (2012). Conceptions of culture: What multicultural educators need to know. Plymouth, UK: Rowman \& Littlefield Publishers, Inc.

Zhai, L. \& Scheer S. D. (2002). Influence of International Study Abroad Programs on Agricultural College Students. Journal of International Agricultural and Extension Education, 9, 23-29. 